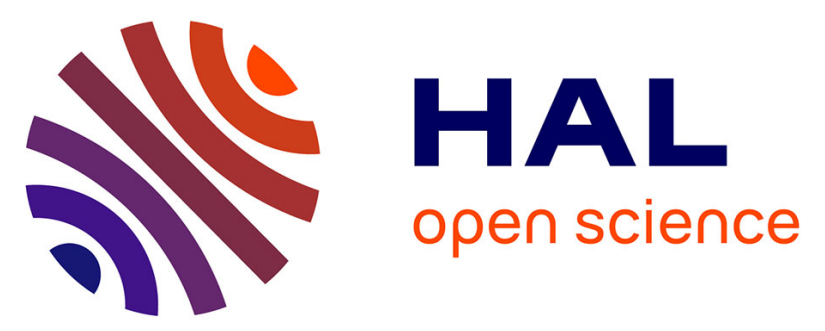

\title{
Inhumations de foetus, nouveau-nés et nourrissons dans les habitats protohistoriques du Languedoc: l'exemple de Gailhan (Gard)
}

\author{
Bernard Dedet, Henri Duday, Anne-Marie Tillier
}

\section{To cite this version:}

Bernard Dedet, Henri Duday, Anne-Marie Tillier. Inhumations de fœtus, nouveau-nés et nourrissons dans les habitats protohistoriques du Languedoc: l'exemple de Gailhan (Gard). Gallia - Fouilles et monuments archéologiques en France métropolitaine, 1991, 48, pp.59-108. 10.3406/galia.1991.2917 . hal-01915362

\section{HAL Id: hal-01915362 \\ https://hal.science/hal-01915362}

Submitted on 19 Jan 2020

HAL is a multi-disciplinary open access archive for the deposit and dissemination of scientific research documents, whether they are published or not. The documents may come from teaching and research institutions in France or abroad, or from public or private research centers.
L'archive ouverte pluridisciplinaire HAL, est destinée au dépôt et à la diffusion de documents scientifiques de niveau recherche, publiés ou non, émanant des établissements d'enseignement et de recherche français ou étrangers, des laboratoires publics ou privés.

\section{(ㅇ)(1) $\$$}

Distributed under a Creative Commons Attribution - NonCommercial - NoDerivatives $\mid 4.0$ 


\title{
Inhumations de foetus, nouveau-nés et nourrissons dans les habitats protohistoriques du Languedoc : l'exemple de Gailhan (Gard)
}

\author{
par Bernard DEDET *, \\ Henri DUDAY et Anne-Marie TILLIER **
}

L'habitat de Gailhan livre, à l'intérieur des maisons ou dans les cours domestiques, des inhumations de fœtus, nouveau-nés et nourrissons : 10 sujets dans la partie dégagée de l'agglomération du dernier quart du ve $\mathrm{s}$. avant $J .-C . ; 12$ ou 13 dans celle qui lui succède dans la première moitié du $\mathrm{IV}^{\mathrm{e}} \mathrm{s}$. avant $\mathrm{J}$.-C. Avec l'étude des individus découverts en connexion anatomique, fouillés selon les méthodes de l'anthropologie de terrain, et celle dĕ̆ous les restes osseux dispersés recueillis dans la partie fouillée du site, pour la première fois en Protohistoire, or dispose de la totalité des restes de sujets périnataux découverts dans une fouille étendue. Le caractère exhaustif de la documentation mise en rapport avec les données architecturales et stratigraphiques permet d'y (d) le mode normal de sépulture des morts en bas âge, qui, étant donnée la très forte mortalité infantile que l'oin est en droit d'attendre à pareille époque, ont toutes chances de ne pas être encore socialisés. L'étude Sint hétique du contexte régional, morts périnataux découverts de plus en plus nombreux dans les habitats de 1. $\mathrm{g}$. du Fer par suite d'une meilleure attention portée par les fouilleurs à ces vestiges, et inversement très in.Fortant déficit de cette classe d'âge dans les nécropoles contemporaines, et l'examen de nombreux exemples historiques et ethnologiques, confortent cette hypothèse. Cette pratique, attestée en Préhistoire récente, s'enracire dans le passé régional.

The site of Gailhan contains a number of burials found in what was the heart of the domestic environment. From the interior of the houses, the inhumations of feluses, newborns and young children include 10 subjects from the last quarter of the 5th century B.C. and 12 or 13 from the first part of the 4th century B.C. These individuals were discovered in anatomical position and excavated according to anthropological methods. All of the skeletal remains were recovered from the excavated section of the site and for the first time during protohistory, the remains of perinatal individuals have been discovered in an extensive excavation. The exhaustive documentation of the architecture, stratigraphy and general archeological context, together with these skeletal remains, permits the visualization of the normal mode of burial of young infants. Further, these data provide evidence of the very high infant mortality during this epoch; clearly, a difficult time for infants who had low chances of surviving childhood. This synthelic study is interesting in the context of the region. Perinatal remains become more and more numerous during the Iron Age in this same area, due to the greater care taken during excavation of these remains. Conversely however, there is a very important deficit of this age category in contemporary graves. The examination of numerous historic and ethnological examples supports this hypothesis. This practice of infant burial, attested to in recent prehistory, is indigenous to the region.

Mots clés : anthropologie, ethno-archéologie, pratiques funéraires, morts en période périnatale, habitat, démographie, Premier Age du Fer, Deuxième Age du Fer, Plan de la Tour, Gailhan, Languedoc, Provence, Espagne.

* B. Dedet, C.NRS, UPR 290 et GDR 742, Centre de documentation archéologique régional, route de Perols, 34970 Lattes.

** H. Duday et A.-M. Tillier, CNRS, LA 376 et GDR 742, Laboratoire d'anthropologie, Université de Bordeaux I. avenue des Facultés, 33405 Talence. 


\section{HISTORIQUE DES RECHERCHES}

Dès les années 1930, pour la première fois dans le Sud de la France, Odette et Jean Taffanel remarquaient la présence dans l'habitat du Cayla de Mailhac (Aude) de squelettes de très jeunes sujets paraissant morts pour la plupart en période périnatale. Ils ont alors conservé ces restes, correspondant en tout à trente-huit individus, et signalé certaines de ces découvertes dans leurs publications (Louis, Taffanel, 1955). Leur mérite est grand car la problématique des fouilles protohistoriques était alors, dans cette région comme ailleurs, axée sur la recherche des mobiliers, "traceurs" des chronologies, des faciès matériels de civilisation et des courants d'échanges commerciaux. D'une manière presque générale, les ossements mis au jour dans les sites d'habitat ne jouissaient pas d'une grande considération et les méthodes d'investigation étaient peu favorables au repérage de pièces aussi petites et fragiles que les os de fœtus, nouveau-nés et nourrissons, d'autant que, sauf exception, ces sujets ne sont pas déposés dans un contenant facilement repérable ni accompagnés d'un mobilier spécifique. Aussi, pendant longtemps, de telles découvertes sont-elles restées très rares, parfois très brièvement signalées, et n'ont suscité aucun commentaire. A l'exception notoire de deux sćpultures de nouveau-nés et de celle d'un fœtus fouillées par Henri Prades à Lattes (Hérault) en 1964 et 1983, et étudiées par $\mathrm{M}^{\mathrm{me}} \mathrm{M}$. Engel (Arnal et alii, 1974, p. 37, 46, 291 et 292) et par le Dr Montoya (Prades, 1984), aucun de ces individus ne fit l'objet d'un examen ostéologique.

$\mathrm{Au}$ cours de ces dernières années, à la suite de l'élargissement de la problématique des fouilles d'habitat et de l'affinement des méthodes d'investigation, les découvertes se sont multipliées, tout particulièrement en Languedoc oriental - Vié-Cioutat à Mons, Monteils (Gard) en 1975, Le Plan de la Tour à Gailhan et Le Marduel à Saint-Bonnet-du-Gard (Gard) à partir de 1982, Lattes à partir de l'ouverture des fouilles extensives sur le site de Saint-Sauveur en 1984 - entraînant une prise de conscience de l'importance culturelle de tels dépôts. Et à cet égard, l'apport des recherches de 1990 en Languedoc et en Roussillon est tout à fait significatif : six habitats protohistoriques faisaient cette année l'objet de fouilles ou de sauvetages programmés et des découvertes de morts périnataux (sept sujets) ont eu lieu sur trois d'entre-eux. A ce jour, le total des enfants protohistoriques décédés en période périnatale découverts en Languedoc-Roussillon s'élève à quatre-vingt-quinze.

Cet intérêt a bénéficié de l'avance prise dans ce domaine par les protohistoriens de l'Espagne du Nord et de l'Est sensibilisés depuis longtemps à cette question par des trouvailles d'autant plus abondantes que les sujets étaient souvent déposés dans des récipients, ce qui facilitait leur conservation et leur découverte. Dès 1958, J. Maluquer de Motes évoqua le sujet pour le Alto de la Cruz à Cortes (Navarre): les nombreuses inhumations de très jeunes enfants sous les sols des maisons du Premier Age du Fer étaient la preuve d'une mortalité naturelle élevée (Maluquer de Motes, 1958, II, p. 143). En 1961, J. Barberá et ses collaborateurs signalèrent de tels ensevelissements au Turo de Can Olivé à Cerdanyola (Barcelone), dans le monde ibérique, et pour eux, ceux-ci résulteraient d'un "rite" (Barberá et alii, 1960-1961, p. 219). Une note de M. Tarradell relaya en 1965 cette information (Tarradell, 1965), et depuis, de nombreuses études sur le sujet, par site, ont vu le jour, aussi bien dans le monde du Premier Age du Fer de la conque de l'Ėbre que dans l'aire côtière ibérique. Une première synthèse rapide, concernant l'ensemble de la péninsule ibérique, a été présentée en 1977 à Barcelone, au symposium sur les "Origines du monde ibérique» (Beltrán Lloris, 19761978 , p. 310-315). Une autre vient d'être consacrée au Pays valencien (Guérin, Martinez Valle, 19871988). Enfin, le tout récent volume 14, 1989, des Cuadernos de Prehistoria y Arqueologia Castellonenses (Castellón de la Plana), intitulé "Inhumations infantiles dans l'aire méditerranéenne espagnole (du $\mathrm{vII}^{\mathrm{e}} \mathrm{s}$. avant $\mathrm{n}$. è. au $\mathrm{II}^{\mathrm{e}} \mathrm{s}$. de n. è.)", regroupe une douzaine de monographies par site, où se rencontrent les deux hypothèses d'explication déjà signalées: mortalité naturelle et rite sacrificiel.

La pratique systématique du sacrifice du premier né à Carthage a été remise en question ces dernières années et le débat rite sacrificiel - moyen de contrôle de la fécondité - mort naturelle s'est largement développé. Il vient d'être résumé par Guerrero (1989) et, en prenant nettement position pour la troisième hypothèse, par MM. Gras, Rouillard, Teixidor (1989, p. 170-191). D'autres travaux récents fournissent des termes de comparaison pour d'autres périodes en d'autres lieux et évoquent différents types de comportements : ainsi l'étude de plusieurs sujets décédés en phase périnatale découverts dans des habitats et des sépultures du Sud de la France datés de la Préhistoire récente, et qui attestent l'ancien- 
neté de telles pratiques (Mahieu, 1984-1985), ou une synthèse historique sur les morts prématurés dans la Rome antique (Néraudeau, 1987).

Le moment nous semble donc venu de faire le point sur la question en Languedoc et de chercher à saisir la signification (ou les significations) des coutumes dont témoignent, dans cette région, les restes de ces petits sujets. Actuellement, l'étude des squelettes découverts sur divers sites, Cayla de Mailhac, Lattes, Le Marduel, confiée à V. Fabre, H. Duday et A.-M. Tillier, est en cours. Mais les recherches menées sur l'oppidum de Gailhan par l'un d'entre nous (B. D.) depuis 1975 permettent d'aborder ces questions de manière privilégiée.

C'est lors de la campagne de 1982 que les deux premiers squelettes en place ont été repérés. L'un a été relevé, photographié et prélevé aussitôt, tandis que le secteur où gisait le second a été mis en réserve et protégé pour être fouillé ensuite en appliquant les méthodes spécifiques à l'anthropologie de terrain. Cette dernière procédure s'est déroulée par la suite à trois reprises, de 1986 à 1988, durant lesquelles nous avons pu fouiller quatre autres squelettes en place et les restes groupés d'un cinquième. Entre temps, un autre squelette mal conservé était prélevé en bloc pour être fouillé en laboratoire. Ces découvertes nous ont conduits à reprendre le tri de l'ensemble des ossements livrés par le site, qui avaient été recueillis par mètre carré pour chaque couche, de manière à rechercher d'éventuels ossements humains parmi les restes de faune. A cette occasion, des ossements isolés ou de petits ensembles composés de plusieurs pièces osseuses, appartenant à des enfants décédés en période périnatale, ont été identifiés. Ainsi, pour la première fois dans la Protohistoire languedocienne, il est possible d'étudier la totalité de tels restes livrés par une fouille d'habitat. De plus, presque tous les sujets en place ainsi que les vestiges groupés de deux autres ont fait l'objet d'observations précises concernant le mode de dépôt. Les conditions sont donc réunies pour mettre en relation ces vestiges avec la population de l'oppidum et son organisation, telles que les structures architecturales permettent de les appréhender, pour connaître les pratiques que ces restes suggèrent, pour mesurer leur importance et tenter de les expliquer. Après une présentation générale des conditions de gisement des individus décédés en phase périnatale, nous examinerons les restes humains eux-mêmes, dans leur cadre topographique et stratigraphique, et les modalités du dépôt des sujets retrouvés en place. La dernière partie s'attachera à donner une vision globale du phénomène à Gailhan, à rechercher sa signification funéraire et culturelle et à la replacer dans son contexte régional et enfin à tenter d'estimer la population protohistorique de cet oppidum ${ }^{1}$.

\section{LES CONDITIONS GÉNÉRALES DE GISEMENT}

Plusieurs publications ont déjà présenté l'oppidum de Gailhan, habitat de $5000 \mathrm{~m}^{2}$ de superficie, situé dans les Garrigues du Languedoc oriental à une quarantaine de kilomètres au nord-ouest de Nìmes (fig. 1) (Dedet, $1980 ; 1987 ; 1990)$. Nous ne mettrons donc ici l'accent que sur les conditions de gisement des restes des individus décédés en période périnatale.

C'est une portion importante de la partie conservée du gisement ${ }^{2}, 700 \mathrm{~m}^{2}$, soit environ un septième de la superficie totale de l'oppidum, qui a été fouillée. Rythmée par différentes phases architecturales, l'occupation humaine s'échelonne du dèbut du $\mathrm{v}^{\mathrm{e}} \mathrm{s}$. à la seconde moitié du Ive s. avant J.-C. et la succession de trois agglomérations protohistoriques a pu être établie. Les lieux ont par ailleurs èté réaménagés, sans doute à des fins agricoles, à la fin du $\mathrm{I}^{\mathrm{er}} \mathrm{s}$. avant $J .-C$. et fréquentés durant le siècle suivant.

Le premier habitat (première moitié et troisième quart du $\mathrm{v}^{\mathrm{e}} \mathrm{s}$. avant J.-C.) a été fouillé sur une centaine de mètres carrés seulement et reconnu sur des surfaces plus réduites dans plusieurs sondages; une maison à deux absides en torchis sur poteaux porteurs et solin en pierres s'y rapporte (Dedet, 1990).

Le deuxième village (dernier quart $d u v^{e} s$. avant J.-C.), dégagé sur environ $700 \mathrm{~m}^{2}$, comprend

1 Les parties "Historique des recherches", "Conditions générales de gisement" et "Synthèse et interprétation" sont dues à B. Dedet; les parties "Dépôts et ossements isolés : inventaire et détermination de l'âge au décès" et "Étude analytique de la disposition des squelettes en connexion A1, A2, A3, A4, A5, A6 et de l'ensemble B2" sont dues à H. Duday et A.-M. Tillier, avec la collaboration de B. Dedet pour le cadre topographique et stratigraphique des vestiges ètudiés. Nous remercions pour leur contribution aux opérations de terrain et de laboratoire P. Courtaud, S. Dedet, M. Duday, F. Houët, $\mathrm{N}$. Roche et $\mathrm{F}$. Simon, ainsi que pour leurs renseignements C.-A. de Chazelles, D. Garcia, Y. Gasco, A. Martin, D. Orliac, A. Pézin, Y. Solier, O. Taffanel et J. Taffanel.

2 Les strates calcaires du substratum présentent un fort pendage et remontent vers le sud-est pour former une arête sommitale en bordure sud-est de la colline. L'épaisseur de la sédimentation humaine, retenue par un mur de soutènement protohistorique, varie beaucoup du nord-ouest $(1$ à $2 \mathrm{~m})$ au sud-est $(0,20$ à $0,30 \mathrm{~m})$. Du fait de l'exploitation agricole des lieux, qui s'est poursuivie jusqu'à l'aube $d u x^{\mathrm{e}}$ s., les couches archéologiques ne sont conservées en place que le long de la bordure nord-ouest du plateau. sur une largeur de $10 \dot{\text { a }} 15 \mathrm{~m}$. 


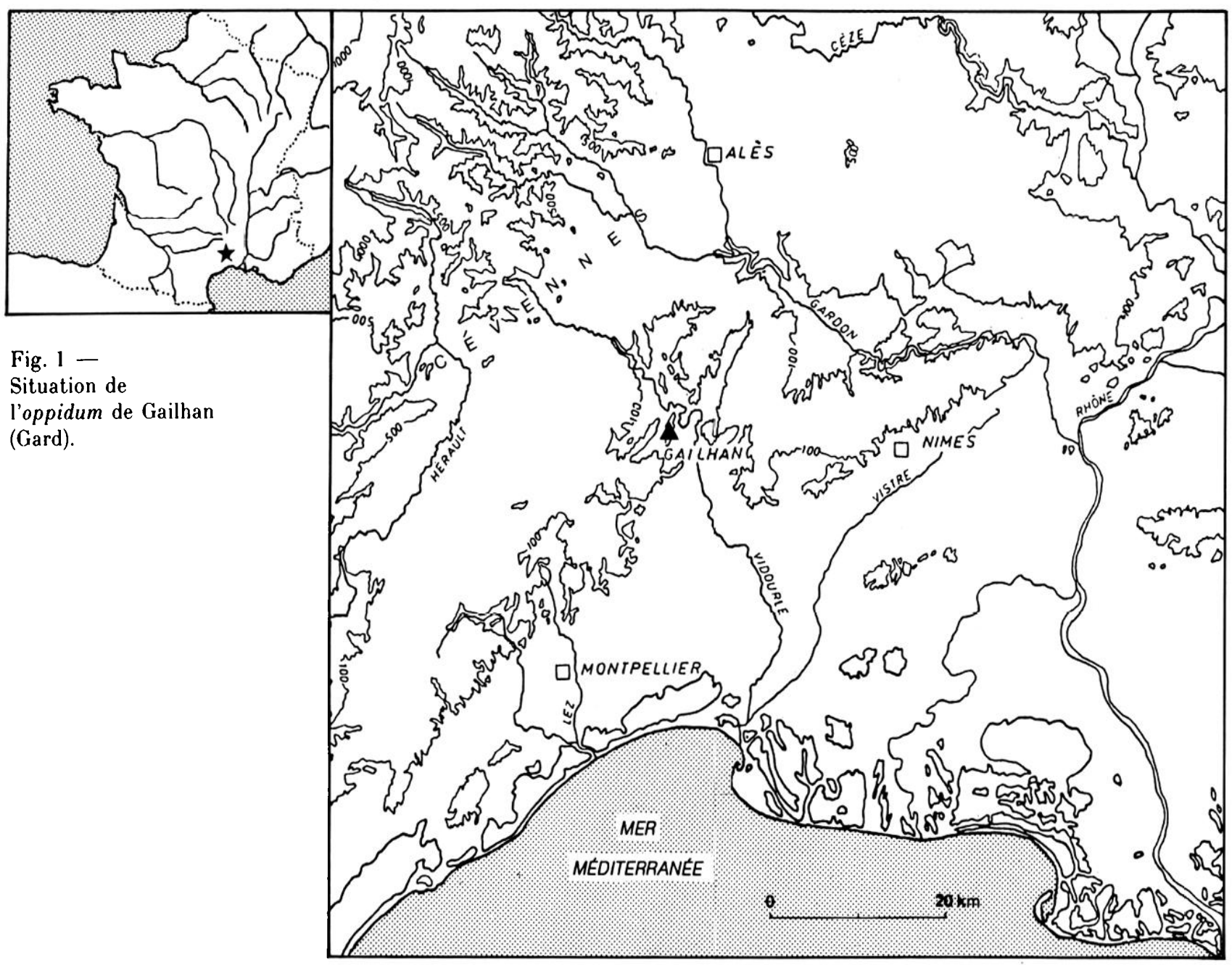

diverses cellules architecturales rectangulaires, appuyées contre le parement intérieur d'un mur d'enceinte. Celles-ci communiquent à l'est vers un probable axe de circulation orienté selon le grand axe du site $^{3}$. Les maisons, rectangulaires, sont désormais bâties avec des murs porteurs en pierre. Du sud au nord, on trouve (fig. 2) :

- cour domestique 6-7, incomplètement explorée vers le sud ${ }^{4}$. Les locaux d'habitation auxquels elle doit se rattacher n'ont pas été fouillés;

- unité domestique 1 , comportant le local d'habitation, une cour domestique, un passage non couvert et un petit bâtiment annexe (Dedet., 1987);

3 Cette hypothèse cependant n'est pas vérifiable du fait des conditions de gisement (cf. supra, note 2).

4 Par cour domestique, nous entendons un espace non couvert, structuré, clôturé ou limité par des constructions, livrant différents vestiges d'activités domestiques et par là ètroitement lié à l'activité de la maisonnée : foyers (notamment culinaires), fours en cloche, fosses, structures de stockage, séchoirs, zones de rejet (Dedet, à paraître a).
- bâtiment rectangulaire $15 \bar{y} .1$ à poteaux porteurs comprenant plusieurs foyers dont un décoré, soit habitation vidée de tout son mobilier, soit local de service. Il ouvre au sud sur une petite cour 15.2.3 qui fait retour à l'ouest;

- aire de circulation non couverte (espace 17);

- lieu difficile à définir, soit cour domestique entourée d'une palissade, soit petit édifice léger à poteaux porteurs ayant servi d'habitation (espace 23.2).

- enclos 16 dépourvu de tout aménagement particulier, peut-être parc à bestiaux (analyses de sédiments en cours à l'INRA);

- zone de passage 23.1 dans l'axe de l'ouverture de l'enclos 16 ;

- petite cour domestique ou petit édifice léger à poteaux porteurs 23.3 faisant le pendant de 23.2 de l'autre côté de la zone de passage 23.1. La connaissance de ces trois espaces $(23.1,23.2$ et 23.3) pâtit beaucoup de la destruction de leur partie orientale;

- unité domestique 21-18, comprenant un local d'habitation (espace 21) et une cour domestique (espace 18); 


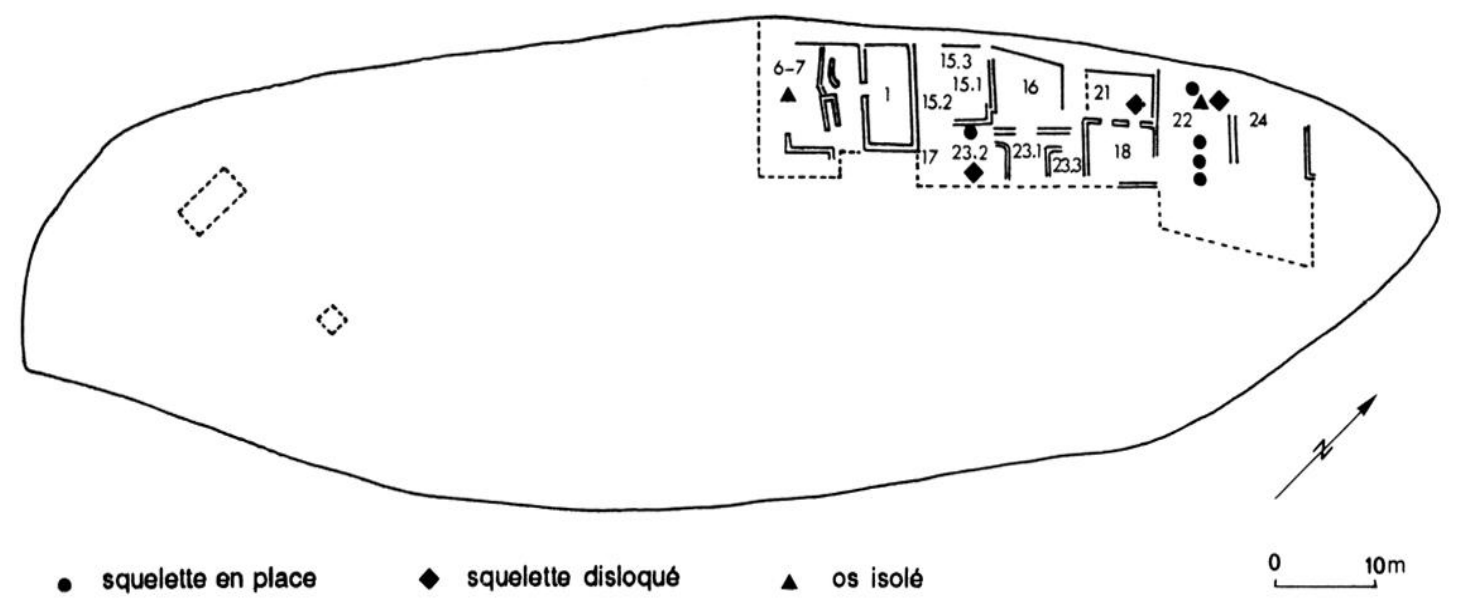

Fig. 2 - Répartition générale des restes de périnataux de la deuxième agglomération de Gailhan (dernier quart du ve $s$. avant $J$.-C.).

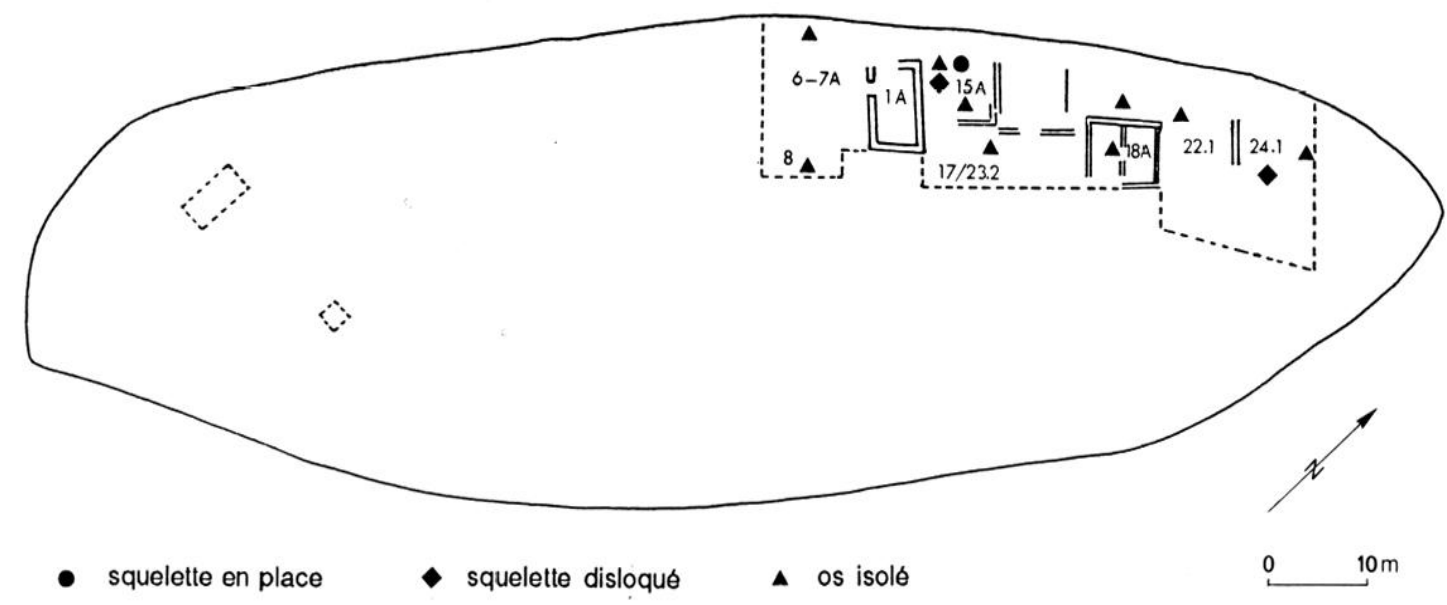

Fig. 3 - Répartition générale des restes de périnataux de la troisième agglomération de Gailhan (première moitié du $\mathrm{IV}^{e} \mathrm{~s}$. avant $\mathrm{J} .-\mathrm{C}$.).

- cours domestiques 22 et 24 dont les habitations correspondantes, peut-être élevées à l'est, restent inconnues.

Durant la première moitié du Ive s. avant J.-C., un troisième établissement est crée sur les ruines du second, abandonné brutalement. Ce sont des constructions plus légères avec des parois de torchis sur poteaux porteurs qui réutilisent pour partie certains murs des maisons précédentes. Toutefois, à la suite des destructions agricoles, cette agglomération est mal connue et ses sols et couches de sédimentation humaine sont le plus souvent bouleversés. Du sud au nord, ont été fouillées les structures ou aires suivantes (fig. 3) :
- enclos ou bâtiment léger sur poteaux porteurs $6-7 \mathrm{~A}$;

- bâtiment $1 \mathrm{~A}$ réutilisant trois murs de la maison 1 (habitation? local de service?);

- cour domestique $15 \mathrm{~A}$ avec divers aménagements ;

- maison $18 \mathrm{~A}$

- bâtiment à poteaux porteurs ou enclos entouré d'une palissade 22.1;

- aire non bâtie 24.1, peut-être parc à bestiaux (analyses de sédiments en cours).

Les restes humains qui font l'objet de la présente étude ont été découverts dans des niveaux appartenant aux deuxième et troisième villages; ils datent donc soit du dernier quart du $v^{e}$ s., soit de la première moitié ou du milieu du siècle suivant. 


\section{DÉPÔTS ET OSSEMENTS ISOLÉS : INVENTAIRE ET DETERMINATION DE L'ÂGE AU DÉCÈS}

La fouille méthodique des six dépôts en place (A1, B2, A3, A4, A5 et A6) a été effectuée en 1982, 1987 et 1988. Les décapages ont été réalisés à l'aide d'instruments fins (matériel de la chirurgie dentaire et ophtalmologique). Le sédiment a été enlevé d'une part avec des pinceaux fins, d'autre part par microaspiration de type chirurgical, le diamètre de la sonde d'aspiration étant de $4 \mathrm{~mm}$.

Chaque décapage a fait l'objet d'un relevé à l'échelle $1 / 2$ et tous les vestiges osseux ont été dessinés; leur orientation anatomique a été notée avec soin et leur profondeur a été relevée à $0,1 \mathrm{~cm}$ près par rapport au niveau 0 de référence du site. Un numéro d'inventaire, porté sur le plan correspondant et sur le cahier d'enregistrement, a été affecté à chacune des pièces.

Le nombre de celles-ci est le suivant :

\begin{tabular}{|c|c|c|}
\hline Espace & Sujet & $\begin{array}{c}\text { Nombre } \\
\text { de pièces }\end{array}$ \\
\hline 15 & $\mathrm{~A} 1$ & 185 \\
\hline 22 & $\mathrm{~A} 3$ & 161 \\
\hline 22 & $\mathrm{~A} 4$ & 237 \\
\hline 22 & $\mathrm{~A} 5$ & 231 \\
\hline 22 & $\mathrm{~A} 6$ & 249 \\
\hline $17 / 23.2$ & $\mathrm{~B} 2$ & 49 \\
\hline
\end{tabular}

Toute la terre extraite de la fouille a été ensachée en tenant compte du dépôt d'origine, du décapage et éventuellement de la couche, puis elle a été tamisée à l'eau à la maille de $500 \mu$. Nous avons également traité le squelette $\mathrm{A} 2$ et les os isolés que nous a procurés le tri effectué sur l'ensemble du matériel osseux.

Les schémas de conservation des squelettes ont été établis d'après la méthode proposée par C. Meiklejohn et T. Constandsee-Westermann, adaptée par deux d'entre nous (H. D. et A.-M. T.) aux sujets périnataux. L'inventaire des os du tronc (colonne vertébrale, côtes et sternum) fait l'objet d'une figure séparée pour chaque sujet.

La détermination de l'âge au décès repose sur la confrontation des données recueillies sur les dents et sur l'ensemble du squelette. Pour ce dernier, les informations sont d'ordre métrique (estimation de la stature) et d'ordre morphologique (degré d'ossification, synostose ...) :

- les dents : le critère le plus couramment utilisé pour des sujets très jeunes est le degré de calcification des germes dentaires. Les données de référence sont nombreuses dans les populations actuelles; nous avons retenu celles qu'a publiées D. Ubelaker (1978), qui tiennent compte de la variabilité individuelle;

- l'estimation de la stature : à l'aide des dimensions prises sur la plupart des os mesurables, nous avons calculé la stature de chaque individu à partir des équations établies par Fazekas et Kosa (1978) pour les fœtus et nouveau-nés. D'une manière générale, ce sont les pièces les plus grandes qui fournissent les meilleurs résultats. Leur discussion doit prendre en considération la variabilité individuelle, que ces auteurs ont également étudiée. La plupart des données métriques ont été regroupées dans le tableau I (voir infra, p. 103).

- lossification du squelette crânien el post-crânien : les données précédentes ont été complétées par des observations morphologiques.

La précision avec laquelle l'âge au moment du décès peut être estimé varie évidemment beaucoup en fonction du degré de conservation du squelette. La marge d'incertitude est donc nécessairement plus grande pour un os isolé que pour un sujet complet.

La détermination du sexe à partir du squelette des sujets immatures demeure un problème non résolu. Quelques auteurs (Fazekas, Kosa, 1978) ont proposé d'utiliser, comme pour les adultes, des caractères métriques de l'os coxal et plus particulièrement de l'ilion. Mais d'une part, il est très difficile de définir avec précision les points ostéométriques de la grande échancrure sciatique chez des sujets aussi jeunes et d'autre part, il semble exister une grande variabilité selon les populations : les résultats obtenus nous paraissent donc être très aléatoires et nous avons préféré renoncer à tenter toute diagnose sexuelle.

\section{ESPACE 6-7}

L'espace 6-7 a livré deux ossements isolés, dans des couches différentes.

\section{Couche 2, ossement $\mathrm{Cl}$}

La couche 2 correspond au niveau superficiel de destruction et d'abandon de l'oppidum, remaniè par les travaux agricoles. Découvert sur le dessus du mur d'enceinte, cet élément osseux doit être rapporté à la dernière occupation du site (première moitié $d u{ } v^{e} s$. avant J.-C.). 
Il s'agit d'une moitié proximale d'ulna gauche, dont le périmètre au milieu est de $12 \mathrm{~mm}$ et le diamètre sagittal proximal de $8,4 \mathrm{~mm}$. Ces dimensions sont compatibles avec un âge voisin du terme.

\section{Couche 7, ossement C2}

La couche 7 correspond à une strate de sédimentation humaine accumulée durant la seconde moitié du $v^{e}$ s. dans une cour domestique de plus de $70 \mathrm{~m}^{2}$ de superficie (mais la limite sud n'a pas été atteinte), comprenant deux secteurs bien distincts : une moitiè ouest vide de tout aménagement et une moitiè est où ont été établis huit foyers successifs. L'os du sujet périnatal provient de la bordure de cette dernière zone.

C'est une moitié proximale d'humérus gauche, dont les dimensions (périmètre au milieu : $18 \mathrm{~mm}$ ) correspondent à un âge proche du terme. Cet os n'appartient probablement pas au même sujet que $\mathrm{Cl}$, dont il est distant de plus de $8 \mathrm{~m}$ et qui se trouve dans une couche beaucoup plus superficielle.

\section{ESPACE 8, OSSEMENT C3}

L'espace 8, incomplètement conservé et délimité, contenait, dans la couche superficielle remaniée (couche 2), une pièce osseuse isolée qui doit être rapportée à la dernière occupation du site (première moitié ou milieu du $\mathrm{IV}^{\mathrm{e}} \mathrm{s}$.).

Ce fémur gauche, complet, a des dimensions très inférieures à celles d'un fémur de nouveau-né (cf. tabl. I, p. 103). Son périmètre au milieu n'est que de $15 \mathrm{~mm}$. La stature peut être estimée à $40,2 \mathrm{~cm}$ à partir de la longueur maximale, $38,7 \mathrm{~cm}$ à partir de la largeur distale, ce qui correspond à un âge au décès de sept mois lunaires et demi à huit mois lunaires (six mois et demi à sept mois de grossesse). Il s'agit indiscutablement d'un prématuré non viable. Ce sujet ne peut donc être confondu avec le sujet C2.

\section{COUR DOMESTIQUE $15 \mathrm{~A}$}

De plan trapézoïdal et d'une superficie de $56 \mathrm{~m}^{2}$, cette cour domestique de la troisième agglomération de Gailhan a livré, dans différentes couches, des os isolés, des restes d'un squelette disloqué et un squelette en connexion anatomique (fig. 4).

\section{Couche 2, squelette disloqué B1 et ossement isolé $\mathrm{C} 4$ bis}

Strate superficielle remaniée, la couche 2 a livré les restes d'un squelette disloqué (B1) et un ossement isolé (C4 bis) qui doivent être rapportés à la dernière occupation (première moitié du $\mathrm{IV}^{\mathrm{e}} \mathrm{s}$. avant J.-C.).

\section{Ensemble B1 :}

- la moitié postérieure d'une première côte gauche et deux fragments de côtes;

- une clavicule gauche incomplète, dont le périmètre au milieu est de $11 \mathrm{~mm}$;

- la moitié distale d'un humérus gauche dont le périmètre au milieu est de $16 \mathrm{~mm}$;

- un cinquième métacarpien gauche (longueur maximale : $10,8 \mathrm{~mm}$ );

- un fémur gauche dont la partie proximale manque (périmètre au milieu : $20 \mathrm{~mm}$ );

- les deux tiers proximaux d'un tibia gauche (périmètre au milieu : $19 \mathrm{~mm}$ ).

Les dimensions générales de ces vestiges sont comparables à celles d'un nouveau-né. On notera que seules ont été retrouvées des pièces se rapportant à la moitié gauche du squelette.

Os C4bis: humérus gauche presque complet (seule l'extrémité proximale de la diaphyse est érodée). Ses dimensions (cf. tabl. I, p. 103; périmètre au milieu : $20 \mathrm{~mm}$ ) indiquent une stature d'environ $62,6 \mathrm{~cm}$. Selon toute vraisemblance, ce sujet (C4 bis) doit être confondu avec le suivant (C4).

\section{Couche 3, ossements isolés C4 et C5}

La couche 3 correspond à un stade d'utilisation de la cour domestique $15 \mathrm{~A}$ (première moitié du IVe $\mathrm{s}$. avant J.-C.). Celle-ci est alors pourvue d'un four en cloche, de quatre foyers construits successifs et près du centre, d'une fosse $(0,30 \mathrm{~m}$ de profondeur et $0,75 \mathrm{~m}$ de diamètre), comblée de pierres et de terre. Les deux ossements $\mathrm{C} 4$ et $\mathrm{C5}$ ont été découverts à une distance de 5 à $6 \mathrm{~m}$ l'un de l'autre : C4 dans la moitié est et $\mathrm{C} 5$ dans la partie sud-ouest (fig. 4).

Os C4 : il s'agit d'un fragment du corps d'une mandibule, compris entre la symphyse mentonnière et l'alvéole de la deuxième molaire déciduale gauche. Aucune dent n'était sortie lorsque le décès est survenu. Les germes des incisives centrale et latérale, de la canine et de la première molaire déciduales gauches sont encore en place dans leurs alvéoles; les couronnes des quatre premières dents sont entièrement calcifiées, celle de la cinquième est formée aux cinq sixièmes, ce qui correspond à un âge d'environ six mois après la naissance.

Os C5: du même espace provient un fragment de fémur gauche (deux tiers proximaux de la diaphyse) dont le périmètre au milieu est de $20 \mathrm{~mm}$. Cet os, dont les dimensions sont analogues à celles d'un fémur de nouveau-né, appartient sans aucun doute à un individu ( $\mathrm{C} 5$ ) beaucoup plus jeune que le sujet C4-C4 bis. 


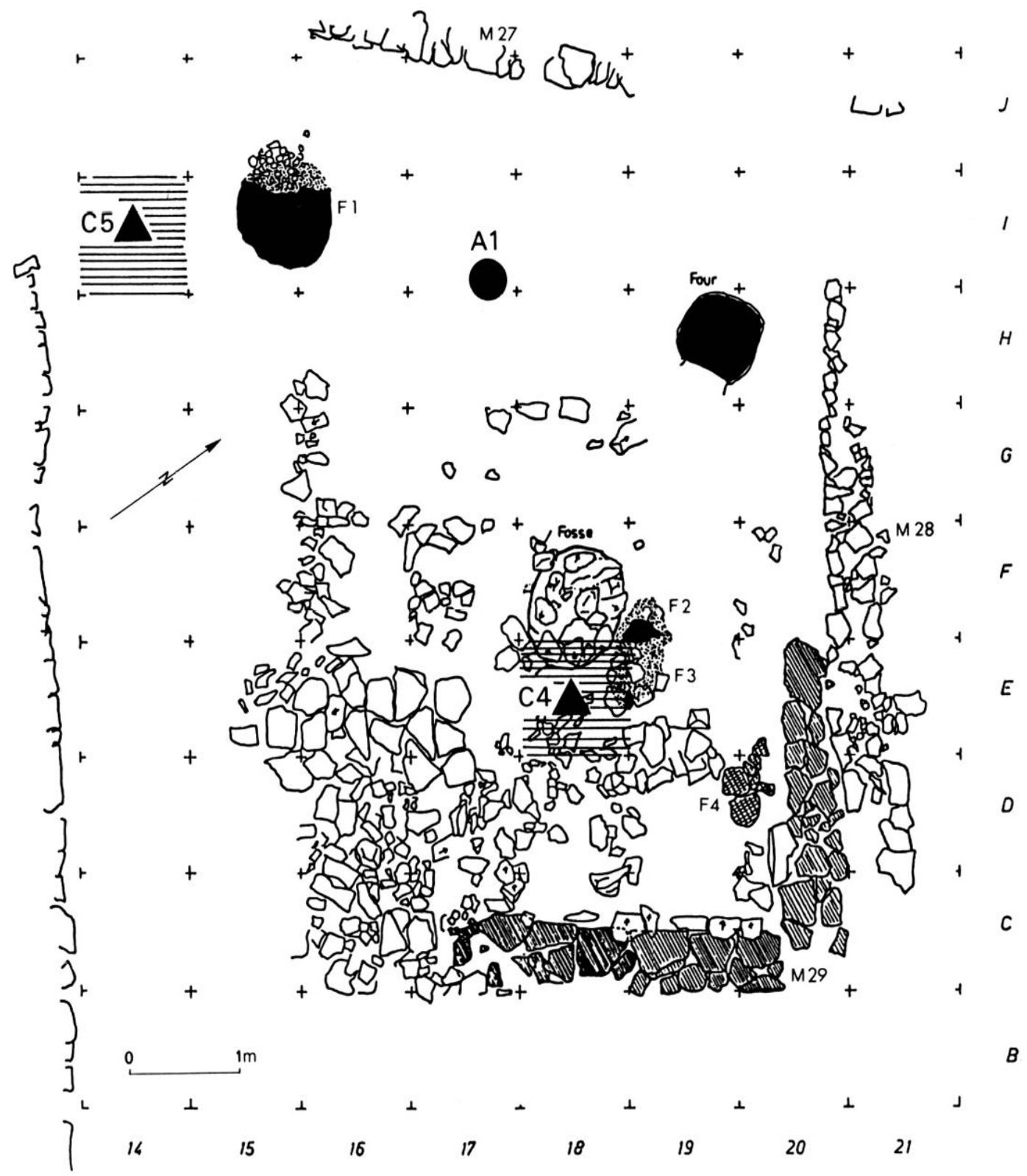

Fig. 4 - Cour domestique 15. (première moitié du IV s. avant J.-C.) : localisation du squelette en place Al et carrés de découverte des ossements isolés $\mathrm{C} 4$ et $\mathrm{C5}$. F1 à F4 : foyers successifs.

\section{Squelette A1}

Le squelette Al était enfoui dans la moitié occidentale de la cour $15 \mathrm{~A}$, à proximité de l'axe longitudinal de celle-ci (fig. 4). Il se trouvait dans une petite fosse peu profonde, creusée dans une couche de sédimentation humaine de la cour (couche 5), datée de la fin du ve ou du début du Ive s. avant J.-C. Celle-ci est surmontée par la couche 3 , formée durant la première moitié du IV $\mathrm{s}$. Aucun indice ne permet toutefois de dire si la petite fosse renfermant le squelette a été creusée également dans la couche 3 après sa constitution ou si cette strate recouvre l'ensemble (couche 5 et fosse renfermant le squelette). On datera donc l'enfouissement de ce sujet entre les dernières années du $v^{e} s$. et le milieu du $\mathrm{Iv}^{\mathrm{e}} \mathrm{s}$. avant $\mathrm{J}$.-C.

Le squelette Al est parfaitement conservé (fig. 5, 16 et 17). La maturation des germes de dents déciduales, qui ont tous été retrouvés en place dans leurs alvéoles, indique un stade voisin du terme. La stature, estimée par la moyenne des valeurs calculées à partir des dimensions des clavicules, des scapulas, des humérus, des radius, des ulnas, des ilions, des ischions, des pubis, des fémurs, des tibias et des fibu- 


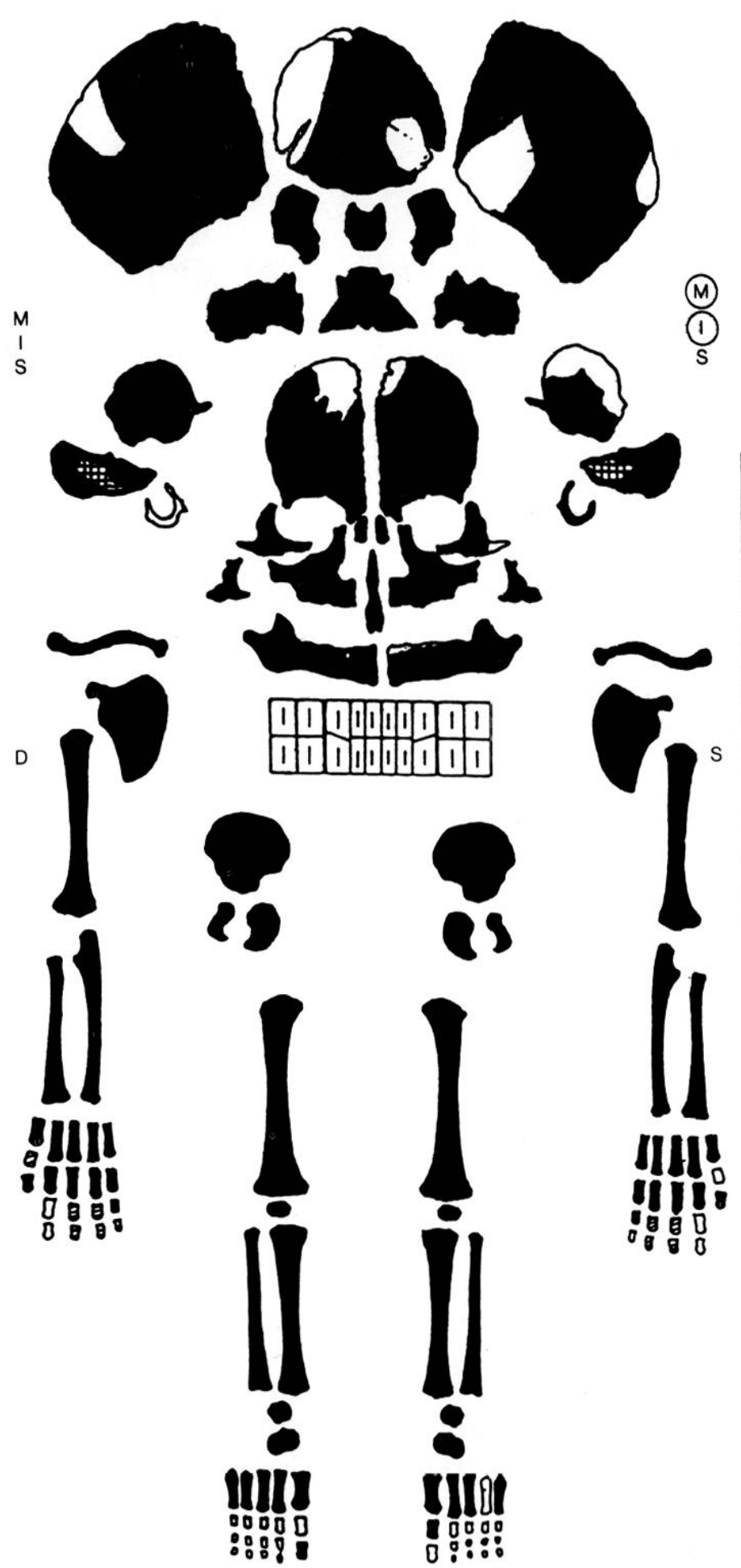

la région est présente et identifiée avec certitude l'os est présent, mais fragmenté et/ou érodé eVou écrasé

fragments présents, dont la situation exacte n'est pas

reconnue

I'attribution de la pièce à une région particulière ou, dans certains cas, à un individu défini n'est que supposée

fragments très incertains quant au coté evou à la nature.

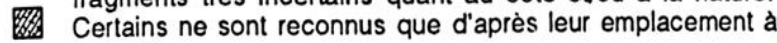
la fouille
Fig. 5 -

Etat de conservation du squelette $\mathrm{Al}$.
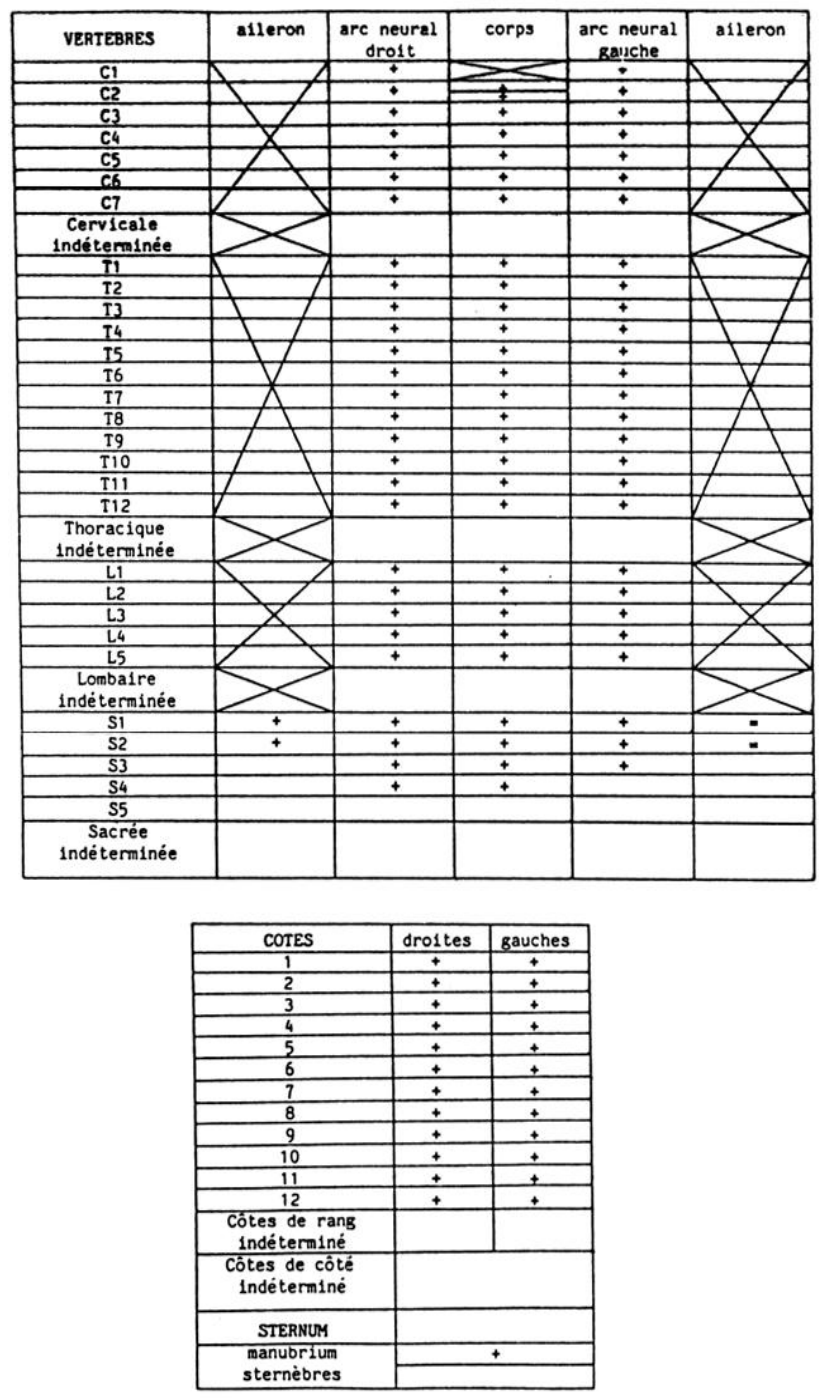

\section{Légende}

des diagrammes dentaires

(1) l'élèment est présent in situ

l'élément isolé est présent et a èté identifié avec certitude

1. la racine est seule présente in situ l'identification de l'élément isolé n'est que supposée

? un de ces deux élements est $\longrightarrow$ présent

$\oplus$ l'élèment est present in situ, mais fragmenté

ff fragment isole de couronne identifiable 


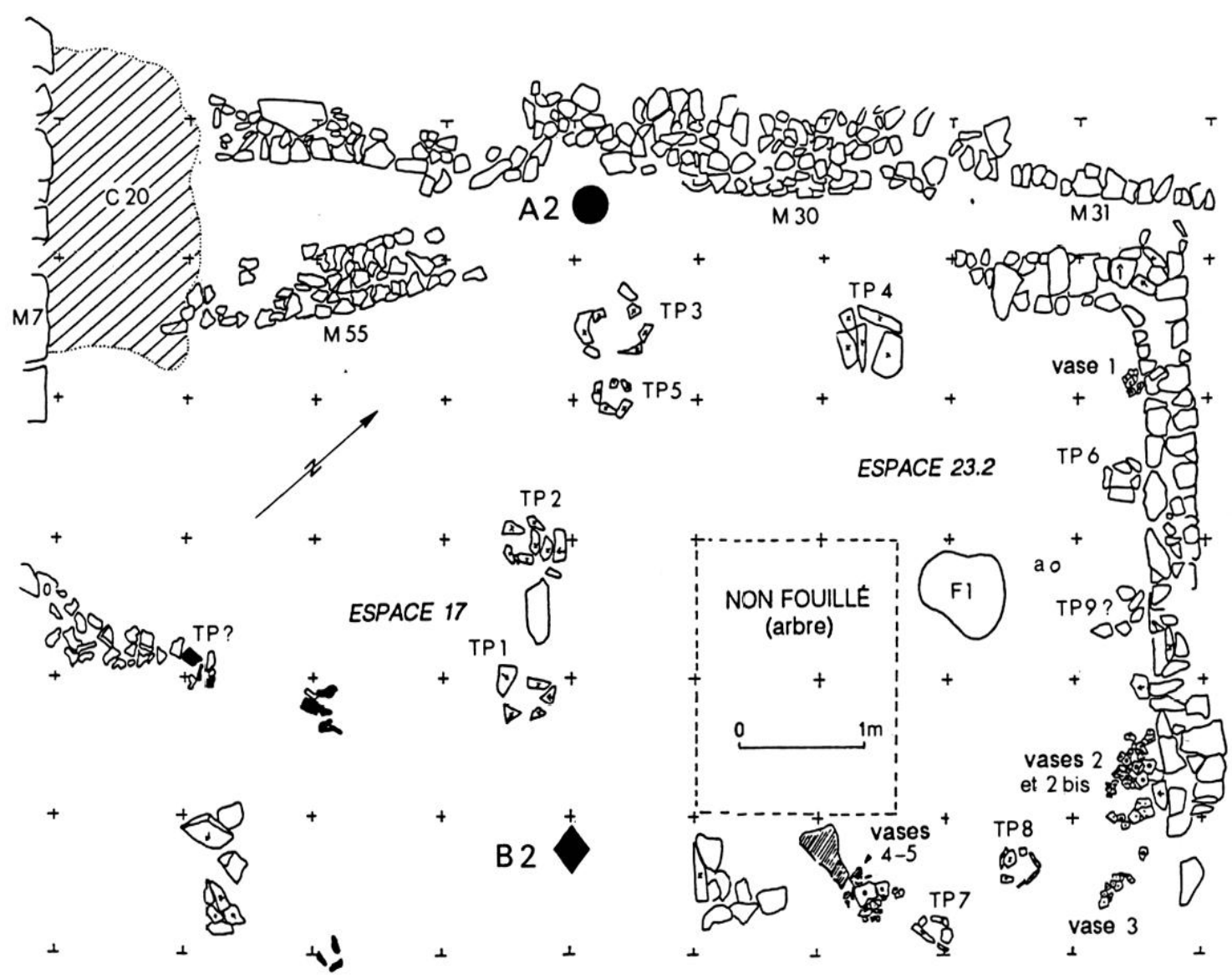

Fig. 6 - Espaces 17-23.2 (dernier quart du ve s. avant J.-C.); localisation du squelette en place A2 et du squelette disloqué B2. TP1 à TP9: calages de poteaux; F1 : foyer 1 .

las (tabl. I, p. 103), est de $52,5 \mathrm{~cm}$. Toutes ces mesures s'inscrivent dans les limites des variations enregistrées en fin de gestation (dix mois lunaires). Les épiphyses distales des deux fémurs ("points de Béclard") étaient partiellement ossifiées, ce qui suggère un âge égal ou supérieur au terme.

Le sujet Al est donc un enfant à terme, mort-né ou décédé durant les premiers jours de la vie.

\section{ESPACE $17 / 23.2$}

On regroupera ici les espaces 17 et 23.2 sous une même rubrique car la limite entre les dcux cst mal définie et les restes osseux sont issus de la partie limitrophe. Il s'agit de deux ossements isolés provenant de la couche 1-2 (C6 et C7), d'un squelette en connexion anatomique (A2) et d'un squelette disloqué (B2) (fig. 6).

\section{Couche 1-2, ossements isolés $\mathrm{C} 6$ et $\mathrm{C} 7$}

La couche 1-2, niveau superficiel remanié, a livré dans la partie ouest de l'espace 23.2 deux ossements isolés que l'on peut rapporter à la dernière occupation du site (première moitié ou milieu du IV ${ }^{\mathrm{e}}$ s. avant $\mathrm{J}$.-C.).

Os C6 : moitié proximale d'ulna gauche, dont le périmètre au milieu est de $12 \mathrm{~mm}$ et le diamètre antéro-postérieur proximal de $9 \mathrm{~mm}$, valeurs comparables à celles d'un nouveau-né à terme. Ce vestige doit être rapporté à un individu (C6) autre que A2, dont l'ulna gauche également a été retrouvée.

Os C7: moitié distale de diaphyse de fémur droit, érodée, trouvée dans le même secteur. Son périmètre au milieu est très faible $(15 \mathrm{~mm})$, égal à cclui du sujet C3. Cet os doit donc être attribué à un fœtus d'environ six à sept mois in utero (C7), qui ne peut être confondu ni avec $\mathrm{A} 2$, ni avec B2, ni encore avec C6.

\section{Squelette A2}

Le squelette $\mathrm{A} 2$ a été découvert en limite des espaces 17, 23.2 et 15 (fig. 2 et 6 ). Plan et nature des lieux nous échappent totalement car, au niveau où gisait le corps, le reste de l'espace 17 vers l'est a été détruit par les travaux agricoles. 


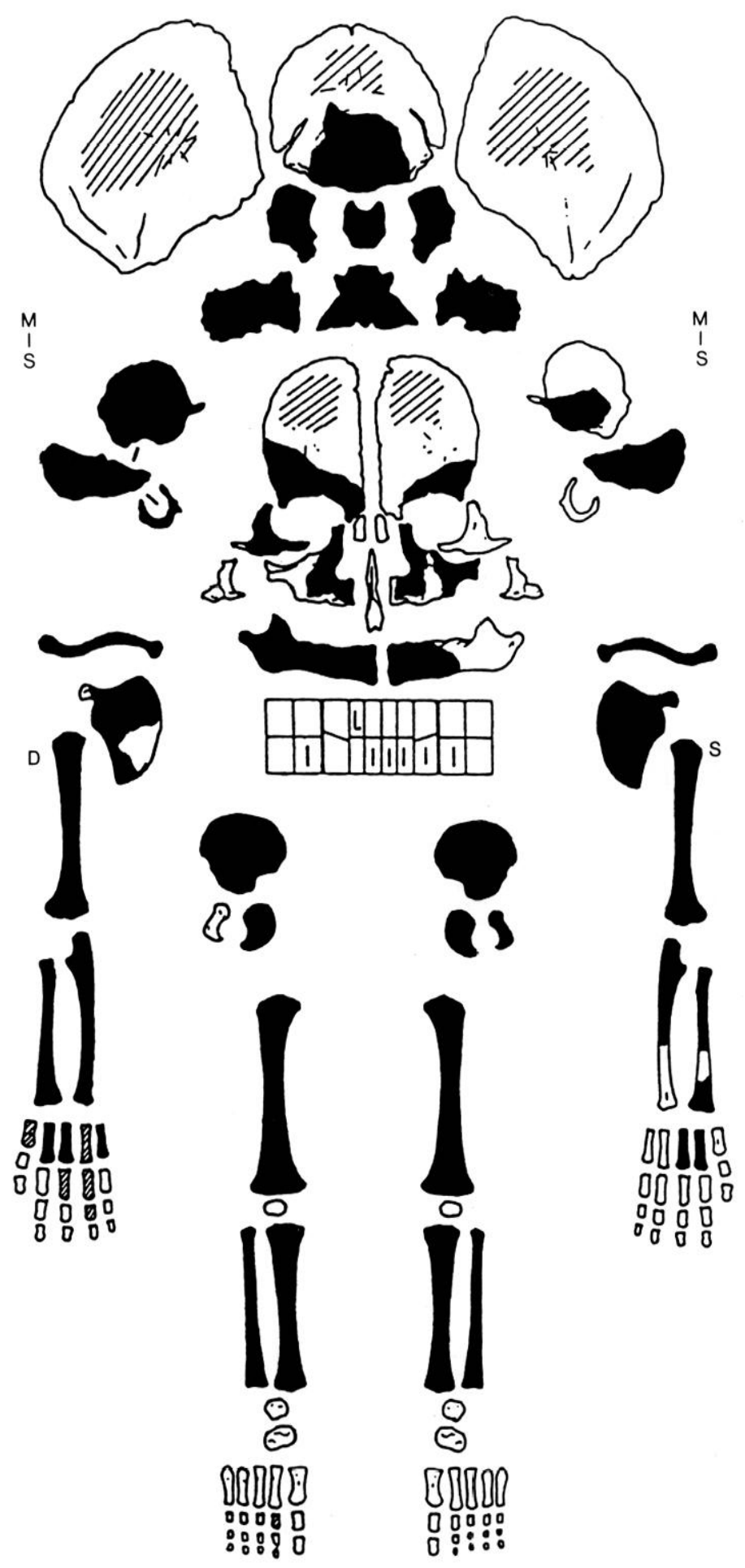

la région est présente et identifiée avec certitude

I'os est présent, mais fragmenté et/ou érodé eVou écrasé fragments présents, dont la situation exacte n'est pas reconnue

圈 I'attribution de la pièce à une région particulière ou, dans certains cas, à un individu défini n'est que supposée

fragments très incertains quant au côté etou à la nature.

Certains ne sont reconnus que d'après leur emplacement à la fouille
Fig. 7 - État de conservation du squelette A2.
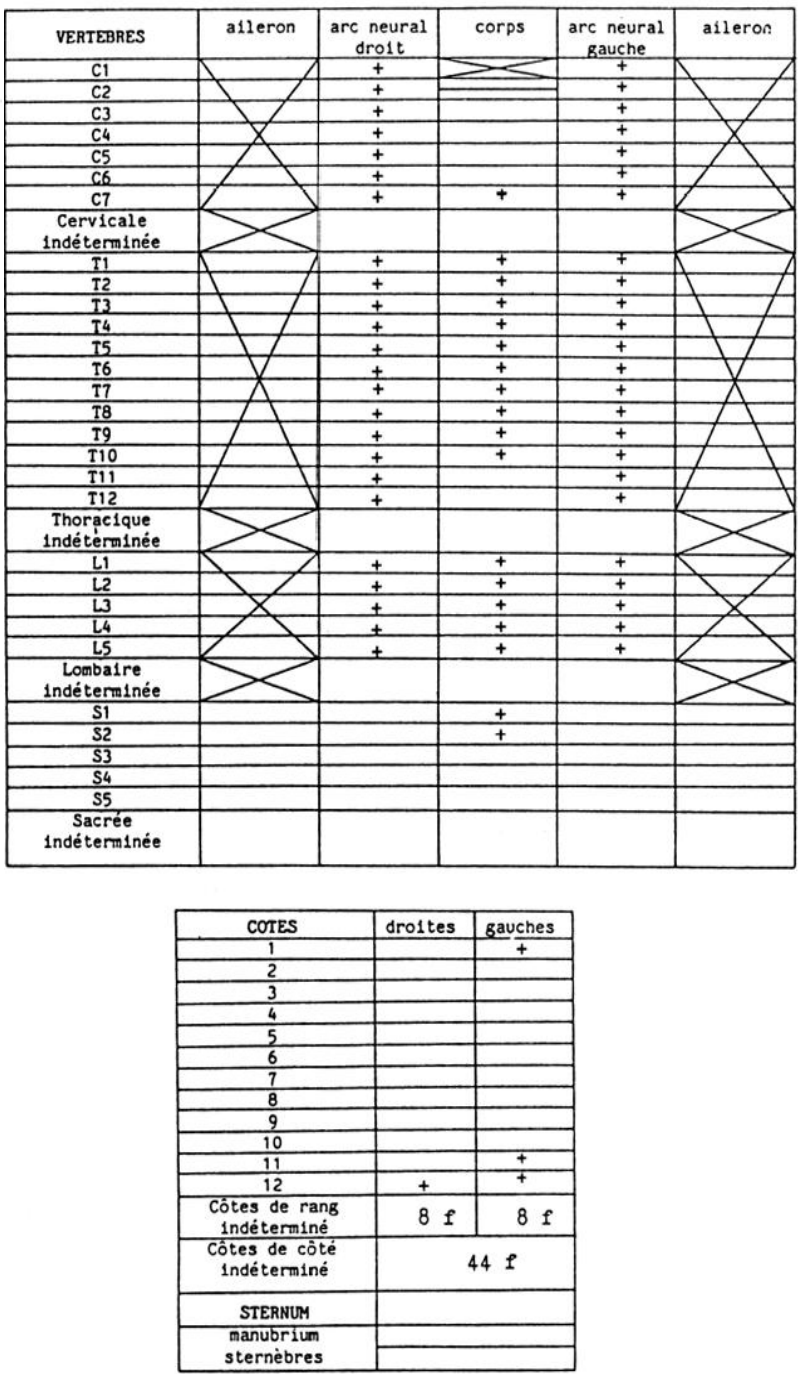

Légende

des diagrammes dentaires

[1] l'élément est présent in situ

17 l'élément isolé est présent et a été identifié avec certitude

10 la racine est seule présente in situ 


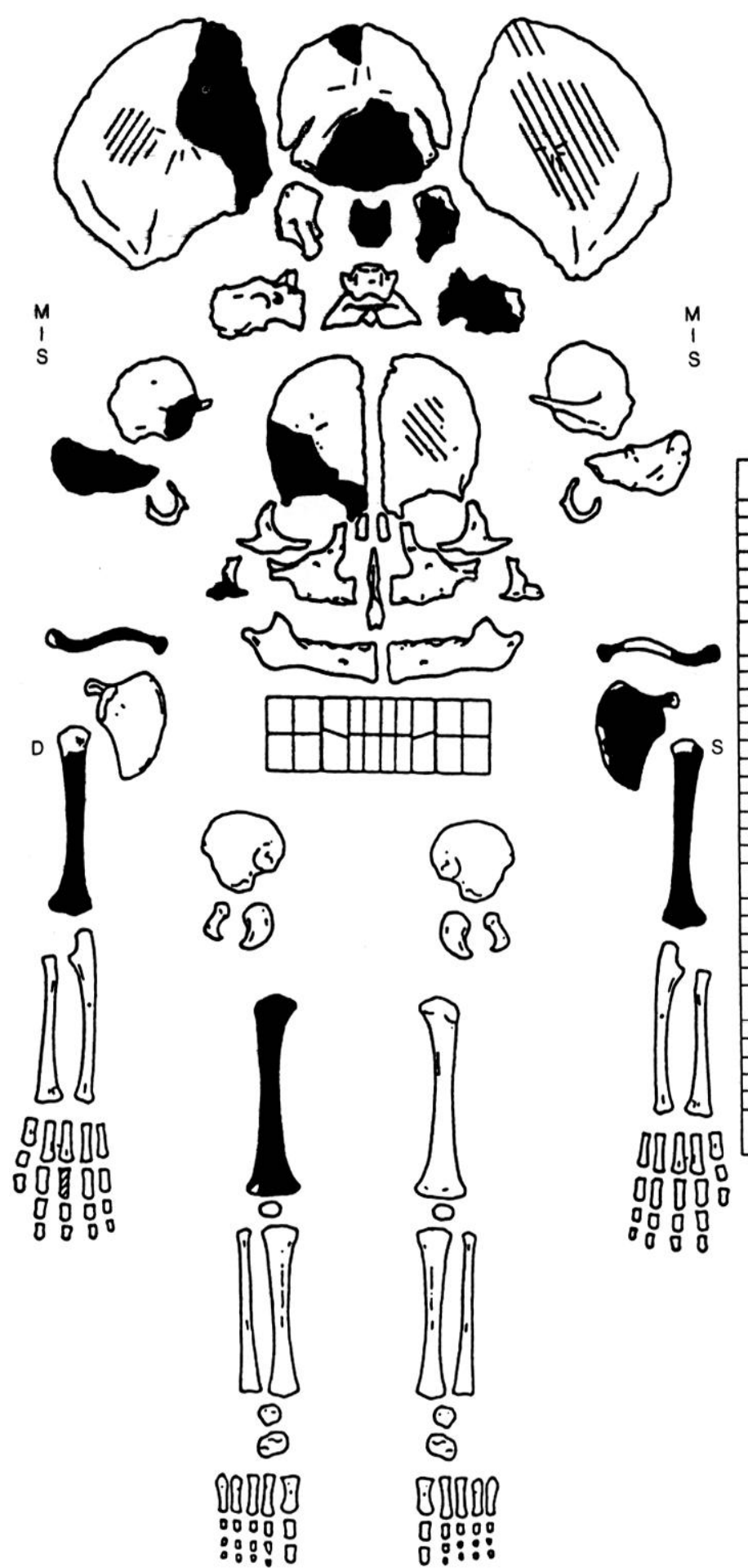

la région est présente et identifiée avec certitude l'os est présent, mais fragmenté et/ou érodé et/ou écrasé fragments présents, dont la situation exacte n'est pas reconnue

l'attribution de la pièce à une région particulière ou, dans certains cas, à un individu défini n'est que supposée

fragments très incertains quant au coté et/ou à la nature.

丝 Certains ne sont reconnus que d'après leur emplacement à la fouille
Fig. 8 - Etat de conservation du squelette B2.
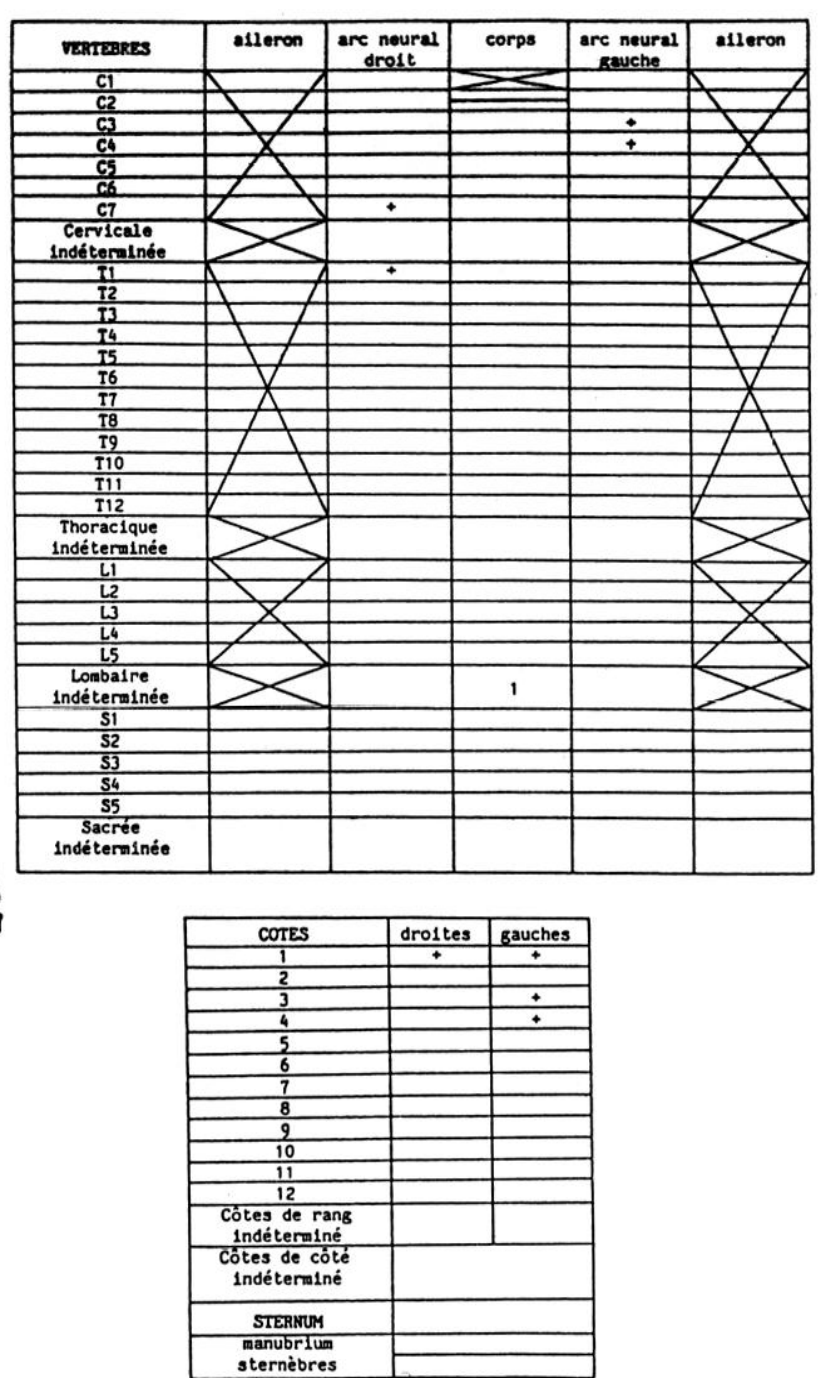

Légende

des diagrammes dentaires

1 l'élément est présent in situ

1 l'élément isolé est présent et a été identifié avec certitude

1. la racine est seule présente in situ l'identification de l'élément isolé n'est que supposée

$?$ un de ces deux eléments est present

f l'élèment est présent in situ, mais fragmenté

fil fragment isolé de couronne identifiable 
Le sujet était déposé dans une petite fosse, profonde de $10 \mathrm{~cm}$, creusée dans la couche de sédimentation humaine sous-jacente, couche 6 , de la seconde moitié du ves. avant $\mathbf{J}$.-C. Cette fosse est scellée par la couche 4, datée de la fin du ve s. ou du début du Ive s. avant J.-C., et un foyer est alors construit en partie au-dessus de cet ensevelissement. Ce dernier doit donc être daté de la fin du $v^{e} s$. ou vers 400 avant J.-C.

Bien qu'il n'ait pas pu être fouillé avec autant de soin que les autres squelettes en place, l'ensemble A2 est relativement complet (fig. 7 et 18). Les quelques germes de dents déciduales qui ont été retrouvés ont un degré de maturation analogue à celui d'un enfant à terme. La taille corporelle, estimée par la moyenne des valeurs calculées pour les deux clavicules, les deux humérus, le radius et l'ulna droits, les deux fémurs, les deux tibias et les deux fibulas (cf. tabl. I, p. 103) est de $52,7 \mathrm{~cm}$. Toutes les mesures relevées sur le squelette post-céphalique s'inscrivent à l'intérieur des variations observées sur des nouveau-nés à terme. En revanche, il existe une discordance évidente avec certains os du squelette crânien (essentiellement le basi-occipital et les exo-occipitaux et, à un moindre degré, les pétreux). Mais l'estimation à partir de ces pièces de dimensions réduites est nécessairement moins précise que celle qui prend en considération les grands os longs des membres.

Nous retiendrons done que le sujet A2 est un enfant à terme, mort-né ou décédé durant les premiers jours de la vie.

\section{Squelette disloqué B2}

Ces restes ont été découverts dans une petite fosse profonde de $0,20 \mathrm{~m}$ et mesurant 0,40 à $0,50 \mathrm{~m}$ de diamètre à l'ouverture, creusée dans un niveau d'aménagement (couche 6-7, formée d'un remblai de pierres et de tessons d'amphore massaliète) d'un espace non couvert, cour ou aire de passage, dont les limites ne sont pas complètement déterminées (fig. 6 et 19). La couche 6-7 est datable du milieu ou de la seconde moitié du $\mathrm{v}^{\mathrm{e}} \mathrm{s}$. avant J.-C. L'ensemble est surmonté par une couche de sédimentation humaine renfermant un mobilier entrant dans le même horizon chronologique. La constitution de ce lot date donc du milieu ou de la seconde moitié du ve s. avant J.-C.

L'ensemble B2 est très incomplet (fig. 8). L'estimation de sa taille corporelle ne peut reposer que sur les dimensions des humérus et du fémur droit, de la scapula gauche et du pétreux droit; la moyenne des valeurs obtenues est de $55,5 \mathrm{~cm}$, résultat légèrement trop fort pour un enfant à terme. Toutes les mesures que nous avons pu relever (cf. tabl. I, p. 103) sont d'ailleurs supérieures à la limite supérieure des variations observées à dix mois lunaires.

Il semble donc que l'ensemble $\mathrm{B} 2$ se rapporte à un nourrisson qui a vècu et dont le décès est survenu durant les premières semaines de la vie.

\section{ESPACE 18A, OSSEMENT C8}

La couche superficielle remaniée (couche 1) a livré dans ce secteur une pièce osseuse isolée qui doit être datée de la dernière occupation de l'oppidum (première moitié ou milieu du $\mathrm{IV}^{\mathrm{e}} \mathrm{s}$. avant $\mathbf{J}$.-C.).

Il s'agit d'une moitié proximale d'humérus droit dont les dimensions (périmètre au milieu : $18 \mathrm{~mm}$ ) sont comparables à celles d'un nouveau-né.

\section{UNITE DOMESTIQUE 21-18; SALLE D'HABITATION 21}

La maison 21 a livré dans deux couches différentes une pièce osseuse isolée (C9) et un squelette disloqué incomplet (B3) (fig. 9).

\section{Couche 2, ossement C9}

Un ossement isolé provient de la strate d'effondrement de la maison 21 (couche 2, carré E33), composée de pierres issues des murs, enrobées d'un sédiment argileux gris-jaune (liant des murs et torchis de la couverture), et renfermant également quelques détritus culinaires, tessons et ossements de faune, datables du début du Ive $^{\mathrm{e}} \mathrm{s}$. Il en résulte que ces ruines, non rebâties, servent alors de lieu de dépotoir pour les habitants sans doute les plus proches, comme ceux de la maison 18A.

Cette diaphyse de tibia gauche a un périmètre au milieu de $22 \mathrm{~mm}$. Sa longueur (cf. tabl. I, p. 103) permet d'estimer la stature à $54,2 \mathrm{~cm}$, valeur compatible avec un âge égal ou légèrement supérieur au terme, mais supérieure à toutes celles qui ont pu être calculées pour les pièces rapportées au sujet B3.

\section{Squelette disloqué B3}

Les restes groupés mais disloqués d'un squelette incomplet se trouvaient dans la salle d'habitation $\mathrm{n}^{0} 21$ de l'unité domestique 21-18, à $1,20 \mathrm{~m}$ de la porte septentrionale, dans l'axe de celle-ci (fig. 9). Ils ont été découverts dans un niveau de sédimentation humaine (couche 4) formé durant l'occupation des lieux dans la seconde moitié ou le dernier quart du $v^{e} \mathbf{s}$. avant $\mathbf{J}$.-C. Le prélèvement en bloc de ces vestiges, en vue de leur fouille en laboratoire, procédure choisie au moment de la découverte par suite du désordre apparent de l'ensemble, ne permet pas de 


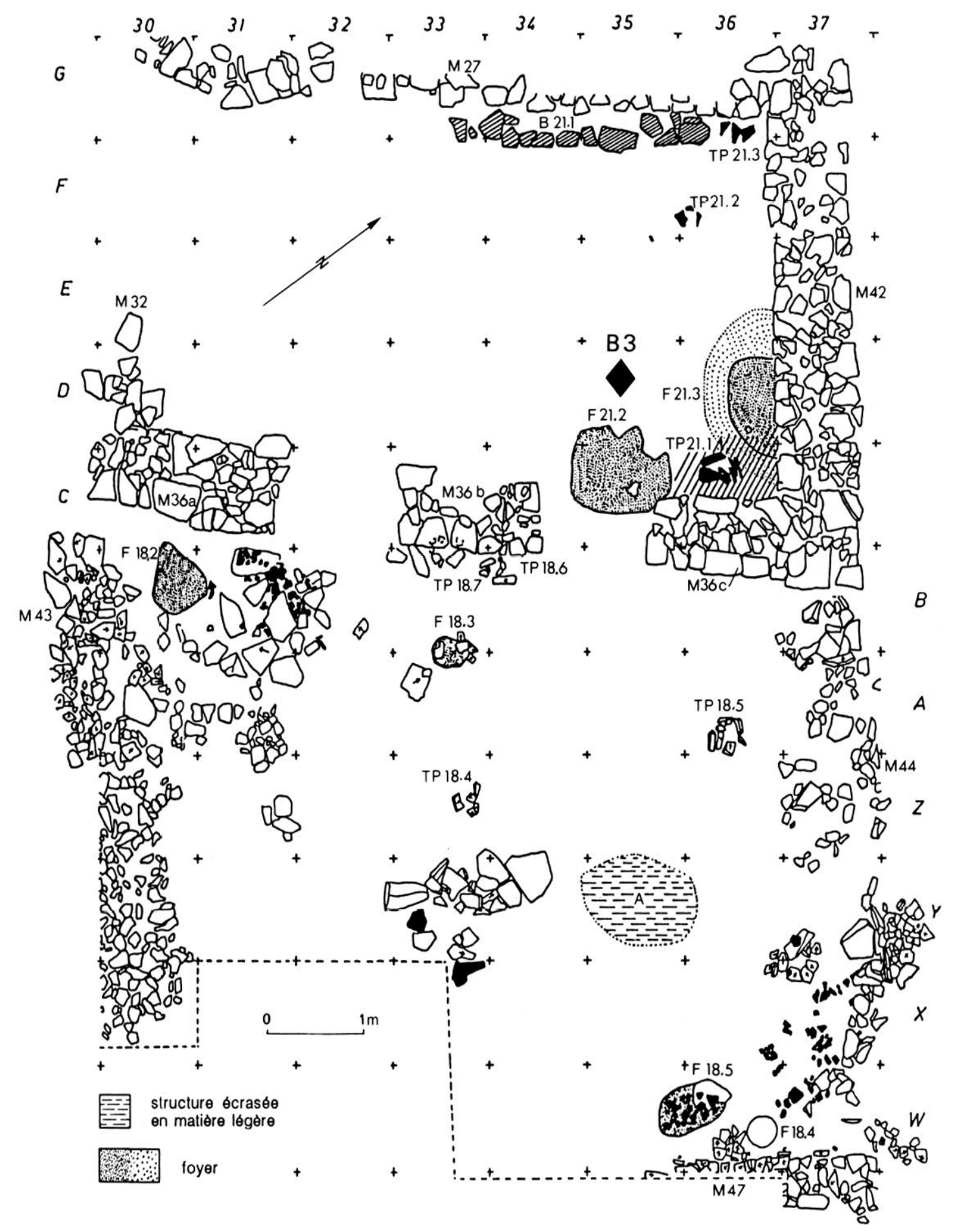

Fig. 9 - Unitè domestique $21-18$ (dernier quart du ve s. avant J.-C.); localisation du squelette en place B3 (F21.2, F21.3 et F18.2 à F18.5 : foyers; TP21.1 à TP21.3 et TP18.4 à TP18.6 : calages de poteaux).

savoir si les ossements appartiennent réellement à la couche 4 ou s'ils ont été déposés dans une petite fosse creusée à partir du sol 3 sus-jacent. Ce dernier correspond au terme de l'habitat dans la maison à la fin du $v^{e}$ s. avant J.-C. Dans les deux cas, les restes du sujet périnatal gisent à proximité d'un foyer : à 0,20 ou $0,30 \mathrm{~m}$ du foyer $\mathrm{F} 21.2$ s'ils appartiennent à la couche 4 , à $0,50 \mathrm{~m}$ du foyer F 21.1 s'ils doivent être rapportés au sol 3. Quoiqu'il en soit la datation de cet individu est à placer dans le dernier quart du $v^{e}$ s. ou les environs de 400 avant J.-C.

Le squelette de l'ensemble $\mathrm{B} 3$ est relativement incomplet (fig. 10). Les germes dentaires retrouvés ont un degré de maturation compatible avec le 


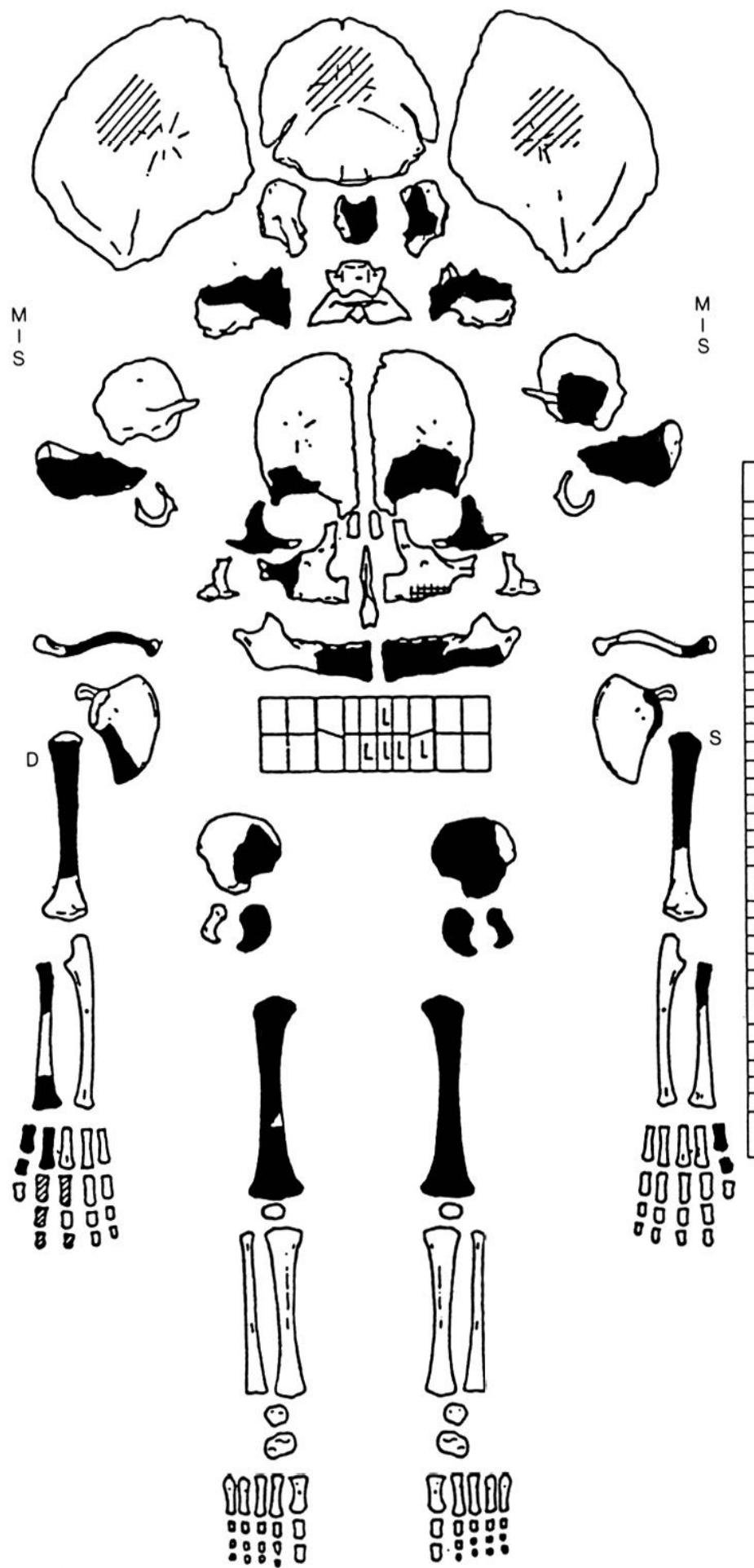

la région est présente et identifiée avec certitude

l'os est présent, mais fragmenté et/ou érodé evou écrasé fragments présents, dont la situation exacte n'est pas reconnue

l'attribution de la pièce à une région particulière ou, dans certains cas, à un individu défini n'est que supposée

fragments très incertains quant au coté evou à la nature.

裉 Certains ne sont reconnus que d'après leur emplacement à la fouille
Fig. 10 - État de conservation du squelette B3.
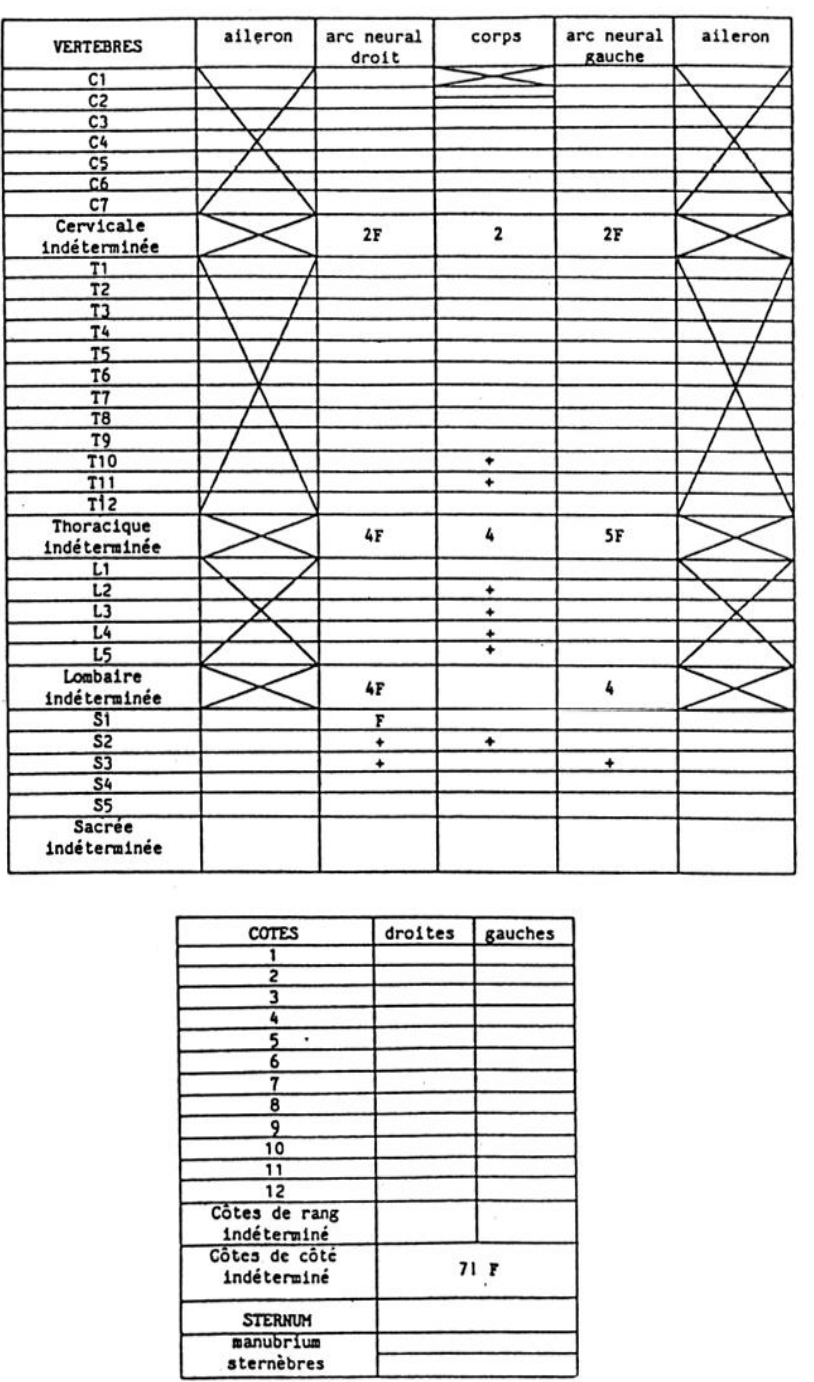

\section{Légende}

des diagrammes dentaires

(1) l'élément est présent in situ

l'elément isolè est présent et a été identifié avec certitude

1 la racine est seule présente in situ
? l'identification de l'élément isolè n'est que supposée

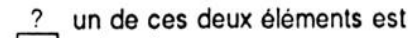
présent

f'élèment est présent in situ, mais fragmenté

[f. fragment isolé de couronne identifiable 


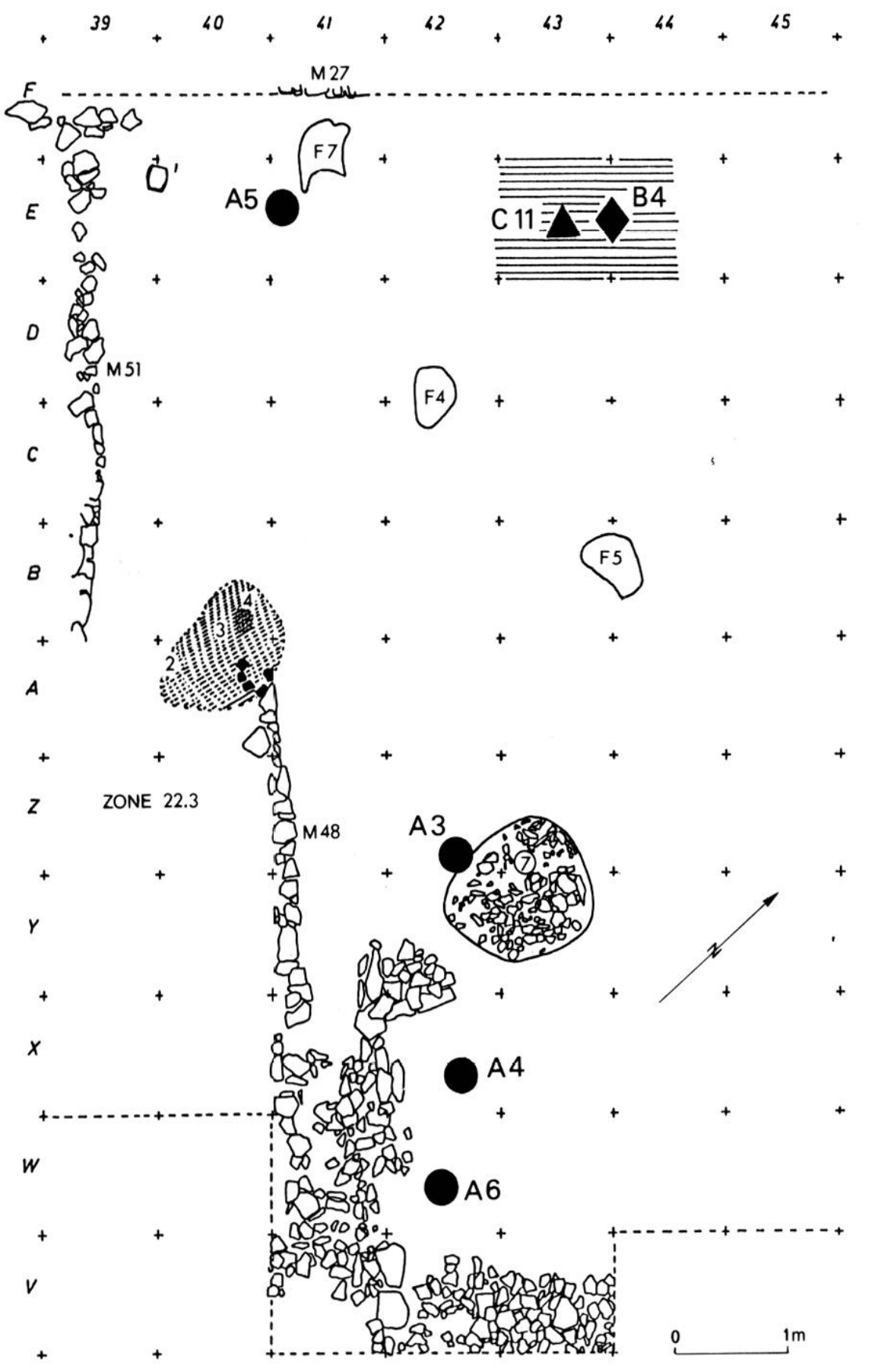

Fig. 11 - Cour domestique 22 (dernier quart du $v^{e}$ s. avant J.-C.). Localisation des squelettes en place $\mathrm{A} 3, \mathrm{~A} 4, \mathrm{~A} 5$ et $\mathrm{A} 6$ et carrés de découverte des pièces du squelette disloqué B4 et de l'ossement isolè C11.

terme. La taille corporelle a été estimée à partir des dimensions du fémur gauche, de l'ilion gauche, des deux ischions, du pubis gauche (cf. tabl. I, p. 103) et des deux premiers métacarpiens; la moyenne des valeurs calculées est de $50,8 \mathrm{~cm}$, ce qui suggère un décès très voisin du terme. Les pièces crâniennes qui ont pu être mesurées (pétreux et zygomatique droits) donnent en revanche une estimation beaucoup plus faible $(44,0 \mathrm{~cm})$, mais moins fiable.

Le sujet B3 est donc vraisemblablement un enfant à terme, mort-né ou décédé durant les premiers jours de la vie.

\section{COUR DOMESTIQUE 22}

La cour domestique 22 renfermait un ossement isolé (C10) dans la couche 2, un ossement isolé (C11), plusieurs éléments d'un squelette disloqué (B4) et quatre squelettes en place (A3, A4, A5 et A6) dans la couche 5 (fig. 11).

\section{Couche 2, ossement $\mathrm{C} 10$}

Un ossement isolé a été découvert dans la couche 2 d'abandon d'une cour domestique (carré C 40), datée de la première moitié du IV $\mathrm{s}$. avant J.-C., à environ $3 \mathrm{~m}$ du foyer $\mathrm{F} 22.1$. 
Il s'agit de la moitié distale d'un humérus gauche, dont la largeur distale (cf. tabl. I, p. 103) et le périmètre au milieu $(17 \mathrm{~mm})$ indiquent un àge voisin du terme. Les documents C8, C9 et C10 sont donc compatibles; cependant, ils ont été découverts à plusieurs mètres de distance les uns des autres, de sorte qu'il est très peu probable qu'ils puissent appartenir au même individu.

\section{Ossement isolé $\mathrm{C} 11$, squelette disloqué $\mathrm{B} 4$ et squelettes en place (A3, A4, A5 et A6) de la couche 5}

La couche 5 est une strate de sédimentation humaine d'une cour domestique de $70 \mathrm{~m}^{2}$ environ de superficie. Formée essentiellement par étalement de vidanges de foyers, terre cendreuse et charbonneuse incluant de très nombreux tessons de poterie, fragments de récipients de stockage en matière légère et ossements de faune isolés, elle s'est constituée durant le dernier quart du $\mathrm{v}^{\mathrm{e}} \mathrm{s}$. avant J.-C., datation que l'on retiendra pour les restes humains qu'elle renferme. Cet état de cour inclut divers aménagements domestiques : trois foyers successifs (F4, F5 et F7), deux silos aériens en matière légère et une fosse de plan ovalaire avec un profil conique et des parois abruptes, de 1,20 à $1,40 \mathrm{~m}$ de diamètre à l'ouverture et $0,63 \mathrm{~m}$ de profondeur (fosse 7). Les autres fosses de Gailhan sont comblées avec un sédiment analogue à celui dans lequel elles sont creusées, incluant des détritus culinaires. Le remplissage de celle-ci présente un certain nombre de particularités qui rendent difficile l'interpretation de la fonction de cette structure : au fond, plusieurs vases intacts associés à deux objets de parure en bronze, une fibule et un bracelet; partie supérieure comblée par une couche épaisse d'environ $0,40 \mathrm{~m}$, composée de tessons de dolium mélangés à quelques pierres. L'absence de tout reste humain, brûlé ou non, rend l'hypothèse d'une tombe peu probable. S'agit-il d'une fosse à offrandes?

\section{Couche 5, squelette incomplet disloqué B4 et ossement isolé C11}

Plusieurs ossements ont été découverts répartis sur une surface de 1 à $2 \mathrm{~m}^{2}$, dans la partie nord-ouest de la cour (carrés E 43-E 44) à plus de $1 \mathrm{~m}$ du foyer le plus proche.

L'ensemble B4 comporte: un hémi-arc neural droit de vertèbre thoracique; une còte moyenne gauche, complète; un fragment de diaphyse indéterminée (fibula?); un humérus gauche (périmètre au milieu : $17 \mathrm{~mm}$ ); un ischion droit; un fémur droit, intact, et un fragment de diaphyse de fémur gauche (périmètre au milieu : $20 \mathrm{~mm}$ ); un tibia droit et la portion moyenne du tibia gauche symétrique (périmètre au milieu : $19 \mathrm{~mm}$ ); une fibula droite et la partie proximale d'une fibula gauche (périmètre au milieu : $11 \mathrm{~mm}$ ).

La stature estimée par la moyenne des valeurs calculées à partir des dimensions données au tableau I (p. 103) est de 49,3 cm; il s'agit donc d'un sujet décédé durant la période périnatale.

Un tibia droit, presque complet, appartient nécessairement à un sujet (C11) autre que B4. Son périmètre au milieu est de $16,5 \mathrm{~cm}$. Sa stature était nettement supérieure à $45,0 \mathrm{~cm}$ (valeur calculée à partir de la longueur maximale estimée par défaut). Cet os appartient donc à un individu décédé à un âge voisin du terme (avec une marge d'incertitude relativement grande). A proximité de ce tibia (carré $\mathrm{E} 43$, décapage 6), ont également été trouvés l'hémi-arc neural droit d'une vertèbre lombaire supérieure et une scapula gauche incomplète; ces deux vestiges ont des dimensions qui sont, elles aussi, compatibles avec le terme et peuvent indifféremment être attribués à $\mathrm{C} 11$ ou $\mathrm{B} 4$.

\section{Squelette $A 3$}

Le squelette A3 git dans une petite fosse que seule la position du corps a permis de repérer partiellement, creusée à l'intérieur de la couche $\overline{5}$, dans la moitić orientale de la cour 22 (carré Z 12), à $3 \mathrm{~m}$ du foyer le plus proche (F 5 ). Il se trouve en bordure de la fosse 7 dont le creusement a entrainé la disparition d'une partie des ossements (fig. 11).

Le squelette $\mathrm{A} 3$ est relativement incomplet (fig. 12, 20 et 21); il a été perturbé par le terrier d'un animal fouisseur et par le creusement de la fosse 7 . La calcification des incisives latérales et des premières molaires supérieures et inférieures est compatible avec le terme. La taille corporelle, estimée par la moyenne des valeurs calculées sur la base des longueurs diaphysaires de l'humérus, du radius, de l'ulna, du fémur et du tibia droits, de la longueur de la clavicule droite, de la hauteur de la scapula droite (cf. tabl. I, p. 103) et de la longueur des deux pétreux, est de $53,0 \mathrm{~cm}$. Les mesures précédentes entrent toutes dans les marges de variation observées sur des enfants à terme (dix mois lunaires) et sont pour la plupart supérieures à la limite supérieure des variations à neuf mois lunaires et demi.

L'ensemble A3 se rapporte donc à un enfant à terme, mort-né ou décédé durant les premiers jours de la vie. 


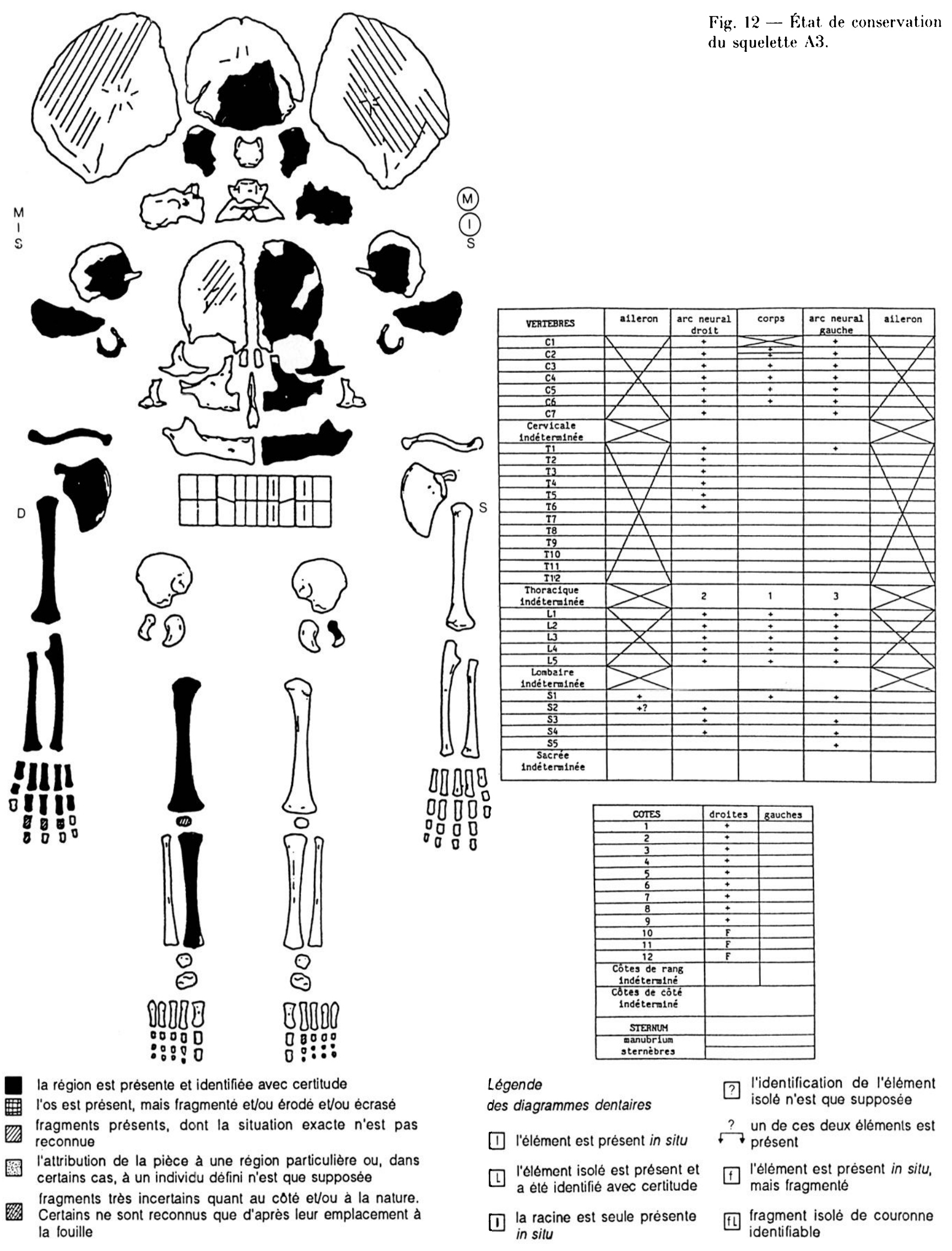




\section{Squelette $A 4$}

Le squelette 14 se trouve également dans la moitié orientale de la cour 22 , à $1,60 \mathrm{~m}$ seulement à l'est du précédent, mais beaucoup plus éloigné encore de la zone des foyers (à 4,20 m du foyer F5) (fig. 11). Il repose dans une petite fosse grossièrement ovalaire de $0,58 \mathrm{~m}$ sur son grand axe, $0,39 \mathrm{~m}$ sur le petit axe et $0,14 \mathrm{~m}$ de profondeur maximum. Le creusement de cette structure a endommagé une jatte non tournée écrasée sur place antérieurement et qui n'a donc aucun lien avec cette inhumation. Le quart de ce récipient a été dispersé alors, et certains tessons ont été retrouvés dans la fosse, contre les parois et dans le remplissage. Le cadavre a été déposé dans la partie ouest de la dépression, appuyé contre un petit amas formé par des pierres et des tessons.

Ce squelette est remarquablement complet (fig. 13,22 et 23 ). Les germes des dents déciduales ont un degré d'évolution compatible avec le terme. La taille corporelle, estimée par la moyenne des valeurs calculées à partir des dimensions des clavicules, des scapulas, des humérus, des radius et des ulnas, de l'ilion et du pubis droits, des ischions, des fémurs, des tibias et de la fibula droite (tabl. I, p. 103) est de $52,8 \mathrm{~cm}$. Toutes les mesures relevées sur ces os entrent parfaitement dans les limites des variations observées à dix mois lunaires. Ce sujet est donc un mort-né à terme ou un enfant décédé durant les premiers jours de la vie.

\section{Squelette A5}

Le squelette $A 5$ a été déposé en bordure occidentale de la cour 22 , à $1 \mathrm{~m}$ du mur denceinte. Il a été découvert à quelques centimètres seulement du foyer $\mathrm{F} 7$ mais la contemporanéité exacte de ces deux faits ne peut ètre établie (fig. 11). Aucun élément de la fosse qui l'a accueilli n'a pu ètre perçu, mais les observations ostéologiques de terrain ont permis de conclure que le corps s'est décomposé dans un espace colmaté.

Le squelette du sujet $A 5$ est lui aussi remarquablement complet (fig. 14, 24 et 25). La maturation des germes de dents déciduales est dans l'ensemble comparable à celle d'un enfant à terme. La taille corporelle, estimée par la moyenne des valeurs calculées sur la base des longueurs diaphysaires des deux humérus, de l'ulna et du radius droits, du tibia et de la fibula gauches (cf. tabl. I, p. 103), est de $47,6 \mathrm{~cm}$. Les mesures qui ont été relevées sur ces os, ainsi que sur l'ilion gauche et les clavicules, entrent dans les variations observées sur des fortus de neuf mois lunaires et demi à dix mois lunaires, certaines étant cependant trop faibles pour correspondre à un enfant à terme. Le sujet tà est donc très probablement un prématuré, mort-né ou décédé durant les premiers jours de la vie.

\section{Squelette A6}

Le squelette $\mathrm{A} 6$ a été découvert vers la bordure orientale de la cour 22 . à $0,70 \mathrm{~m}$ seulement à l'est du squelette A4 (carré W 42) (fig. 11). Il gisait dans une petite fosse perceptible seulement par l'weffet de paroi" de certains éléments du squelette ou du comblement.

Le squelette du sujet 16 est relativement complet, mais fragmenté (fig. 15 et 26). Tous les germes dentaires qui ont été retrouvés ont une maturation légèrement plus avancée que celle qui peut ètre observée chez un enfant à terme. La taille corporelle, estimée par la moyenne des valeurs relevées sur l'humérus, le radius, l'ulna, l'ilion et l'ischion droits (cf. tabl. I, p. 103) et sur les deux premiers métacarpiens et métatarsiens, est de $56,5 \mathrm{~cm}$; elle est donc également trop forte pour un individu à terme. Les os du crâne (petite et grande ailes droites du sphénoïde, pétreux droit et écaille du temporal droit) donnent une estimation plus basse $(49,8 \mathrm{~cm})$. mais ici encore moins fiable.

Nous retiendrons donc que le sujet A6 est un enfant qui a vécu, et dont le décès est survenu entre un et trois mois après la naissance.

\section{AIRE 24.1, SQUELETTE DISLOQUÉ INCOMPLET B5}

Un petit lot d'ossements a été découvert dispersé sur environ $1 \mathrm{~m}^{2}$ (carré $\mathrm{X}$ 48) dans la couche 3 de l'espace 24.1, lieu non couvert dont la limite septentrionale n'a pas été atteinte et la bordure orientale a été détruite par les travaux agricoles. Cet espace dépourvu de tout aménagement domestique semble ètre un terrain vague entre des secteurs plus structurés. Le mobilier de la couche 3 , issu des rejets des unités domestiques voisines, le date de la première moitié du $\mathrm{IV}^{\mathrm{e}} \mathrm{s}$. avant J.-C. Les ossements humains doivent provenir d'un squelette disloque anciennement, peut-ètre avant la fin de l'occupation protohistorique du site.

L'ensemble B5, relativement important, se compose de : un zygomatique gauche incomplet; un exo-occipital gauche érodé; un fragment de voùte crânienne; les hémi-ares neuraux gauches d'un atlas. d'un axis, de deux vertèbres cervicales movennes. d'une vertèbre thoracique supérieure (sans doute la 

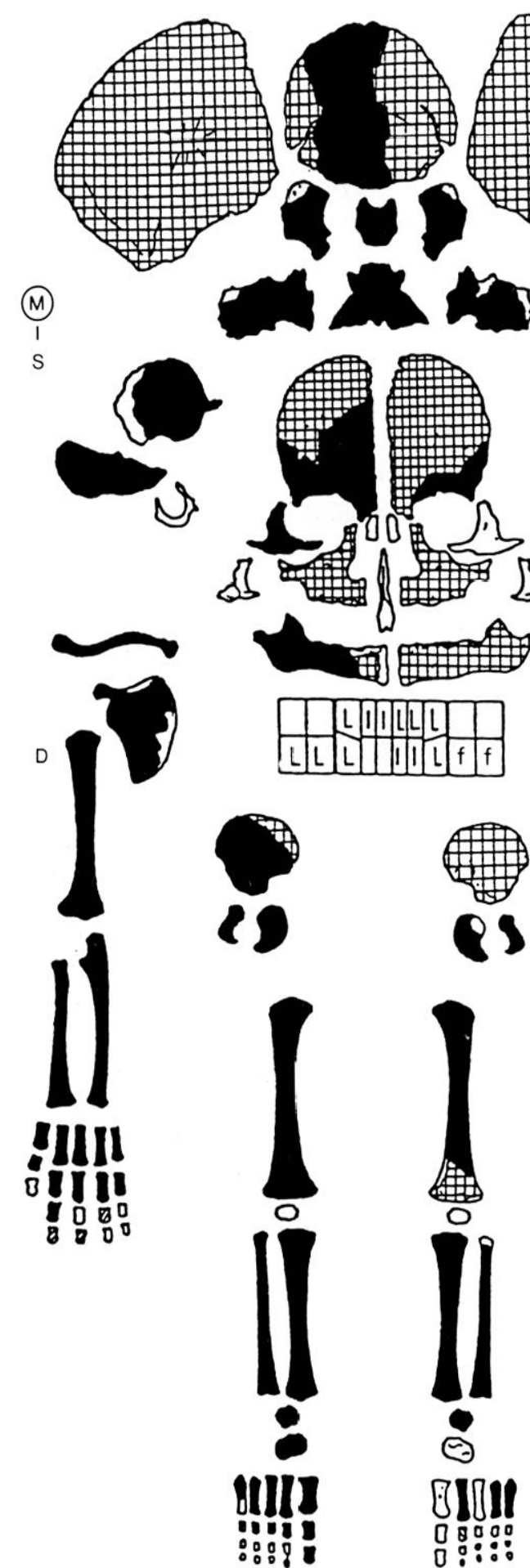

la région est présente et identifiée avec certitude

曹

etrésent, mais fragmente et/ou érodè etou ècrase

fragments presents, dont la situation exacte n'est pas reconnue

I'attribution de la pièce à une région particulière ou, dans certains cas, à un individu dẻfini n'est que supposée

fragments très incertains quant au côté et/ou à la nature.

Certains ne sont reconnus que d'après leur emplacement à la fouille
Fig. 13 - État de conservation du squelette $\mathrm{A} 4$.
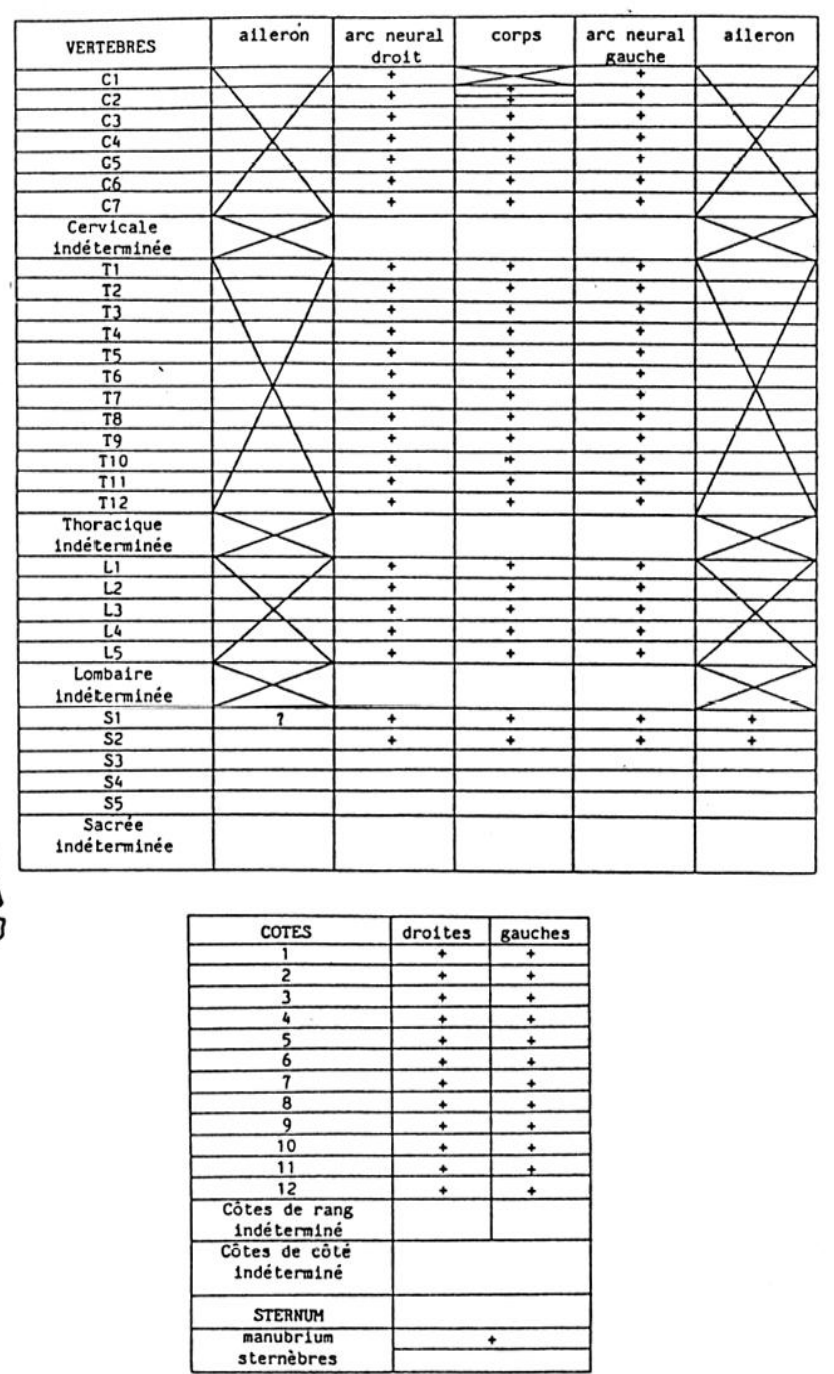

Légende

des diagrammes dentaires

1 l'élément est présent in situ

l'élément isolé est présent et a éte identifié avec certitude

1 la racine est seule presente in situ l'identification de l'élément isolé n'est que supposée

$?$ un de ces deux éléments est present

f l'élément est présent in situ, mais fragmenté

fl fragment isolè de couronne identifiable 


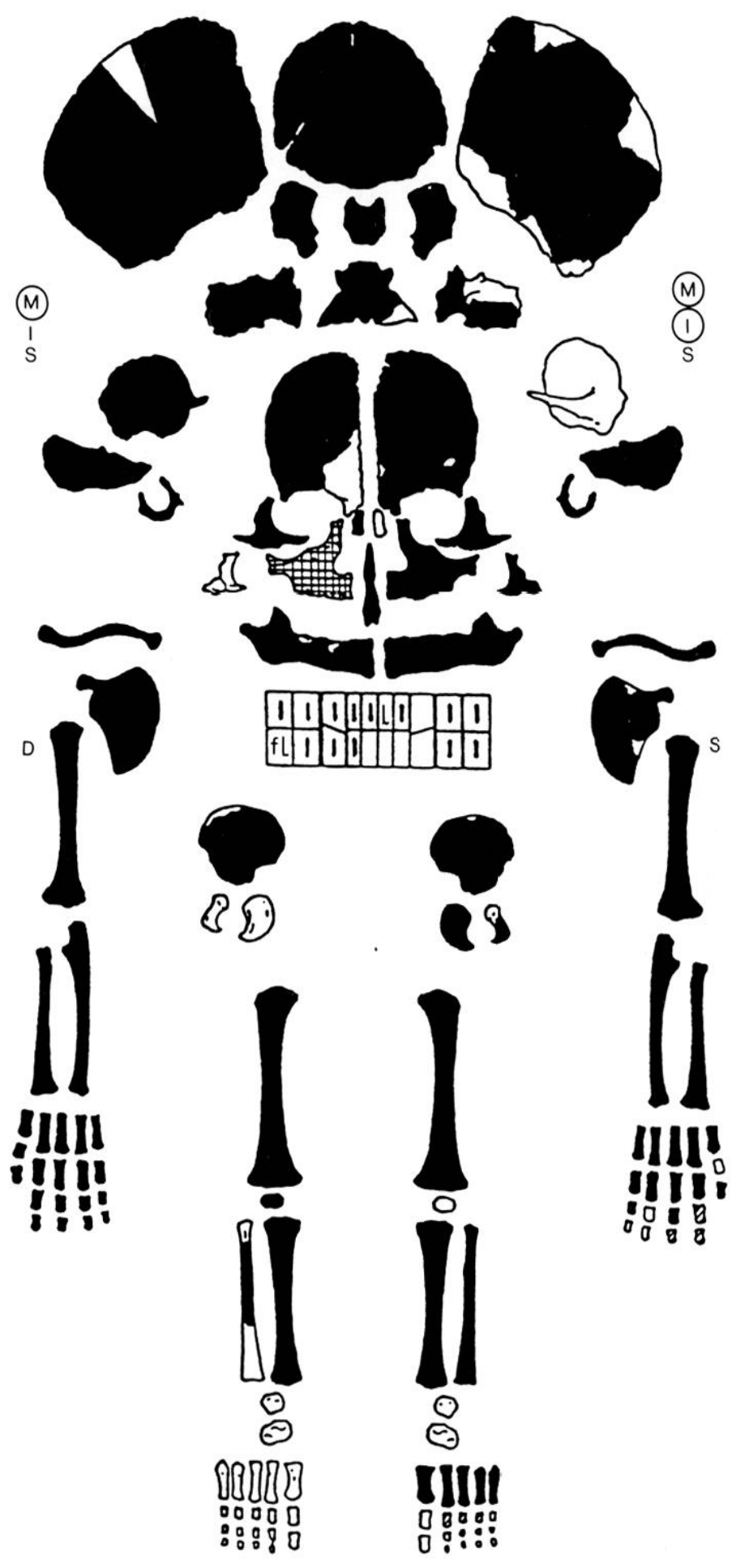

la région est présente et identifièe avec certitude

I'os est présent, mais fragmenté et/ou érodé etou écrasé fragments présents, dont la situation exacle n'est pas reconnue

l'attribution de la pièce à une région particulière ou, dans certains cas, à un individu défini n'est que supposée

fragments très incertains quant au côté et/ou à la nature.

Certains ne sont reconnus que d'après leur emplacement à la fouille
Fig. 14- État de conservation du squelette tis.
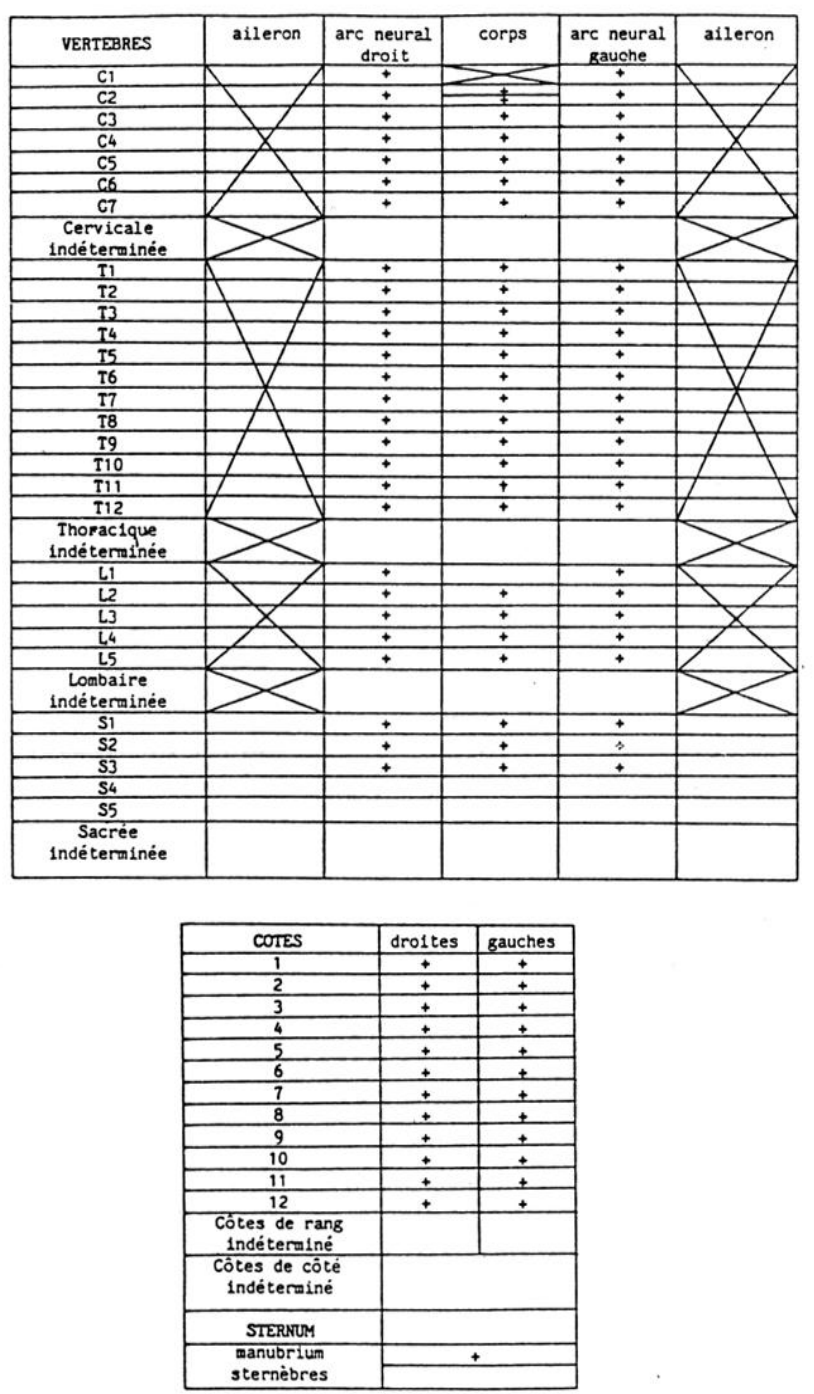

Légende

des diagrammes dentaires

1 l'élément est présent in situ

l'elément isolé est présent et a èlé identifié avec certitude

(1) la racine est seule présente in situ
? l'identification de l'élément isolé n'est que supposée

? un de ces deux éléments est $\longrightarrow$ présent

l'élèment est present in situ. mais fragmenté

[f fragment isolé de couronne identifiable 


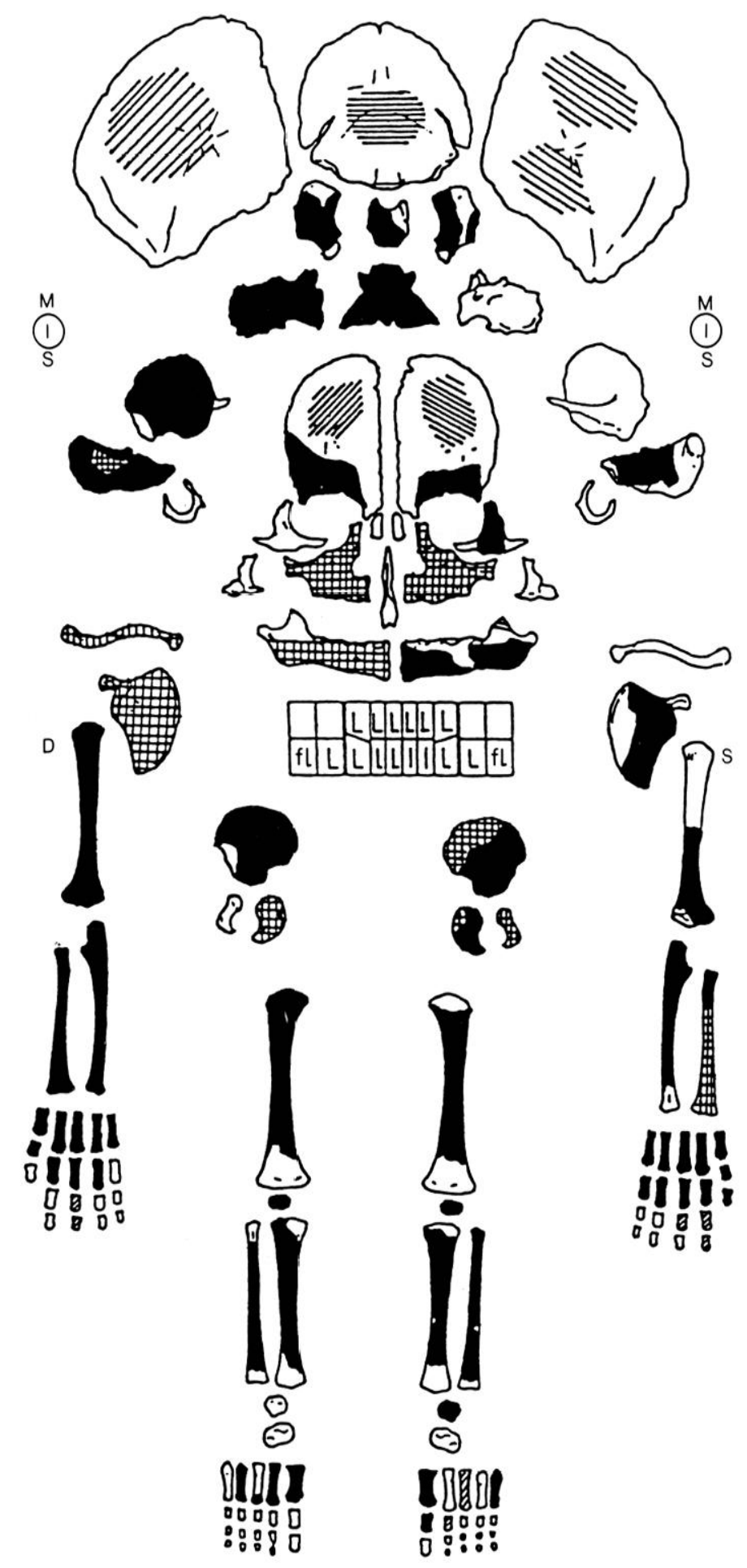

la région est présente et identifièe avec certitude

l'os est présent, mais fragmenté et/ou érodè etou écrasé

fragments présents, dont la situation exacte n'est pas reconnue

l'attribution de la pièce à une région particulière ou, dans certains cas, à un individu défini n'est que supposée

fragments très incertains quant au coté et/ou à la nature.

Certains ne sont reconnus que d'après leur emplacement à la fouille
Fig. 15 - Etat de conservation du squelette A6.
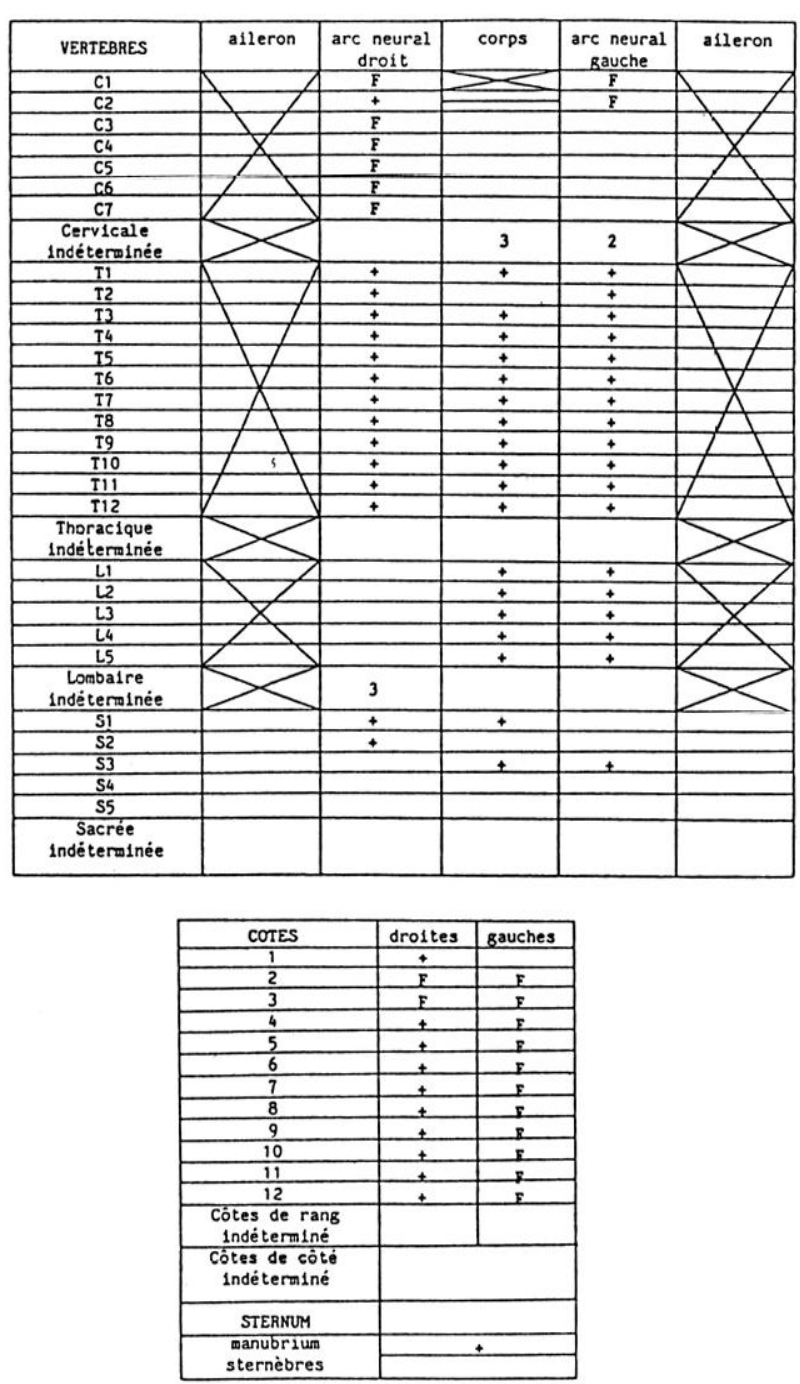

Légende

des diagrammes dentaires

1. l'élément est présent in situ

l'élément isolé est présent et a élé identifié avec certitude

1. la racine est seule présente in situ l'identification de l'élèment isolè n'est que supposée

? un de ces deux éléments est present

ff l'élèment est présent in situ, mais fragmenté

fil fragment isole de couronne identifiable 
première) et d'une vertèbre lombaire, et trois fragments d'hémi-arcs neuraux de vertèbres thoraciques; un fragment de scapula; la partie moyenne d'une clavicule droite (périmètre au milieu : $11 \mathrm{~mm}$ ); une diaphyse incomplète d'humérus droit, dont le périmètre au milieu est de $16 \mathrm{~mm}$; un radius droit (périmètre au miliẹı : $11 \mathrm{~mm}$ ); deıx fragments jointifs d'une ulna droite (périmètre au milieu : $11 \mathrm{~mm}$; diamètre antéro-postérieur proximal : $8,8 \mathrm{~mm}$ ).

Toutes les mesures qui ont été relevées sont comparables à celles d'un enfant à terme. La stature, estimée par la moyenne des valeurs calculées à partir de la longueur du radius et de la largeur distale de l'humérus, est de $51,0 \mathrm{~cm}$. Il est donc probable que le sujet $B 5$ est un enfant à terme, mort-né ou décédé durant les premiers jours de la vie.

\section{COUR 24, OSSEMENT C12}

Un ossement isolé provient de la couche 5 (carré Z 52) de la cour domestique 24, datée du début du Iv"s. Cette cour paraît alors peu utilisée: pour tout aménagement, elle possède un four en cloche et deux calages de poteaux; ses clotures sont alors en ruine.

Il s'agit d'un hémi-arc neural droit isolé se rapportant à une vertèbre thoracique inférieure (probablement la onzième ou la douzième), dont les dimensions sont identiques à celles d'un sujet à terme. Ce sujet (C12) pourrait en théorie être confondu avec l'ensemble B5, qui en est cependant éloigné de plus de $3,15 \mathrm{~m}$ et a été trouvé dans une couche moins profonde; il est donc probable que $\mathrm{C} 12$ et $\mathrm{B} 5$ relèvent bien de deux individus différents.

\section{ÉTUDE ANALYTIQUE}

\section{DE LA DISPOSITION DES SQUELETTES} EN CONNEXION (A1, A2, A3, A4, A5 ET A6) ET DE L'ENSEMBLE B2

Les méthodes utilisées pour la fouille ont été exposées précédemment. Les plans qui seront donnés pour illustrer la discussion (fig. 17, 19, 20, 23, 25 et 26) sont des plans synthétiques, obtenus par la superposition de tous les relevés successifs (en moyenne six) effectués pour un même dépôt. Afin de ne pas en alourdir la présentation, nous n'y avons généralement pas reporté les numéros d'inventaire de chaque pièce squelettique.

\section{LE DÉPÔT Al}

Lors de la fouille de la cour domestique $15 \mathrm{~A}$, le crâne complet, mais un peu écrasé, d'un sujet qui semblait être mort en période périnatale, a été mis au jour. Ces vestiges furent donc photographiés, repérés sur plans et prélevés; le secteur fut mis en réserve dans l'attente d'une fouille spécialisée qui eut lieu quelques semaines plus tard.

Le corps (fig. 16 et 17) était adossé contre la face verticale (tranche de section) d'une plaque de calcaire d'assez grandes dimensions, qui présente un faible pendage du nord-ouest au sud-est. La position de la tête par rapport au tronc a pu être restituée avec précision à partir des éléments de la base du crâne qui étaient restés en place lors de l'enlèvement du squelette céphalique : rocher gauche, exo-occipitaux droit et gauche et basi-occipital. Elle paraît avoir été appuyée sur le bec que forme l'angle nordouest de la dalle, de sorte qu'elle était surélevée de quelques centimètres par rapport au reste du corps. Le rachis cervical est en hyperextension.

Le thorax apparaît par sa face antéro-latérale droite; les cottes droites sont en connexion parfaite. Le manubrium sternal est descendu au niveau de l'extrémité antérieure de la cinquième còte droite. Les còtes gauches se sont ouvertes en éventail.

Le membre supérieur droit est fléchi, avec un angle brachio-antébrachial d'environ $90^{\circ}$. La scapula, l'humérus, le radius et l'ulna se présentent par leur face postérieure : ils ont probablement été rabattus vers l'avant sous le poids des sédiments. I)e ce fait, il existe une petite disjonction au niveau du poignet; les métacarpiens, qui sont en connexion, s'appuient sur l'avant-bras gauche, ou plus exactement sur l'ulna car le radius gauche a été légèrement. remanié et passe en pont au-dessus du premier métacarpien droit. Ces mouvements limités, survenus après la disparition d'une partie au moins des contensions musculo-ligamentaires, sont sans doute aussi à l'origine de la dislocation des doigts, dont les os ont été dispersés au-dessus de la cuisse gauche.

Le membre supérieur gauche semble avoir été en extension. L'humérus est engagé sous le gril costal, mais son extrémite proximale se trouve à quelque distance de la cavité glénoïde de la scapula qui, elle, est en relation conforme avec la clavicule. I.e coude est également disjoint; le radius et l'ulna se croisent en pronation : la main gauche, ramenée en avant du bassin, devait done initialement apparaitre par sa face dorsale. Tous les os de la main sont cependant épars et il est certain que le radius n'occupe pas exactement sa position originelle. 
Fig. 16 -

Le squelette $\mathrm{Al}$

en cours de dégagement.

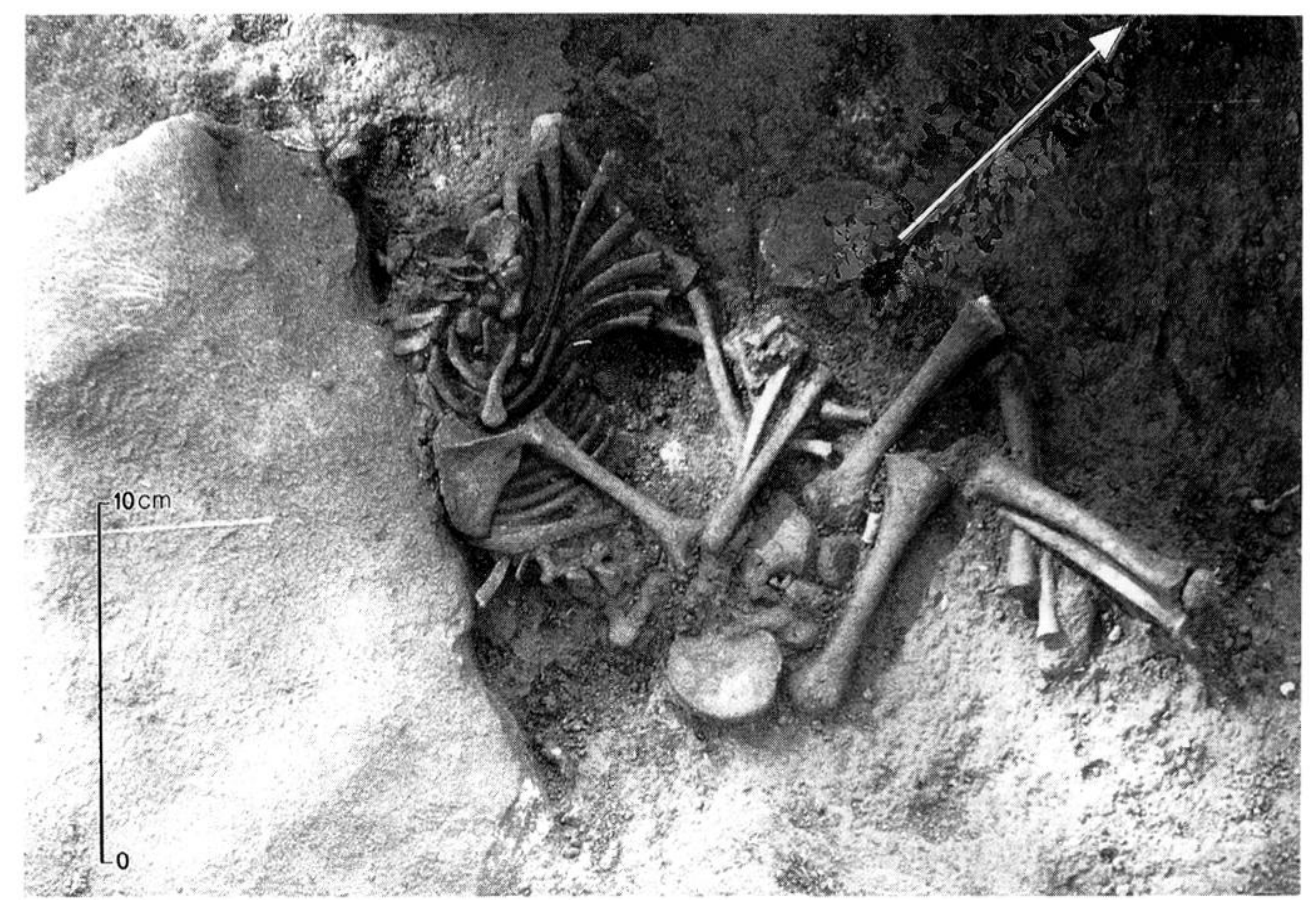

Fig. $17-$

Relevé du squelette A1.

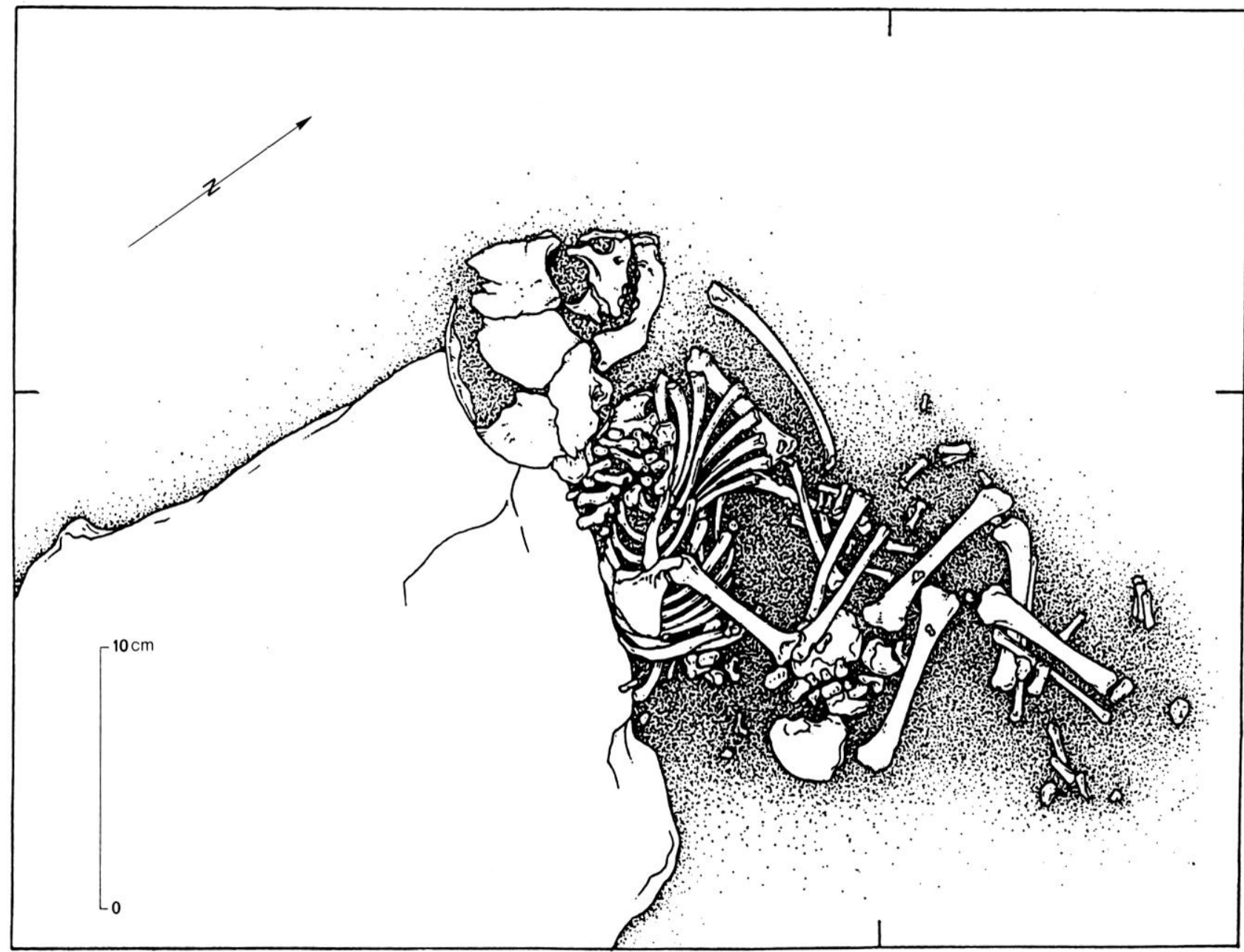


Fig. $18-$

Le squelette $\mathrm{A} 2$

en cours de dégagement.

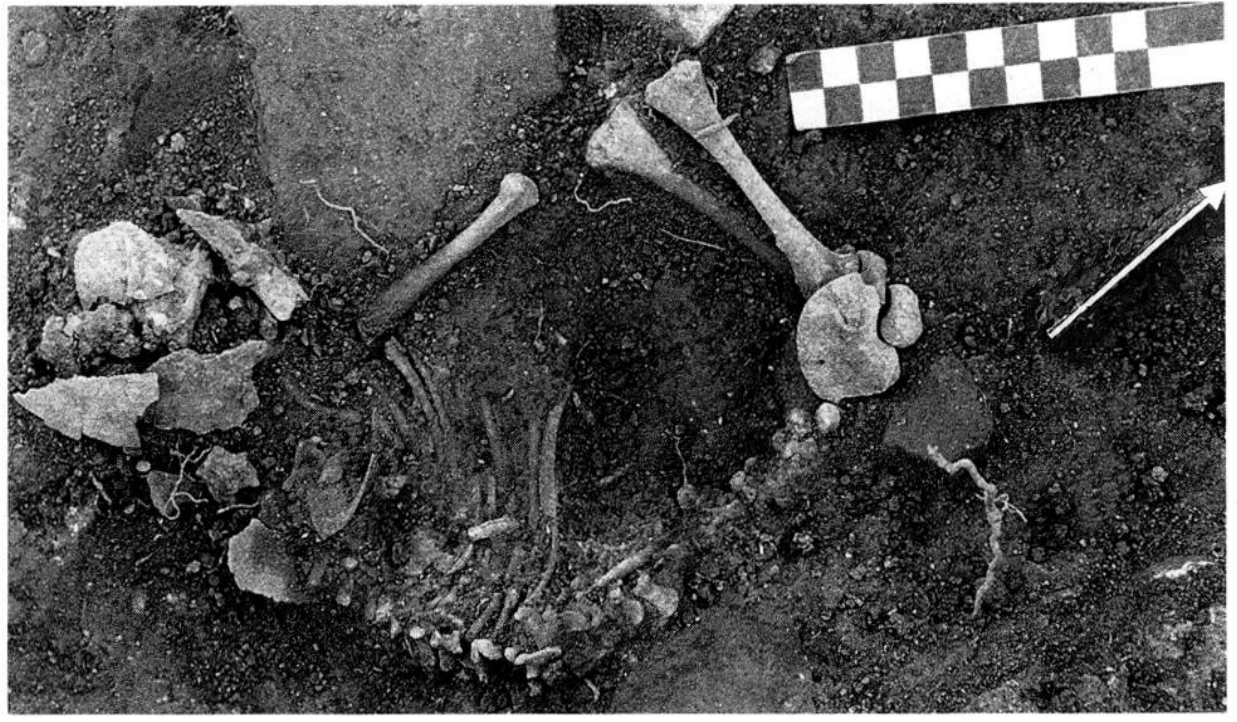

Les membres inférieurs sont fléchis, le genou gauche formant un angle d'environ $45^{\circ}$, le droit d'environ $80^{\circ}$. La jambe gauche est engagée sous la partie proximale de la droite. Les os des pieds (tarse proximal et métatarsiens) sont partiellement désunis; néanmoins, les troisième, quatrième et cinquième métatarsiens droits sont demeurés en connexion : s'ils occupent leur emplacement initial, ce qui est vraisemblable, il faut admettre que le genou droit s'est un peu refermé sous la poussée du sédiment environnant.

L'inhumation stricto sensu, par opposition à un dépôt ou un abandon à la surface du sol, est corroborée par deux faits:

- d'une part, le maintien remarquable des ossements dans leurs rapports réciproques de connexions anatomiques et ce malgré les faibles dimensions de la plupart des pièces. Les quelques anomalies que nous avons notées résultent de petits déplacements dus à la gravité ou à la poussée des sédiments, à l'intérieur de l'espace vide libéré par la décomposition des parties molles;

- d'autre part, la découverte, au voisinage immédiat du squelette, de plusieurs coquilles d'un petit gastéropode, Cecilioides acicula. Ce petit escargot qui mesure à peine 3 à $4 \mathrm{~mm}$ sur moins de $1 \mathrm{~mm}$ est fréquent dans les sépultures. La présence exclusive de cette espèce, d'écologie souterraine, est un indice important en faveur de l'ensevelissement rapide du corps.

Il est donc certain que le cadavre a été enterré dans une fosse creusée pendant la période de constitution de la couche 5 , au détriment de celle-ci et du sommet de la couche 6 . C'est probablement au cours de cette opération qu'a été dégagée une partie de la dalle de calcaire contre laquelle le dos a été appuyé.

\section{LE DÉPÔT A2}

Ce squelette est le seul qui n'ait pas èté fouillé selon les méthodes qui ont été précédemment décrites. De ce fait, nous ne disposons pas de relevés graphiques portant les indispensables observations ostéologiques; nous devrons nous borner à commenter brièvement la photographie qui en a été prise au cours du décapage (fig. 18).

Il s'agit manifestement d'un individu reposant en décubitus latéral gauche; l'axe vertex-coccyx est dirigé du sud-ouest au nord-est.

Le squelette céphalique est éclaté et certains vestiges ont de toute évidence été déplacés lors de leur découverte. On reconnaît un pétreux (le droit?) et le basi-occipital qui se présente par sa face inférieure.

La colonne vertèbrale est dans l'ensemble en connexion anatomique; cependant, un hémi-arc neural gauche de vertèbre cervicale, visible par sa face inférieure, a glissé vers l'avant. Les segments thoracique et lombaire sont en continuité et décrivent un arc convexe vers le sud-est; la courbure est plus accentuée au niveau thoracique. Tous les hémi-arcs neuraux droits semblent apparaitre par leur face latérale; ils masquent les hémi-arcs neuraux gauches et, sans doute aussi en partie, les corps vertébraux qui n'apparaissent pas encore à ce stade du dégagement.

Les côtes droites sont en place, visibles par leur face exothoracique. Il est probable que certaines côtes gauches sont également apparentes par leur extrémité sternale.

Il semble que l'on distingue un fragment de la scapula droite (épine), reposant à plat par sa face antérieure contre le gril costal droit. Lne clavicule 
(la droite?) pourrait s'engager sous le squelette céphalique. L'humérus droit est en abduction et antépulsion; il apparaît par sa face postéro-latérale. Le reste du membre supérieur droit et l'ensemble du membre supérieur gauche ne sont pas visibles.

L'ilion droit a été déplacé à la fouille : il est retourné et se présente par sa face médiale, alors qu'il devrait être vu par sa face latérale. L'ischion droit est en revanche en position normale. En avant de celui-ci, on repère une petite pièce osseuse, en partie masquée par l'ilion droit : il s'agit vraisemblablement du pubis droit, qui serait alors en place. Le fémur droit apparaît par sa face postérieure, mais il n'est pas certain qu'il soit rigoureusement à son emplacement originel. Il est sensiblement perpendiculaire à l'axe de la colonne lombaire.

Le fémur gauche est légèrement plus fléchi sur le tronc que le droit; il est probablement visible par sa face antérieure. L'hémi-bassin gauche, les os des jambes et des pieds ne sont pas encore dégagés.

Malgré le caractère limité de ces observations, il est possible d'en tirer quelques informations : il s'agit indiscutablement d'un dépôt primaire (maintien de connexions labiles et notamment de la jonction scapulo-thoracique droite). La parfaite conservation des relations entre les divers éléments vertébraux plaide en faveur d'un effet de paroi qui se serait exercé sur toute la face dorsale du tronc; il correspond sans doute à la limite de creusement de la fosse. Aucun des légers déplacements que nous avons relevés - et qui ne sont pas dus à l'activité de fouille

ne semble avoir fait "sortir" les pièces concernées du volume initial du cadavre. Le fait que les vertèbres lombaires, pourtant en léger surplomb par rapport à la partie gauche de la région abdominale, soient restées en connexion après la disjonction des contensions cartilagineuses et ligamentaires, plaide même en faveur d'un processus de colmatage progressif des volumes libérés par la décomposition des viscères. Si cette observation s'avérait exacte, il faudrait en conclure à une décomposition dans un espace colmaté et donc à un dépôt en pleine terre.

\section{LE DÉPÔT B2}

Le squelette de ce sujet est totalement disloqué, les os étant répartis dans une aire trapézoïdale qui mesure approximativement $45 \mathrm{~cm}$ dans le sens nordsud et $45 \mathrm{~cm}$ dans le sens est-ouest (fig. 19).

Les éléments du crâne sont dispersés sur la presque-totalité de cette surface. On distingue plusieurs ensembles: au nord-est, des fragments de l'hémi-frontal droit ( 1,2 et 5$)$; au nord, la grande aile gauche du sphénoïde (10) et au sud de celle-ci, plusieurs éléments des pariétaux recassés sur place (7-9, $13-20,23,24,26)$; au sud-ouest, le pétreux droit (30), qui se trouve à plus de $30 \mathrm{~cm}$ de l'hémi-frontal droit, alors que la distance sur le cadavre est d'environ $5 \mathrm{~cm}$; au sud-est, l'exo-occipital gauche (42), qui est à $32 \mathrm{~cm}$ de la grande aile du sphénoïde, dont il n'est normalement séparé que de $4 \mathrm{~cm}$ !

Le rachis cervical est totalement disloqué : l'hémi-arc neural gauche de C33 (33) a été trouvé au sud-ouest, celui de C4 sous une pierre, à mi-distance entre l'humérus gauche (41) et la troisième côte gauche (34) : ces deux pièces vertébrales, contiguës sur le cadavre, sont ici distantes d'environ $35 \mathrm{~cm}$. L'hémi-arc neural droit de la première thoracique (6) est au voisinage de l'hémi-frontal droit.

Les premières côtes droite (29) et gauche (45) sont à $17 \mathrm{~cm}$ l'une de l'autre. Les troisième (34) et quatrième (12) côtes gauches sont également disloquées.

Le membre supérieur droit est représenté par :

- la clavicule (11), presque complète, qui recouvre la première côte droite (29); c'est là la seule relation de contiguïté qui soit à peu près préservée, mais il ne s'agit pas véritablement d'une connexion anatomique, la clavicule étant verticale et la côte horizontale;

- l'humérus droit, incomplet (36), qui est engagé sous le pétreux droit (30).

Du membre supérieur gauche ont été conservés :

- l'extrémité médiale (35) et latérale (44) de la clavicule, dans l'angle sud-est; taux ;

- la scapula (28), près des morceaux des parié-

- l'humérus (41), dont l'extrémité proximale est à $1 \overline{\mathrm{cm}}$ de la scapula.

Des membres inférieurs, nous n'avons retrouvé que le fémur droit (43), à l'extrémité sud de l'aire de répartition des ossements humains.

Il existe donc une dislocation totale du corps. Toutes les pièces que nous venons d'énumérer se trouvaient dans un sédiment grumeleux grisâtre, parmi de très nombreuses pierres anguleuses de moyen module et des tessons de céramique commune et surtout d'amphores massaliètes. Cet ensemble paraît ètre limité vers le nord par deux pierres plates de plus grandes dimensions, dont le pendage du nord au sud est assez accusé.

Il ne peut en aucune façon s'agir d'une sépulture primaire qui aurait été ultérieurement remaniée par un agent naturel (terrier, racine ...). Mais la disposition observée ne semble pas davantage cadrer 


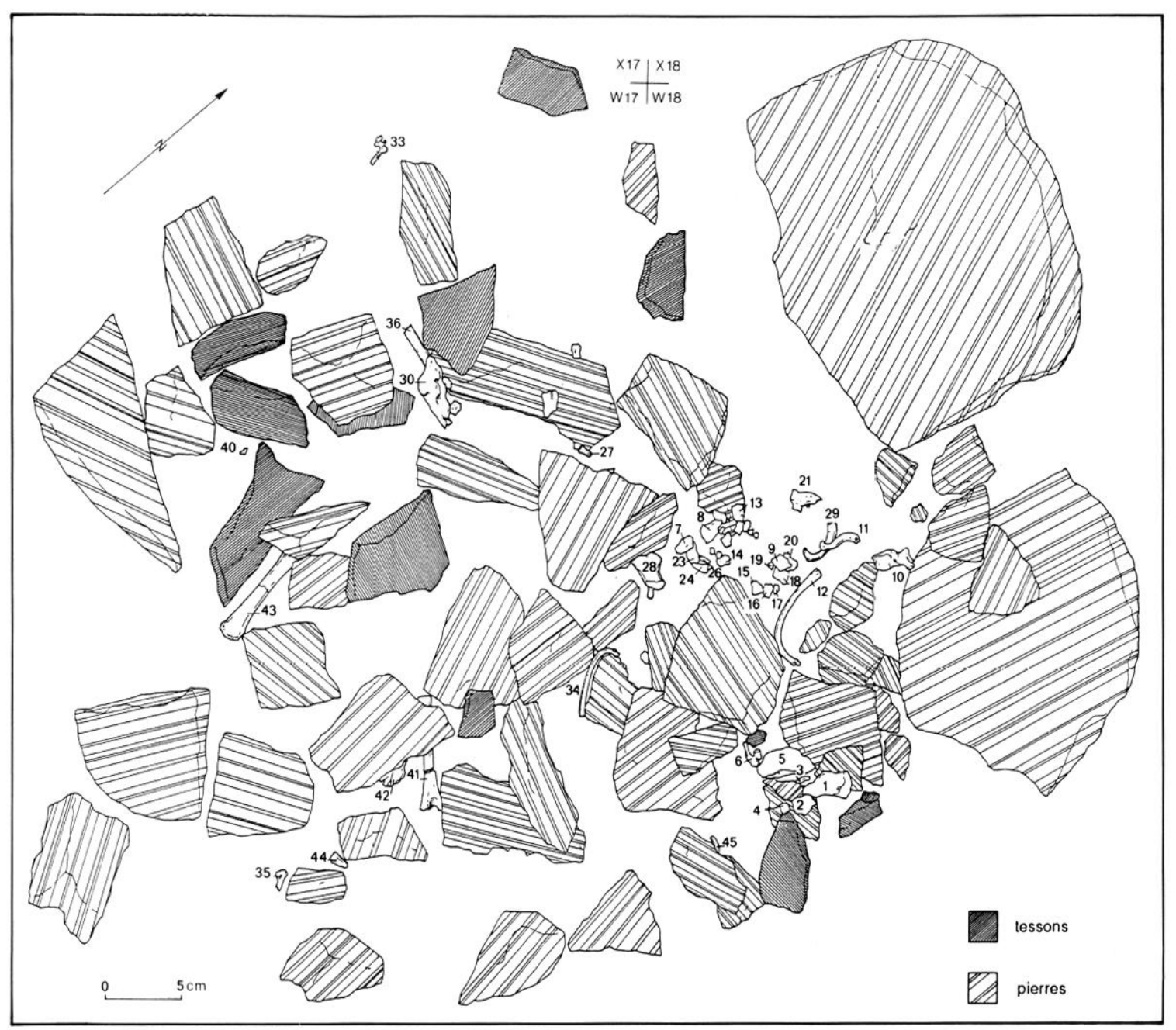

Fig. 19 - Relevé du squelette disloqué B2.

avec l'hypothèse d'une sépulture secondaire, les ossements étant dispersés sur une aire trop vaste. L'interprétation de cet ensemble reste donc en suspens.

\section{LE DÉPÔT $A 3$}

Les ossements de ce sujet sont conservés de manière très inégale : au niveau du squelette céphalique, on note une nette prédominance de la moitié gauche; la colonne vertébrale est pratiquement complète, à l'exception du segment thoracique, pour lequel la presque-totalité des corps $(11 / 12)$ et des hémi-arcs neuraux gauches $(9 / 12)$ ont disparu, contrairement aux hémi-arcs neuraux droits, dont l'effectif conservé est de 8/12. Cette asymétrie s'accentue encore en ce qui concerne les côtes (nous avons trouvé toutes les côtes droites et aucune côte gauche) et le squelette des membres (fig. 20 et 21).

La tête repose sur un amas de petites pierres anguleuses (fig. 20); elle a été écrasée par une pierre oblongue, un peu plus grosse. Cependant, sa disposition originelle peut être aisément définie : elle apparaît par sa face latérale droite; l'axe postéro-antérieur du crâne est dirigé de l'ouest vers l'est. L'hémi-mandibule gauche, brisée en trois fragments, est en situation anatomique normale par rapport au crâne. L'exo-occipital droit s'est rabattu sur le gauche, ce qui est normal lorsque la tête se présente par son profil droit : ces pièces apparaissent respectivement par leurs faces postéro-inféro-latérale et postéro-supéro-médiale.

Le rachis cervical est en connexion stricte et apparaît par sa face antéro-latérale droite. La lordose naturelle de ce segment (courbure à convexité antérieure) est préservée et même accentuée (extension de la tête sur le cou). Les deux hémi-arcs neuraux de la première vertèbre thoracique (Tl) sont en connexion stricte avec la septième cervicale (C7). Les hémi-arcs neuraux droits de T2 à $\mathrm{T} 6$ sont en connexion lâche, légèrement décalés vers la droite 


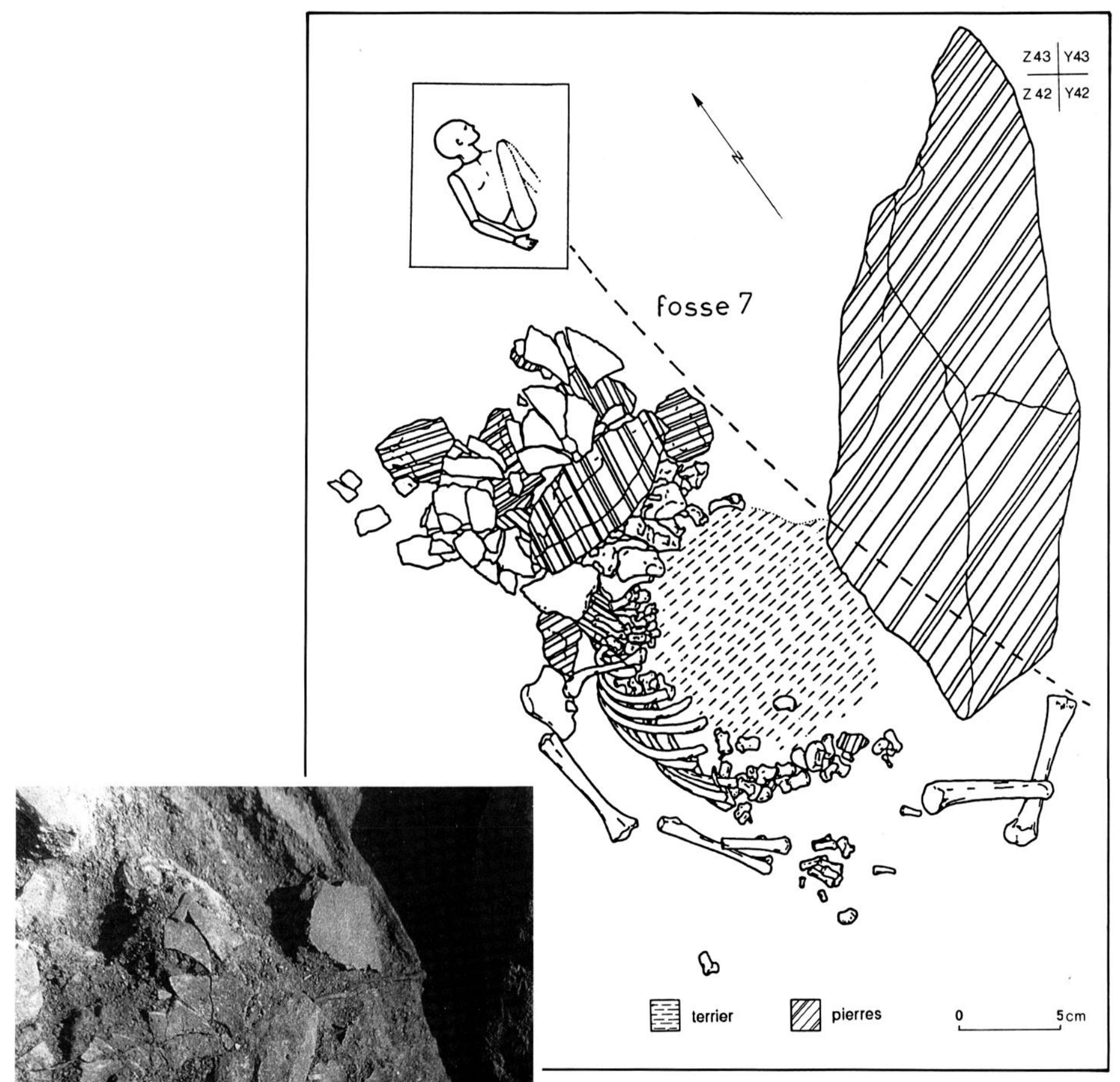

Fig. 20 - Relevé du squelette A3.

Fig. 21 - Le squelette A3 en cours de dégagement. 
par rapport à $\mathrm{T} 1$ et recouverts par l'extrémité sternale des côtes supérieures droites. Deux hémi-arcs neuraux droits de vertèbres thoraciques inférieures ont été trouvés à l'est de l'extrémité sternale des côtes moyennes droites, sans doute à proximité immédiate de leur emplacement originel.

Un corps vertébral et trois hémi-arcs neuraux gauches, se rapportant également à des thoraciques inférieures, sont dispersés aux alentours de la main droite. Les segments lombaire et sacré sont en connexion lâche, leurs éléments étant alignés selon un axe est - nord-est/ouest - sud-ouest.

Dans son ensemble, la colonne vertébrale "s'enroule" donc sur un arc de cercle convexe vers l'est, dont le rayon de courbure est particulièrement faible (environ $65 \mathrm{~mm}$ ).

Les côtes droites sont en connexion stricte. Elles se présentent toutes par leur face antéro-supéro-latérale droite, ce qui confirme bien les observations que nous avons réalisées au niveau du rachis : le tronc apparait en trois-quarts antérieur droit.

Le membre supérieur droit est pratiquement complet. La clavicule est sensiblement perpendiculaire à la colonne cervicale. La scapula apparaît par sa face antéro-latérale et l'humérus droit, parallèle à l'axe du thorax, est en légère rotation médiale. Son extrémité distale est un peu plus haute que son extrémité proximale (la différence entre les deux côtes est de $1 \mathrm{~cm})$. Le coude est à peine fléchi : l'angle humérus/ulna est d'environ $155^{\circ}$, ce qui correspond à une flexion de $25^{\circ}$. Le radius, dont la partie proximale a été déplacée avant la fouille, croise l'ulna au milieu de sa diaphyse. La main droite est dans le prolongement de l'avant-bras; les cinq métacarpiens sont en connexion stricte, les phalanges légèrement disloquées. La main se présentait donc par sa face dorsale, la paume plaquée sur le fond de la fosse.

Le membre supérieur gauche a totalement disparu. Du bassin ne subsiste que le pubis gauche, déplacé au niveau de la main droite.

Le membre inférieur droit est représenté par le fémur et le tibia; ces deux os ne sont manifestement pas à leur emplacement initial : l'extrémité proximale de la diaphyse fémorale, dirigée vers le sudouest, est à environ $7 \mathrm{~cm}$ des vertèbres sacrées; elle est recouverte par l'extrémité distale du tibia droit.

Une phalange proximale d'orteil a été découverte près de la base du cinquième métacarpien droit.

Le maintien en connexion stricte d'articulations particulièrement labiles (scapulo-thoracique droite, rachis cervical, costo-vertébrales droites, main droite notamment), dont la dislocation survient très précocement dans la décomposition du cadavre, indique clairement qu'il s'agit là d'un dépôt primaire.

La courbure rachidienne très accentuée ne peut s'expliquer que par la position hypercontractée du corps; les cuisses auraient donc été fléchies sur le tronc, les genoux étant ainsi ramenés en avant du thorax, presque au niveau du cou. Dans ce cas, les genoux auraient nécessairement été en flexion forcée, les pieds se trouvant au voisinage des fesses. Il est donc possible que la seule phalange d'orteil que nous ayons découverte, près de la main droite, soit relativement proche de son emplacement originel.

L'hypothèse d'une hyperflexion des membres inférieurs pourrait être corroborée par la présence d'une grande pierre située à l'est de la tombe, dont elle marque peut-être la limite du creusement. Mais sa base se trouve au niveau du fond de la fosse, ainsi que l'indiquent les cotes inférieures des os de l'hémiface gauche, et des vertèbres lombaires et sacrées; il n'est donc pas absolument certain que cette pierre appartienne à la couche dans laquelle la fosse a été aménagée.

L'absence d'une partie importante du squelette ne saurait être mise sur le compte d'un processus de conservation différentielle : toutes les pièces qui ont été retrouvées sont dans un parfait état de conservation et, parmi elles, figurent les symétriques de nombreux os qui ont disparu. En fait, il est clair que, si notre interprétation de la position du corps est exacte, tous les éléments manquants devaient se trouver dans un espace sub-circulaire circonscrit par les fragments de l'hémi-mandibule gauche, le rachis cervical, l'extrémité sternale des côtes droites, la colonne lombaire et sacrée, et la paroi ouest de la grande pierre. A la fouille, cette zone est apparue comblée d'un sédiment très fin, noirâtre, totalement dépourvu de pierres, de tessons de poterie et de restes de faune, parcouru par de nombreuses racines. Sans doute s'agit-il là d'un terrier, auquel on doit peut-être imputer aussi le déplacement du fémur et du tibia droits. Ce terrier est hachuré de traits interrompus sur la figure 20. Rappelons aussi que ce dépôt a été en partie affecté par le creusement de la fosse 7 . La dislocation du membre inférieur droit et la disparition totale du gauche peuvent ètre liées à son creusement.

En aucun point, nous n'avons relevé de véritable effet de paroi. Il n'est cependant pas certain que le corps se soit décomposé dans un espace vide : le seul indice qui pourrait plaider dans ce sens réside dans la dispersion de quelques fragments crâniens 
vers l'est, en dehors du volume initial du cadavre. Mais ces petits morceaux de pariétaux ont une disposition variable, certains apparaissant par leur face exo-crânienne, d'autres par leur face endo-crânienne; en fait, ils peuvent avoir été déplacés très longtemps après la décomposition du corps et peutêtre même très récemment puisqu'ils étaient pratiquement en surface au début de notre intervention.

\section{LE DÉPÔT A4}

Il a livré les reste d'un sujet reposant sur le dos, dont l'axe vertex-coccyx est dirigé du sud au nord (fig. 22 et 23). L'orientation du neurocrâne et la dispersion du squelette facial à la partie supérieure du thorax montrent que la tête était fléchie sur le tronc, sans doute en raison de la remontée assez rapide du fond de la fosse ; la cote inférieure de la voûte crânienne est en effet de $197,4 \mathrm{~cm}$ alors que celle des vertèbres thoraciques moyennes est de $200,7 \mathrm{~cm}$, soit une différence de $3,3 \mathrm{~cm}$ pour une distance horizontale de $7 \mathrm{~cm}$ environ.

Les connexions vertébrales (corps et hémi-arcs neuraux) sont préservées avec seulement une très légère dislocation $\mathrm{du}$ rachis lombaire inférieur et sacré; le relevé systématique des profondeurs a mis en évidence plusieurs irrégularités : le segment cervical est horizontal, puis une inflexion relativement brutale crée un dénivelé de $3,1 \mathrm{~cm}$ entre $\mathrm{C} 6$ et T4; la colonne thoracique et lombaire redevient ensuite strictement horizontalc; la fosse remonte à nouveau assez brusquement à partir de $\mathrm{L} 4$ : le dénivelé entre les corps de $\mathrm{L} 3$ et $\mathrm{S} 1$ est de $1,4 \mathrm{~cm}$ pour une distance horizontale de $3 \mathrm{~cm}$ à peine. Il existe aussi une angulation dans le sens transversal: le rachis est rectiligne entre l'atlas et T10, puis s'incurve vers l'est. Cette inflexion à convexité droite s'accompagne d'une rotation axiale vers la gauche.

Le manubrium sternal a été trouvé au voisinage immédiat du corps de T1. Les côtes droites ont un agencement très inhabituel : elles sont presque verticales dans le sol, l'extrémité sternale étant très surélevée par rapport à la tête (le dénivelé atteint $3,2 \mathrm{~cm}$ pour la cinquième côte); de plus, elles ont basculé vers le haut et se présentent par leur face antéroinférieure, alors que dans la plupart des dépôts en décubitus dorsal, la mise à plat du thorax fait apparaître les côtes par leur face antéro-supérieure. Ce remarquable effet de paroi marque la limite abrupte de la gouttière dans laquelle le tronc a été déposé.

Les côtes gauches sont beaucoup plus étalées. Les côtes supérieures ont été ouvertes "en éventail" par l'appui d'une pierre anguleuse dont le sommet se

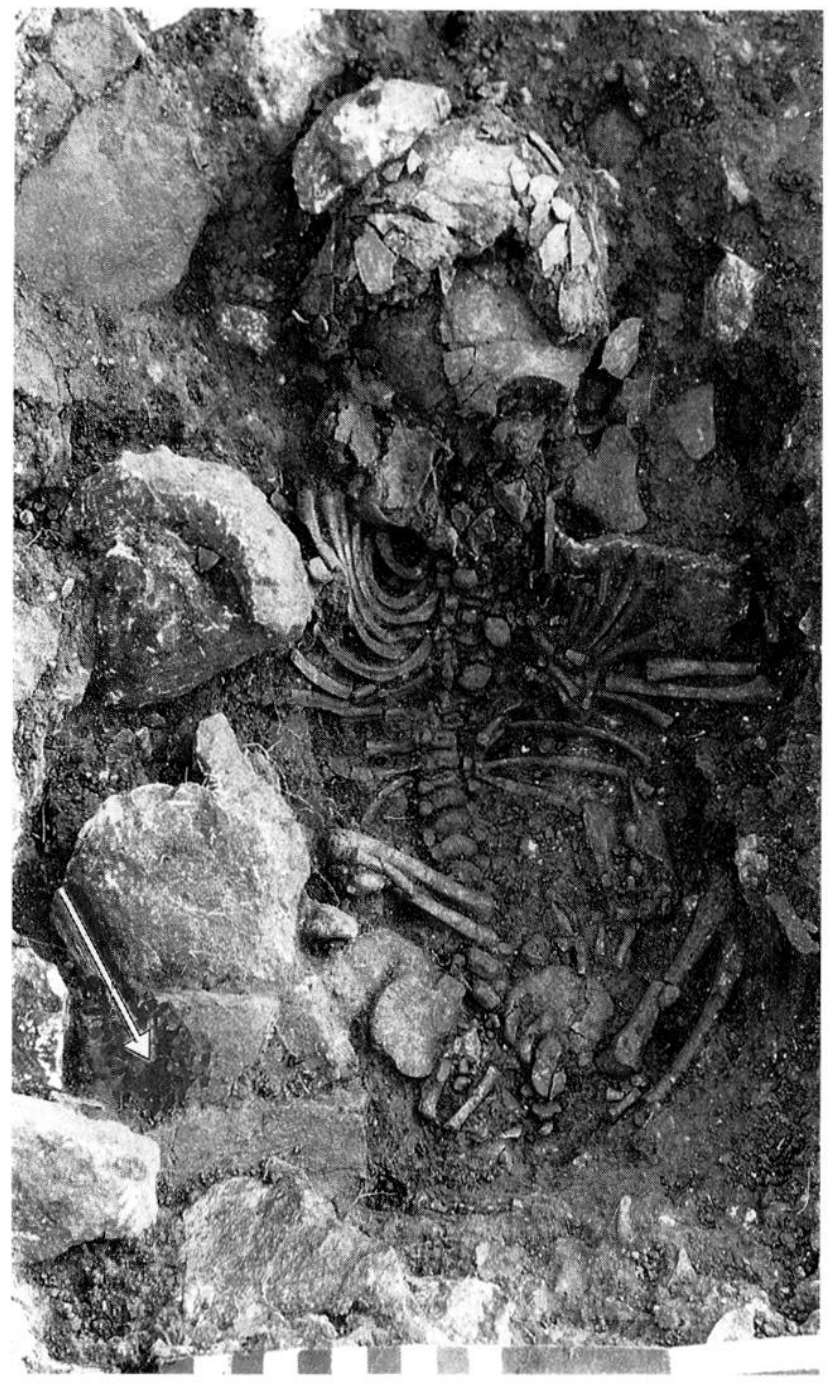

Fig. 22 - Le squelette A4 en cours de dégagement.

situe en arrière de l'épaule gauche et dont la face supérieure présente un fort pendage vers le nord-est. Cette même pierre a probablement formé la "marche" qui surélève le rachis cervical par rapport aux vertèbres thoraciques.

Le membre supérieur droit est dans l'ensemble bien conservé. La clavicule a été partiellement recouverte par l'effondrement des os de la face et par la remontée de l'extrémité antérieure des côtes supérieures droites. La scapula est demeurée dans sa situation originelle, plaquée presque sur chant contre la paroi verticale de la fosse; l'humérus est en légère abduction. Bien que l'avant-bras soit disloqué, sa position originelle est connue gràce à l'agencement des os de la main : le coude était en flexion presque maximale et la main apparaissait par sa face palmaire, le pouce en dedans. L'écartement du membre 


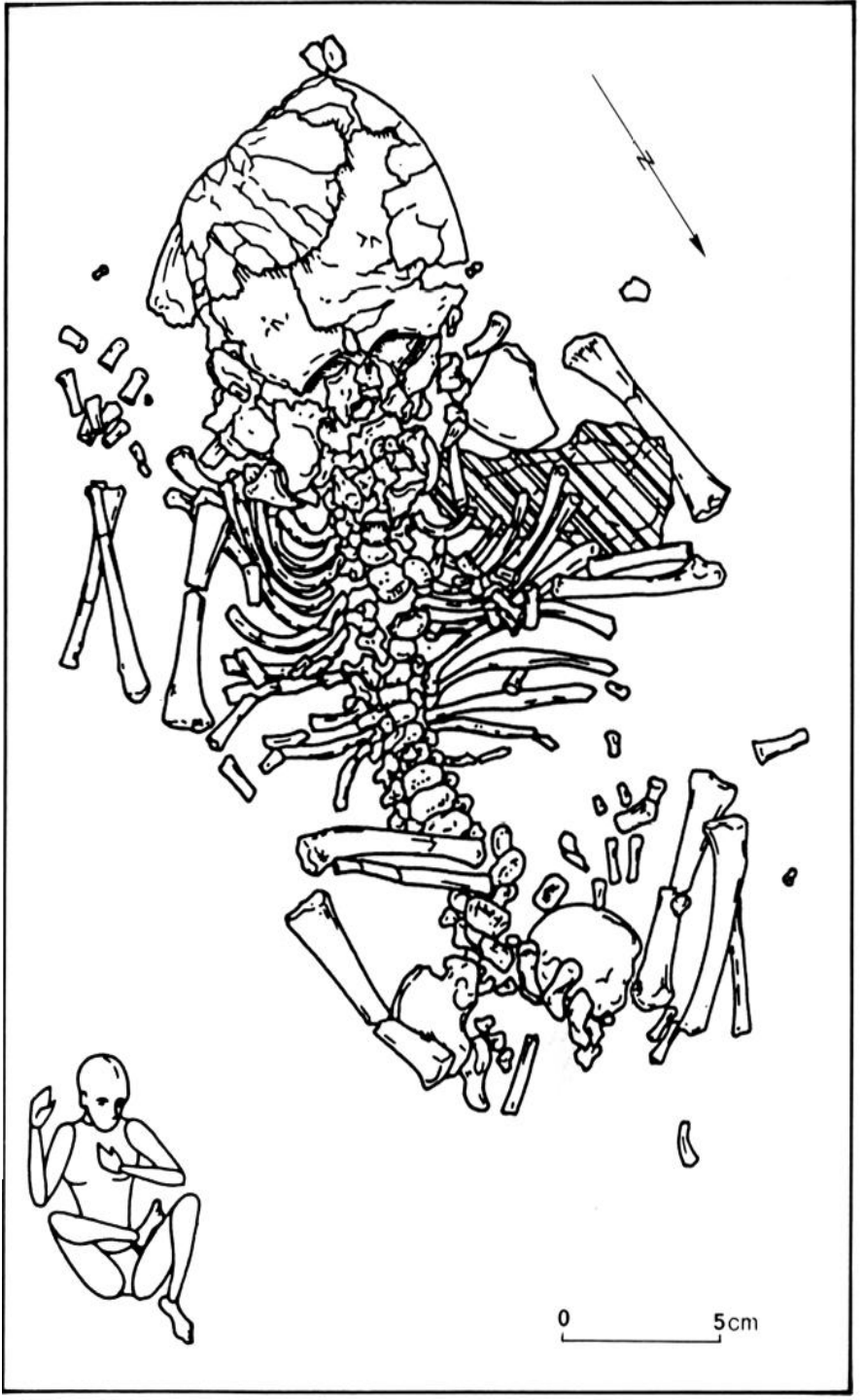

Fig. 23 - Relevé du squelette A4.

supérieur semble à première vue incompatible avec la limite de la fosse que semblent indiquer les côtes et la scapula droites. En fait, le membre supérieur repose sur une banquette qui domine la partie centrale de la cuvette; ainsi, le coude est à la cote 190 , soit $11 \mathrm{~cm}$ plus haut que les vertèbres lombaires! Cette banquette redescend faiblement vers le sud, les os de la main se trouvant à des cotes comprises entre 192,4 et $194,7 \mathrm{~cm}$ soit encore $3 \mathrm{~cm}$ plus haut que la partie postérieure du crâne...

La scapula et la clavicule gauches semblent avoir glissé vers le sud, en amont de la pierre sur laquelle reposaient l'épaule et l'hémithorax gauches. L'humérus, en connexion relativement lâche avec la scapula et les os de l'avant-bras, est en abduction marquée; il s'engage sous l'extrémité de cette pierre qui appartient pourtant au substrat de la tombe. Le bras reposait sans doute sur l'arête supérieure de la pierre et s'est ensuite effondré à l'ouest de celle-ci. La limite du creusement était donc à distance de la paroi thoracique gauche : le trone occupe d'ailleurs une situation très dissymétrique dans la gouttière : le point le plus profond (cote 201,8) correspond à la partie moyenne des côtes inférieures gauches et le membre supérieur gauche se trouve bien au fond de la fosse (la cote de l'humérus est de 199,2 soit, environ $7 \mathrm{~cm}$ plus bas que le droit). Le coude est fléchi; le tiers proximal du radius a été retrouvé à $6 \mathrm{~cm}$ de son emplacement originel, près du genou gauche et relativement haut dans le remplissage : ce remaniement nécessairement tardif ne peut être expliqué sans l'intervention d'un agent extérieur, peut-être un petit fouisseur (?). Enfin, les os de la main gauche ont été trouvés rassemblés dans l'hémi-thorax gauche; la main reposait donc sur la région médiane de la poitrine. La position des métacarpiens et phalanges semble indiquer qu'elle était en inclinaison radiale.

Le bassin est en connexion lâche; les coxaux ont été mis à plat par dislocation de la symphyse pubienne, phénomène classique dans la décomposition du cadavre lorsque le sujet est en décubitus dorsal. La disparition des masses charnues de la région fessière rend ce mouvement possible même dans un espace colmaté.

La cuisse droite est très fortement fléchie sur le tronc. Le genou est en outre surélevé, la différence des cotes entre les extrémités distale $(194,6)$ et proximale $(196,9)$ du fémur étant de $23 \mathrm{~mm}$ pour une distance horizontale de $65 \mathrm{~mm}$ (soit un pendage de $20^{\circ}$ ) : on retrouve ici l'effet de paroi qui s'est exercé tout le long du côté droit. La jambe est fléchie sur la cuisse, ramenant le pied droit au niveau du flanc gauche. Le pendage de la jambe est encore plus accentué que celui de la cuisse : le dénivelé entre les extrémités proximale $(196,7)$ et distale $(200,3) \mathrm{du}$ tibia est de $36 \mathrm{~mm}$ pour une distance horizontale de $58 \mathrm{~mm}\left(30^{\circ}\right)$; l'obliquité de ce segment a cependant été exagérée par la décomposition, le pied s'étant affaissé à l'intérieur de l'abdomen.

La cuisse gauche est elle aussi fléchie sur le tronc mais le fémur est strictement horizontal sur le fond de la fosse. Le genou est en flexion forcée : la jambe devait prendre appui contre la limite de la fosse. Quelques os du pied gauche ont été trouvés dans le prolongement du tibia, au contact de la fesse gauche.

Cet ensemble correspond manifestement à un dépôt primaire. La décomposition du cadavre s'est opérée dans un espace colmaté : s'il avait existé un espace vide autour du corps, les pièces osseuses qui 


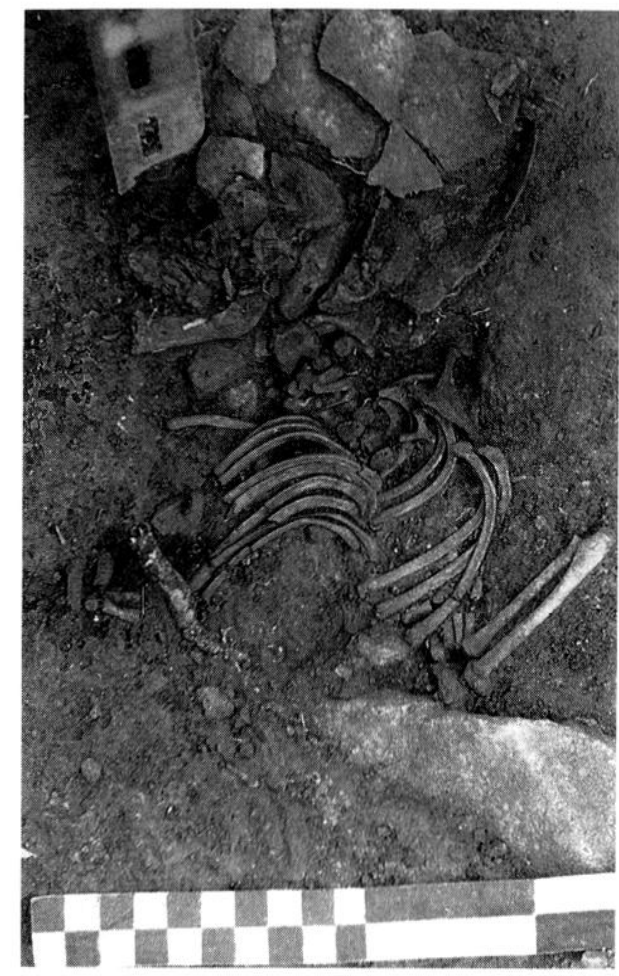

Fig. 24-Le squelette A5 en cours de fouille.

présentent un fort pendage se seraient effondrées sur le fond de la fosse. Les rares déplacements que nous avons observés se sont pour la plupart produits à l'intérieur du volume initial du cadavre et ne sont donc pas significatifs. A la partie proximale du membre supérieur gauche, on peut éventuellement supposer l'existence d'un petit espace vide résiduel au-dessous du corps, l'épaule reposant sur l'arête d'une pierre anguleuse. L'enregistrement systématique des cotes de chaque pièce nous a permis de définir les limites et la forme précises du creusement.

\section{LE DÉPÔT A5}

Cette sépulture est un peu moins bien conservée que la précédente : les membres inférieurs ont été en partie tronqués, sans doute anciennement; par ailleurs, l'une des cornières qui servent de support au carroyage général du site a èté implantée dans la région frontale. Ces dégâts sont heureusement très limités.

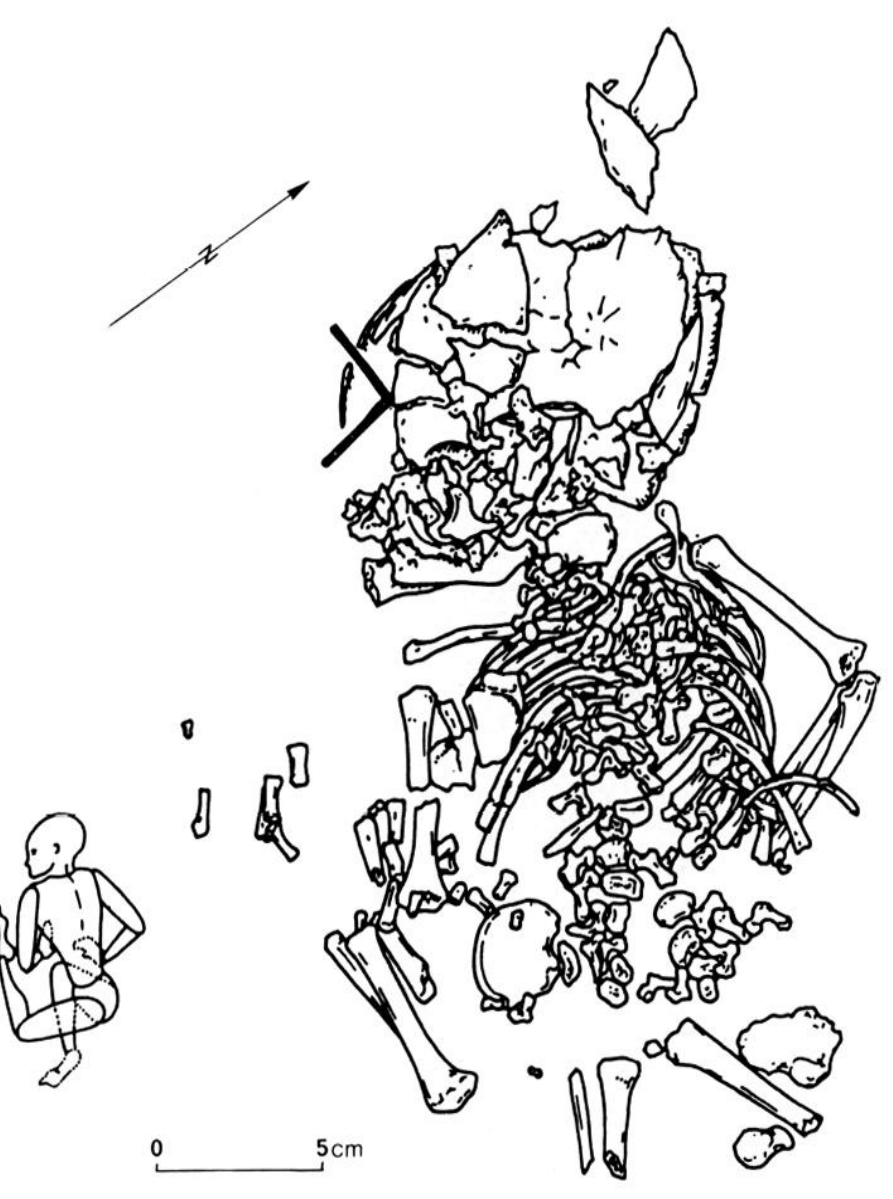

Fig. 25 - Relevé du squelette A5.

Le squelette occupe un espace très court (fig. 24 et 25) : sa longueur (à peine $28 \mathrm{~cm}$ ) est certes sousestimée car la moitié distale de la jambe droite et le pied droit ont disparu, mais la valeur réelle ne devait guère dépasser $31 \mathrm{~cm}$.

Le corps repose sur le sol par sa face ventrale (procubitus); l'axe vertex-coccyx est orienté du nord-ouest au sud-est. La tête est en rotation marquée vers la gauche et se présente presque de profil. Les relations anatomiques entre les pièces crâniennes sont dans l'ensemble préservées, mise à part une légère dislocation des éléments de la base.

La colonne vertébrale décrit une courbe irrégulière et sinueuse : les vertèbres cervicales et les trois premières thoraciques sont en connexion stricte, alors que les vertèbres thoraciques moyennes et inférieures sont dispersées sur la face postérieure du tronc (arcs neuraux) et dans l'hémi-thorax droit (corps). On note un hiatus d'environ $3 \mathrm{~cm}$ entre le corps de T11 et celui de T12, qui est en connexion avec les trois premières lombaires; les deux dernières 
lombaires et les vertèbres sacrées sont éparpillées dans le prolongement et à l'est du segment précédent. Ces mouvements d'amplitude limitée résultent de l'effondrement des pièces vertébrales dans l'espace correspondant aux viscères thoraciques et abdominaux.

Les côtes sont en connexion satisfaisante, les gauches plus étalées que les droites dans le sens transversal; leurs têtes dessinent une courbe convexe vers la droite qui reproduit, d'une manière plus régulière et plus précise, celle des vertèbres thoraciques. Le thorax apparaissait donc de trois-quarts, par sa face postéro-latérale gauche.

Le membre supérieur droit est parfaitement conservé. La clavicule, qui repose direclement sur le fond de la fosse, est perpendiculaire à l'axe longitudinal du thorax. La scapula est très oblique, plaquée sur le gril costal et bloquée par la clavicule et l'humérus. Celui-ci est en abduction moyenne, le coude en semi-flexion de sorte que la main se trouve entre l'hypochondre droit et le fond de la fosse sur lequel elle repose par sa face palmaire. Les phalanges proximales sont sensiblement perpendiculaires aux métacarpiens, basculées en direction médiale.

Le membre supérieur gauche est plus perturbé. L'humérus diverge nettement par rapport au thorax; il présente en outre un fort pendage dû à la surélévation du coude : la différence des cotes entre ses extrémités distale $(196,4)$ et proximale $(198,6)$ est de $2,2 \mathrm{~cm}$. Encore cette obliquité ne concerne-t-elle que la partie proximale de l'os dont le pendage atteint $37^{\circ}$ : sa moitié distale s'est affaissée en contrebas de l'extrémité proximale du radius qui, elle, remonte jusqu'à la cote 195,2. Les deux os de l'avant-bras plongent donc en avant de l'humérus, le poignet se trouvant à la cote 198,6 . On observe ainsi un dénivelé de $34 \mathrm{~mm}$ entre les deux extrémités du radius, alors que la longueur diaphysaire est de $46,8 \mathrm{~mm}$ (ce qui correspond à un pendage de près de $\left.50^{\prime \prime}\right)$ ! La main, qui repose sur le fond de la fosse par sa face palmaire, est donc presque à l'aplomb du coude, à gauche de l'abdomen ; les métacarpiens sont dirigés du sud-ouest au nord-est.

Les os coxaux sont complètement dissociés, les deux ilions distants de $9 \mathrm{~cm}$ : le bassin s'est donc ouvert vers l'avant et les pièces qui le constituent sont tombées dans l'espace libéré par la disparition des parties molles.

Le fémur droit, incomplet, est replié sous l'abdomen; il est en adduction, mais ce mouvement a été exagéré par le glissement latéral de la hanche. Le genou, moyennement fléchi, se trouvait probablement dans la région pubienne.
Le fémur gauche a été enlevé lorsque la tombe a été découverte en 1987. D'après la position de la jambe, la cuisse devait être perpendiculaire à l'axe du tronc. Le pied gauche est ramené en dehors du bras, non loin de l'épaule; les métatarsiens sont encore en place, tandis que quelques phalanges des orteils ont été trouvées dispersées à proximité. Une telle attitude n'est en général possible que chez les jeunes enfants en raison de la très grande laxité articulaire qu'elle nécessite.

Il s'agit évidemment d'un dépôt primaire. En aucun point il n'a été possible de mettre en évidence d'effet de paroi qui puisse indiquer les limites de la fosse. Il est en revanche manifeste que le cadavre s'est décomposé dans un espace colmaté : le maintien presque parfait des grands os longs du membre supérieur gauche dans leur position initiale, malgré leur très fort pendage, est en effet totalement incompatible avec l'hypothèse d'une décomposition en espace vide.

\section{LE DÉPÔT $A 6$}

Cet ensemble correspond à un sujet qui repose sur le côté gauche et dont l'axe vertex-coccyx est dirigé du sud-est au nord-ouest (fig. 26). Le squelette était directement recouvert de pierres anguleuses de moyen et petit module (3 à $14 \mathrm{~cm}$ d'arêtes) dont l'appui a occasionné quelques fractures et perturbations.

Les os de la voûte sont très brisés et partiellement disloqués ; les éléments de la base du cràne sont en connexion lâche, mais l'exo-occipital droit s'est retourné, apparaissant par sa face inférieure, alors que le gauche est visible par sa face supéro-médiale. La face est tournée vers le sud-ouest.

La colonne vertébrale est en connexion satisfaisante ; quelques hémi-arcs neuraux thoraciques supérieurs gauches ont été déplacés vers l'arrière et les corps vertébraux corespondants ont glissé à l'intérieur de la cage thoracique. L'axe rachidien présente une rotation axiale: les vertèbres lombaires et sacrées se présentent par leur face antéro-latérale droite, les vertèbres thoraciques par leur face latérale droite, les vertèbres cervicales par leur face postérolatérale droite. Ces dernières ont donc une disposition qui ne correspond pas exactement à celle du squelette céphalique.

Les côtes gauches sont décalées vers l'avant par rapport aux droites : le thorax n'apparaît pas exactement de profil, mais en trois-quarts antérieur droit. Le manubrium sternal a glissé en avant de la douzième vertèbre thoracique. 
Fig. 26 - Relevé du squelette $\mathbf{A 6}$.

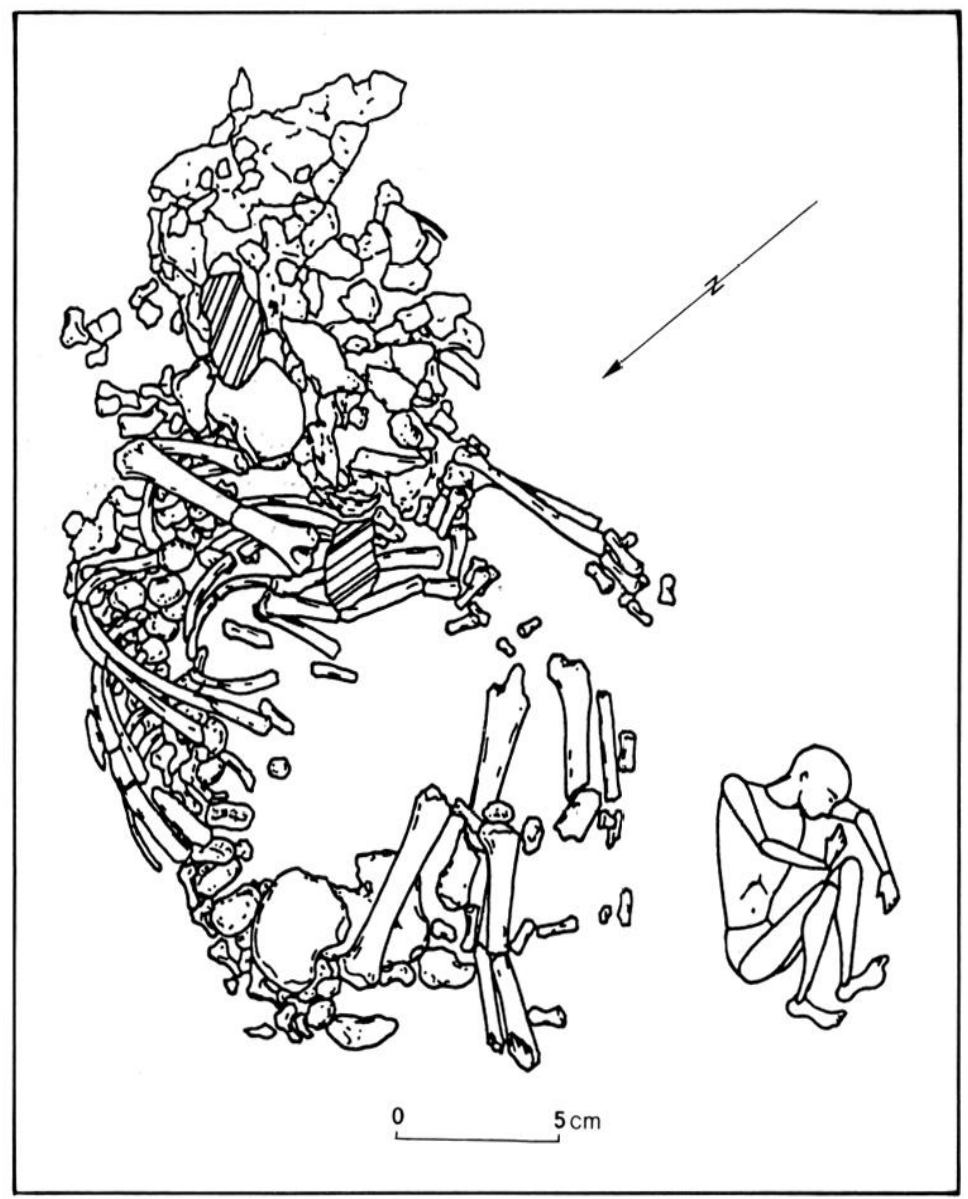

La scapula droite, de chant, était plaquée contre la face dorsale du thorax. L'humérus parait avoir glissé vers le haut et vers l'avant par rapport à la scapula; son extrémité distale se trouve protégée en avant de la région thoracique supérieure. Les deux os de l'avant-bras, légèrement enfoncés par l'appui d'une petite pierre, sont en connexion stricte et apparaissent par leur face postérieure. Le coude est disjoint, sans doute en raison du déplacement de l'humérus. La main est en inclinaison radiale accentuée: tous les métacarpiens sont en place, visibles par leur face dorsale. Les phalanges proximales de la main sont fléchies sur la paume.

La scapula gauche, brisée et incomplète, apparaît par sa face antérieure et repose à plat sur le fond de la fosse; par rapport à la droite, elle est décalée d'environ $13 \mathrm{~mm}$ vers l'avant et vers le haut, ce qui confirme la rotation du tronc vers la droite (alors que la colonne cervicale "s'enroule" vers la gauche). La clavicule est très incomplète : nous n'en avons retrouvé que la partie médiale, recouverte par le massif facial, comme la moitié distale de l'humérus qui est sensiblement parallèle à l'humérus droit. Le coude faiblement fléchi est en connexion stricte: le radius et l'ulna remontent sur le fond de la fosse en direction distale, la différence des cotes entre les deux extrémités étant de $1,4 \mathrm{~cm}$ pour le radius, $1,3 \mathrm{~cm}$ pour l'ulna. Leurs diaphyses se croisent (pronation), de sorte que la main gauche est visible par sa face dorsale. Les métacarpiens sont en connexion, dans le strict prolongement de l'avant-bras, alors que les phalanges sont pour la plupart disloquées.

Le bassin est en connexion lâche : l'ilion et le pubis droits ont basculé en direction médiale, l'ischion est resté de chant à son emplacement originel. Leurs homologues gauches reposent sur le fond de la fosse et se présentent par leur face médiale.

Le fémur droit est fortement fléchi sur le tronc; le genou se trouve à environ $4 \mathrm{~cm}$ en avant de la première vertèbre lombaire. L’épiphyse distale du fémur ("point de Béclard») a été trouvée en place au contact du tibia. Le genou est fortement fléchi; le tibia et la fibula remontent sur le fond de la fosse en direction distale, avec une différence de cotes de $1,2 \mathrm{~cm}$ entre leurs deux extrémités. Les métatarsiens droits ont été dispersés en avant du tibia, entre son quart proximal et son quart distal. 
Le fémur gauche est sensiblement parallèle au droit, mais il est décalé vers le haut: le genou se trouve ainsi au niveau des mains et repousse la droite en inclinaison radiale forcée. Tibia et fibula, fortement flechis sur la cuisse, remontent sur le fond de la fosse en direction distale, mais leur partie distale est écrasée et légèrement disloquée. Le talus, les métatarsiens et phalanges du pied gauche sont dispersés au voisinage du genou droit et en avant de la jambe gauche.

Le maintien de connexions particulièrement labiles (jonction scapulo-thoracique. extrémites) prouve qu’il s'agit d'une sépulture primaire. Ia plupart des remaniements se sont produits à l'intérieur du volume initial du cadavre: effondrement du cràne et de la cage thoracique, glissement vers le haut de l'humérus droit, mise à plat du bassin...

Dans quelques cas cependant, les pièces déplacées sont "sorties" de ce volume et ces observations doivent ètre discutées, car elles pourraient a priori ètre l'indice d'une décomposition dans un espace vide :

- les os des pieds sont remontés au niveau des jambes ; mais ils ne sont guère écartés des diaphyses tibiales contre lesquelles plusieurs métatarsiens se sont mème alignés. Etant donné l'aspect plutôt "potelé» des membres des nouveau-nés, ces translations dues au pendage relativement accentue des jambes ont pu se produire dans le volume libéré par la décomposition des parties molles;

- il ne saurait en ètre de mème pour les pièces vertébrales découvertes en arrière de l'épaule droite et du cou. Mais on a noté dans le même secteur le retournement paradoxal d'un exo-oceipital et la disparition de certains éléments (clavicule gauche, moitié proximale de l'humérus gauche): ces faits doivent probablement ètre imputés au passage d'un fouisseur: un petit terrier incomplètement colmaté a d'ailleurs été repéré immédiatement au-dessous de la main droite.

Le maintien de la scapula droite, d'hémi-arcs neuraux thoraciques et lombaires et de lischion droit dans leur situation originelle, pourtant instable apres la disjonction des contensions cartilagineuses, tendineuses et ligamentaires, traduit un effet de paroi à la face dorsale du tronc. Ce phénomène peut être lié au comblement immédiat de la fosse (décomposition dans un espace colmaté) ou à l'appui du corps contre la paroi de celle-ci.

Il semble que l'on ait ici affaire à un dépôt primaire dans une fosse étroite, comme en témoignent l'attitude contractée du corps et surtout le fort pendage de lavant-bras gauche et des deux jambes.
Cette fosse a sans doute été comblée aussitòt après la mise en place du cadavre: dans le cas contraire, certains os de la main gauche auraient probablement glissé vers la partie la plus déclive de la dépression (le dénivelé entre les os des deux mains etant de $2,1 \mathrm{~cm}$ pour une distance en plan denviron $5 \mathrm{~cm}$ ). Certes. deux phalanges de la main gauche ont bien été déplacées, mais dans un sens différent de celui que laisserait attendre le pendage du fond de la fosse ; ces remaniements de faible amplitude semblent plutòt liés au fait que la couche de comblement, riche en pierres, pouvait avoir une texture relativement aérée.

\section{SYNTHÈSE ET INTERPRÉTATION}

\section{SUR L'OPPIDUM DE GAILHAN...}

A Gailhan, l'étude anthropologique fait apparaître un total de vingt-deux ou vingt-trois individus : six sont représentés par le squelette en totalité ou en majeure partie en connexion anatomique, cinq par des groupes plus ou moins importants d'ossements provenant de squelettes disloqués et onze à douze sujets par un os isolé. Pour la plupart ces individus sont morts durant la période périnatale, soit à la naissance, soit dans les premiers jours qui ont suivi : dix-huit ou dix-neuf sur les vingt-deux ou vingt-trois sont dans ce cas. Ln sujet (Aj) semble avoir été légèrement prématuré. Deux seulement sont décédés largement avant terme : foctus de six à sepl mois attestés chacun par un os isolé (C:3 el (C:7). Deux autres (B2 et A6) semblent avoir vécu quelques semaines; un enfin, environ six mois (C4).

Ces dépòts se répartissent à l'intérieur des deuxième et troisième agglomérations qui se sont succédé sur l'oppidum et qui couvrent en chronologie absolue une période comprise entre le dernier quart du $v^{e}$ et le milieu du IV s. avant J.-C., soit moins d'un siècle. Aux ossements isolés et aux squelettes disloqués, en l'absence d'argument contraire, nous attribuons la datation de la couche qui les renferme. Par ailleurs, les fosses contenant les squelettes en connexion ne semblent pas avoir été creusées profondément. En particulier, celle du squelette A2 qui était en partie recouverte par un foyer construit. Nous avons donc pour chaque reste représenté une fourchette de datation. En synthétisant ces données nous pouvons regrouper ces sujets selon deux horizons chronologiques :

- au deuxième village (entre 425) et 400 environ avant J.-C.) se rapportent dix sujets : A2, A3, A4. A5, A6, B2, B3, B4, Cil et Ci2: 
- au troisième village (entre 400 et 350 environ avant J.-C.) se rapportent douze ou treize individus : $\mathrm{A} 1, \mathrm{~B} 1, \mathrm{~B} 5, \mathrm{C1}, \mathrm{C} 3, \mathrm{C} 4, \mathrm{C} 5, \mathrm{C} 6, \mathrm{C} 7, \mathrm{C} 8, \mathrm{C} 9, \mathrm{C} 10$ et C12.

Aucun n'appartient à la première phase d'occupation du site (première moitié et troisième quart du $v^{e}$ s. avant J.-C.). Mais cet habitat n'est connu que sur une surface trop restreinte pour qu'une telle absence soit significative et puisse être opposée à la situation ultérieure.

\section{LE MODE DE DÉPÔT}

Les six squelettes découverts en place (A1, A2, $\mathrm{A} 3, \mathrm{~A} 4, \mathrm{~A} 5$ et $\mathrm{A} 6$ ) témoignent d'un mème mode de dépôt.

Ce sont tous des ensevelissements individuels. Le corps est placé dans une petite excavation et se décompose dans un espace colmaté. Forme et dimensions de ces fosses ne sont qu'exceptionnellement connues (A4). Celles-ci sont creusées dans des couches stratigraphiques très semblables, dont les divers niveaux ne présentent à l'œil nu aucune différence de couleur ou de texture : sédiment gris, cendreux et charbonneux incluant de nombreux tessons de poterie et des ossements de faune isolés, résultant de l'étalement des vidanges des foyers. Elles sont recomblées avec la même terre que celle qui les environne. Leurs limites ne sont donc décelables que dans certains secteurs, par "effet de paroi" donné soit par des éléments entrant dans le comblement (lesson de polerie, petite pierre, ossement de faune), soit par la position de certaines pièces osseuses ou parties du squelette du sujet. Ces derniers faits montrent cependant que les fosses ont des dimensions juste suffisantes pour accueillir le corps dont les membres sont le plus souvent contractés. Par ailleurs la profondeur de la fosse n'est connue précisément que dans un cas (A2, profondeur : $0,14 \mathrm{~m}$ ), car celle-ci ne peut être repérée la plupart du temps qu'à partir du moment où la fouille met au jour les restes du squelette.

Les corps, toujours fléchis ou contractés, sont le plus souvent en décubitus latéral gauche (squelettes $\mathrm{A} 1, \mathrm{~A} 2, \mathrm{~A} 3$ et A6). Mais ce n'est pas une règle, puisque le squelette A4 est en décubitus dorsal et le squelette A5 est en procubitus. Les orientations, pour leur part, sont très variables : tête au nord (A3), au sud-est (A6), au sud-ouest (A2 et A4), à l'ouest (A1) ou au nord-ouest (A5).

Les cadavres ne sont accompagnés d'aucun objet, pièce d'habillement, offrande ou autre... Les quelques tessons de poterie et ossements de faune découverts dans le remplissage de la plupart des fosses sont absolument comparables au matériel que livrent les couches environnantes et ont très probablement été apportés involontairement avec la terre de comblement.

En surface, il semble qu'aucun élément conservable n'a signalé ces dépôts. Le fait que la fosse 7 de la cour domestique 22 a tronqué le dépôt du squelette A3 confirme d'ailleurs cette observation.

En prenant en compte les squelettes en place et ceux qui sont plus ou moins disloqués, il apparaît que le lieu le plus souvent utilisé est la cour domestique; neuf squelettes sur les dix sont dans ce cas (A1, A2, A3, A4, A5, A6, B2, B4 et B5). La pièce d'habitation elle-même n'est affectée qu'une fois (B3). Mais ce rapport ne reflète pas forcément un choix car les fouilles ont mis au jour davantage de lieux non couverts que de pièces d'habitation ou liées à des habitations : pour la partie de l'agglomération de la seconde moitié du ve s. avant J.-C. qui a été dégagée, le rapport surfaces couvertes/surfaces non couvertes, soit $57 \mathrm{~m}^{2} / 700 \mathrm{~m}^{2}$, est du mème ordre; de plus, le sous-sol de la maison d'habitation de l'unité domestique $\mathrm{n}^{\circ} 1$, compté dans les $57 \mathrm{~m}^{2}$, n'a pas été fouillé.

A l'intérieur des cellules la distribution des dépôts ne semble obéir à aucune règle. En particulier, on ne remarque aucune relation privilégiée avec le foyer ou la zone des foyers successifs, pas de lien étroit non plus avec un mur ou une paroi (ni contiguïté avec celle-ci, ni superposition de cette dernière). Cependant la concentration des dépôts dans la cour 22 est remarquable - quatre squelettes en connexion anatomique et deux disloqués (A3. A4, $\mathrm{A} 5, \mathrm{~A} 6, \mathrm{~B} 4$ et $\mathrm{C} 11$ ) - et notamment dans la partie orientale de cet espace où trois squelettes (A3, A4 et A6) ont été découverts sur $4 \mathrm{~m}^{2}$ seulement. Ceux-ci se trouvaient à proximité de la fosse 7 au contenu bien particulier et à la signification non établie. Y-a$t$-il une relation intentionnelle entre cette fosse et ces trois dépôts de nouveau-nés? Il est impossible d'apporter une réponse car il est prouvé que le creusement de la fosse 7 , qui a partiellement recoupé le dépôt du sujet $\mathrm{A} 3$, est postérieur à ce dernier.

La distinction entre squelettes en connexion anatomique, disloqués et ossements isolés est-elle révélatrice d'une diversité dans les modes de dépôt? En fait, la position stratigraphique respective des uns et des autres ne plaide pas en faveur d'une telle hypothèse. Dix des douze ossements isolés (C1, C3, C4, C5, C6, C7, C8, C9, C10 et C12) proviennent des couches supérieures du gisement qui sont les moins bien conservées et cinq d'entre eux du niveau superficiel remanié par les travaux agricoles. Étant donné 
le mode de dépôt peu profond et donc peu favorable à une bonne conservation, dont témoignent les squelettes en place, il est possible que les pièces osseuses isolées correspondent aux restes de squelettes en connexion anatomique détruits anciennement lors de l'occupation protohistorique de l'habitat, ou par la suite lors de son abandon et de l'exploitation agricole qui a succédé. Il en va de même des groupes d'os découverts sur un espace restreint en dehors de toute connexion anatomique. Sur les cinq ensembles, l'un se trouvait dans une couche remaniée par les travaux agricoles (Bl) et trois dans des niveaux du dernier quart du ve s. avant J.-C. qui ont pu souffrir de la prolongation de l'habitat sur les mêmes lieux au cours du siècle suivant. Malgré ces remarques, il est évident qu'on ne peut toutefois pas exclure que les os isolés ou les groupes d'os dispersés sur une surface restreinte proviennent de corps enterrés moins profondément par les habitants voire abandonnés en surface du sol.

\section{RÉPARTITION SPATIALE}

Les vingt-deux ou vingt-trois sujets ont été découverts sur une surface totale fouillée de $700 \mathrm{~m}^{2}$. En prenant en compte l'existence de deux horizons architecturaux distincts, la densité des enterrements est de l'ordre d'un pour $70 \mathrm{~m}^{2}$ dans le deuxième village (10 sujets) et d'un pour $53 \mathrm{~m}^{2}$ dans le troisième (12 à 13 sujets).

Entre 425 et 400 environ avant J.-C., le nombre d'unités domestiques auxquelles se rapportent les structures dégagées est de l'ordre de cinq. Les dépôts d'enfants périnataux affectent pratiquement toutes les unités domestiques (U.D.), avec des variations de un à six : un dépôt dans la cour domestique 6-7 (U.D. incomplète); deux dépôts dans le lieu non couvert de l'espace 17/23-2 (U.D. incomplète); un dépôt dans l'unité domestique 21-18 et six dépôts dans la cour domestique 22 (U.D. incomplète). L'absence d'inhumation dans l'unité domestique $\mathrm{n}^{\circ} 1$ n'est peut-être pas significative puisque le sous-sol de cet ensemble n'a pas été fouillé.

D'après les dimensions ( 40 à $60 \mathrm{~m}^{2}$ de superficie) et les aménagements des exemples les mieux connus (U.D. 1 et 21-18), les unités domestiques correspondent chacune à un groupe restreint d'habitants de l'ordre de 6-7 personnes, soit la famille nucléaire comprenant un couple et sa descendance non adulte (Dedet, 1987, p. 172). En moyenne nous aurions donc deux enterrements par famille sur une duree d'environ un quart de siècle (425-400 avant J.-C.).

La structure du village de la première moitié du Ive s. avant $J$.-C. est beaucoup moins bien connue, de même que la forme des dépôts de périnataux. On se contentera de noter que ceux-ci se répartissent à peu près équitablement sur l'ensemble de la surface fouillée; indice probable que la situation démographique n'a guère varié par rapport à la phase précédente, compte tenu d'une durée peut-être plus longue de ce village le plus récent.

\section{SIGNIFICATION FUNÉRAIRE ET CULTURELLE}

Mis à part le fœtus de six mois environ (C3) qui peut résulter d'un accident dans la gestation, deux possibilités se présentent pour expliquer la présence de ces inhumations de nouveau-nés dans l'habitat de Gailhan, l'infanticide ou la mort naturelle.

L'infanticide nous renvoie à des pratiques qui sont attestées dans différentes sociétés anciennes ou subactuelles sous des formes et pour des raisons diverses. Il a longtemps constitué, sans doute dès la Préhistoire, le moyen le plus simple et le plus efficace de contrôle de la fécondité (Masset, 1986, p. 83-87). Concernant les nouveau-nés de sexe féminin, comme en Chine (Cartier, 1986, p. 472), il a des causes plus particulièrement économiques et sociales. Deux éléments peuvent à Gailhan inviter à une telle explication : l'âge des décédés tout d'abord, qui se situe, sauf exception, autour de la naissance; le peu de cas aussi que les habitants ont semble-t-il fait de leurs restes. Dans cette optique, la détermination du sexe d'après le squelette revêtirait une très grande importance, mais nous avons vu qu'elle ne peut être effectuée avec sûreté pour des sujets aussi jeunes.

L'hypothèse de sacrifices à caractère religieux a été avancée pour plusieurs habitats de la Catalogne et du Levant espagnol. Dans certains cas, il s'agit d'individus regroupés dans des lieux "cultuels communautaires": La Escudilla à Zucaina, province de Castellon de la Plana, à la fin du $\mathrm{VI}^{\mathrm{P}}$ ou au début du ve s. avant J.-C. (Gusi Jener, 1970; 1989); La Moleta del Remei à Alcanar, province de Tarragone, entre la fin $\mathrm{du}^{\mathrm{e}} \mathrm{s}$. et le début du iII ${ }^{\mathrm{e}} \mathrm{s}$. avant $\mathrm{J}$.-C. (Gracia et alii, 1989); Puig de Sant Andreu à Ullastret, province de Gérone, dans la première moitié du $\mathrm{IV}^{\mathrm{e}} \mathrm{s}$. avant J.-C. (Agusti el alii, à paraître). Ailleurs, ce sont des nouveau-nés isolés dans certaines habitations, alors que dans d'autres ont été effectués des dépôts d'animaux "sacrifiés" interprétés comme offrandes de substitution des nouveau-nés : Penya del Moro à Sant Just Desvern, province de Barcelone, dans la première moitié du $\mathrm{IV}^{\mathrm{e}} \mathrm{s}$. avant $\mathrm{J}$.-C. (Barberá et alii, 1989). Ailleurs encore, on a affaire à des sujets isolés, dans certaines maisons, en relation avec un élément constitutif de celles-ci ou des struc- 
tures liées à une activité particulière, en l'occurrence métallurgique, dispositifs interprétés comme des dépôts de fondation ou d'abandon : Castellet de Bernabe à Liria, province de Valence, dans la première moitié du IV s. avant J.-C. (Guérin et alii, 1989, p. 71-74). Mais en fait, c'est seulement à la Escudilla que l'hypothèse d'un rite sacrificiel présente de solides arguments. La salle $\mathrm{H} 1$ de ce site possède un foyer, une fosse contenant des restes d'animaux en connexion anatomique, une pierre dressée et vingtdeux inhumations (quatre fœetus, sept mort-nés ou nouveau-nés de moins d'un mois et onze nourrissons de un à six mois) réparties dans dix urnes. I.'auteur de la fouille propose d'y voir les restes de sacrifices effectués périodiquement, peut-être chaque année, un par un ou deux par deux, selon un rite destiné à assurer la fécondité des champs et des troupeaux (Gusi Jener, 1989, p. 32). A Gailhan tout indice d'une signification sacrificielle fait défaut. Les lieux où sont placées les inhumations de morts périnataux ne présentent aucun caractère cultuel ni communautaire. Celles-ci ne sont pas non plus situées sous des murs, des foyers, des seuils ou autre dispositif constitutif des maisons comme on pourrait s'y attendre pour des dépôts de fondation. On ne trouve aucun objet ou offrande accompagnant le défunt ou pouvant être mis en relation avec lui. Le dépôt lui-mème n'est pas signalé en surface. Le squelette ne présente jamais de trace de traumatisme...

Pour sa part, le depôt des nouveau-nés et petits enfants, décédés naturellement, hors des lieux funéraires réservés aux autres défunts, et leur ensevelissement dans la sphère domestique, est une réalité bien connue dans maintes sociétés passées, y compris dans un passé très récent. Cette mise à part relève d'une des représentations collectives concernant la mort les plus communément répandues dans les sociétés traditionnelles des cinq continents. Selon les conditions dans lesquelles se trouve le défunt, la mort est jugée bonne par les survivants parce que féconde pour eux, ou mauvaise car stérile et dangereuse tant pour la société que pour le décédé. De la sorte il y a de bons morts et de mauvais morls, et les funérailles comme le tombeau varient en conséquence.

Ce système a èté particulièrement bien décrit pour l'Afrique Noire (Thomas, 1982, p. 101-108). Les critères de "bonne mort" sont:

- mourir chez soi, parmi les siens (ce qui permet de réaliser la totalité de tous les rites funèbres);

- mourir de vieillesse et d'usure, sans maladie apparente, ou bien dans la fleur de l'âge, au combat pour le guerrier ou par obligation rituelle;
- avoir eu une nombreuse progéniture;

- avoir préparé sa mort en accumulant les biens qui serviront lors des funérailles;

- avoir vécu en accord avec la loi des ancêtres.

La "bonne mort" permet au défunt, ou à la défunte, après des funérailles complètes, d'accéder à une existence dans l'au-delà. C'est un idéal que chacun s'efforce d'atteindre.

Les critères de "mauvaise mort" sont symétriques des précédents :

- mourir jeune ou sans enfant : le groupe est ainsi privé d'un producteur et d'un procréateur potentiel;

- mourir durant le séjour initiatique, pour l'adolescent;

- mourir enceinte ou à l'accouchement;

- mourir de mort subite et surtout accidentelle ou violente;

- mourir de mort infamante;

- mourir victime d'un sorcier, si celui-ci n'est pas puni ;

- mourir loin de chez soi, et des siens : impossibilité d'accomplir le rituel en l'absence du corps.

Les "mauvais morts" disparaissent à jamais ; ils n'ont pas d'existence dans l'au-delà et sont voués à un anéantissement sans retour. De ce fait, ils n'ont pas droit à des funérailles normales et sont inhumés sans rituel ou avec un rituel très sommaire, voire simplement jetés et abandonnés dans la nature.

Le décès du nouveau-né ou du nourrisson constitue un cas en marge de ces mauvaises morts. C'est que la mortalité infantile est très importante dans les populations qui échappent aux règles de l'hygiène et de la médecine actuelles : un quart des individus meurt avant la fin de la première année et un autre quart dans les quelques années suivantes. Ainsi, par exemple, à Genève entre 1625 et 1684 , $31 \%$ des enfants meurent avant un an et $46 \%$ ne dépassent pas leur dixième année (Perrenoud, 1975), p. 230-231), en France entre 1740 et $1789,28 \%$ des enfants décèdent dans leur première année et un sur deux disparaît avant dix ans et demi (Blayo, 1975, p. 128-133). Toutes les sociétés ont répondu à ce fléau de la même manière : en retardant la reconnaissance sociale et affective des enfants jusqu'à un âge où le risque de les perdre devienne acceptable (Leclerc, Masset, 1982, p. 56). En Afrique Noire, l'enfant n'est intégré à la vie sociale qu'au moment de l'apparition des dents, ce qui coincide avec la baisse de la mortalité infantile. On lui donne alors son nom et on lui reconnait une existence sociale (Thomas, 1980, p. 184). Si elle survient auparavant, 
sa mort ne concerne pas toute la communauté et le rituel funéraire qui l'accompagne est faible ou nul.

Cette attitude à l'égard des morts en bas àge, est attestée, avec des variantes dans les délais observés, dans l'Antiquité, notamment chez les Hébreux et les Grecs (Guérin, Martinez Valle, 1987-1988, p. 248). Un traitement spécial des jeunes morts existe aussi à Rome : dès le vile s. avant J.-C. des tombes d'enfants sont établies dans ou près des habitations (Néraudeau, 1987, p. 196). L'évêque Fulgence se fait l'écho au $\mathrm{vI}^{\mathrm{r}} \mathrm{s}$. de cette pratique : "Priori tempore suggrundaria antiqui dicebant sepulchra infantium qui necdum quadraginta dies implessent" (cité dans Bloch, 1975 , p. 16); à la fin de la République et sous le Haut-Empire, alors que l'incinération est devenue le rite funéraire romain prédominant, les enfants décédés avant la première dentition doivent ètre inhumés et non brûlés, selon Pline, Histoire Naturelle, VII, 16. Et dans les pays christianisés, jusqu'à une époque toute récente, les nouveau-nés décédés avant le baptème faisaient l'objet de traitements spéciaux : ségrégation dans les cimetières en France (Van Gennep, 1946, p. 771); au Pays-Basque, inhumation sous l'avancée du toit de la maison, entre la rigole d'écoulement des eaux et le mur, ou dans le verger attenant à l'habitation (Barandiarán, 1966, p. 308) ...

A Gailhan, trois séries de faits plaident fortement en faveur d'un mode de sépulture normal pour nouveau-nés décédés naturellement :

- la localisation des enterrements au sein de la sphère domestique paraît indiquer que la mort du nouveau-né ne concerne pas toute la communauté villageoise, mais seulement la famille au sens strict du terme;

- le manque de toute trace tangible du rituel, hormis l'ensevelissement dans une petite fosse si, tant est que cette action puisse ètre considérée comme rituelle; cela peut traduire un rituel funéraire affaibli, réduit à sa plus simple expression, voire absent;

- le rapport entre le nombre de périnataux enterrés et le nombre estimé d'unités domestiques et de familles nucléaires, notamment pour le village le mieux conservé, celui du dernier quart du $v^{e}$ s. avant J.-C. : dix périnataux pour la portion de l'oppidum fouillée qui comprend un nombre de maisonnées de l'ordre de cinq unités. Pour assurer leur renouvellement naturel, compte tenu d'un taux de mortalité très élevé pour les plus jeunes sujets, ces cinq familles nucléaires devaient compter au minimum sept ou huit enfants chacune, dont deux disparaissaient avant l'âge d'un an et deux autres (non enterrés dans l'habitat) avant la douzième année. La situation paraît semblable pour le troisième village (première moitié du $\mathrm{IV}^{\mathrm{r}}$ s. avant J.-C.), une douzaine de sujets enterrés pour la même surface de l'oppidum, mais l'estimation est beaucoup plus floue puisque la durée de cette phase est moins précise et que les unités domestiques demeurent très mal connues.

Ainsi donc la pratique funéraire "normale" pour les enfants morts en bas âge à Gailhan serait l'enterrement dans l'unité domestique. A l'appui de ce propos, il serait du plus grand intérêt de pouvoir constater la répartition des classes d'âge dans la nécropole de l'oppidum, mais celle-ci n'a pas été découverte. I) 'une façon générale, on ne connaît de "nécropole" en I anguedoc oriental que pour le premier Age du Fer, du viI" au $\mathrm{VI}^{\mathrm{C}} \mathrm{s}$. avant .J.-C. et pour les $\mathrm{II}^{\mathrm{r}}$ et $I^{\circ r} s$. avant J.C. Et une constatation intéressante simpose. Pour l'ensemble des tumulus du Premier Age du Fer des Garrigues du Languedoc oriental, sur 226 individus (près de $40 \%$ seulement sont incinérés) dont les ossements ont pu être étudiés et l'àge déterminé, les nouveau-nés sont extrêmement rares : deux seulement sont présents, soit $0,9 \%$ du total de l'effectif (Dedet, à paraitre b, chapitre 3). C'est une situation à peu près du même ordre que reflètent les deux nécropoles à incinération du Languedoc occidental dont le matériel ostéologique a fait l'objet d'une étude, Le Peyrou à $\Lambda$ gde (Hérault) à la fin du $\mathrm{vil}^{\mathrm{e}}$ s. et Las Peyros à Couffoulens (Aude) au vic s. (Duday, 1981; 1989) : à Agde, sur 165 individus, deux seulement sont des enfants nouveau-nés soit $1,2 \%$ el à Couffoulens, il y a un nouveau-né pour 52 décès soit $1,9 \% \%^{5}$. Une telle rareté dans les cimetières n'est évidemment pas représentative de la mortalité infantile d'un système démographique antérieur au Xvıı s. Elle est plutôt significative de l'existence de lieux d'ensevelissement des périnataux différents de ceux des adultes.

En outre, le mode de traitement du corps souligne, en partie du moins, cette différence entre mort-nés et autres défunts : les morts périnataux, en habitat, et pas seulement à Gailhan, nous y reviendrons, sont toujours inhumés. Pour les autres individus, placés dans les nécropoles, les traitements sont variables : incinération exclusive en Languedoc occidental; incinération ou dépôt non incinéré en Languedoc oriental (Dedet, à paraître b).

5 Ces pourcentages doivent cependant ètre considérés avec une certaine prudence car les nouveau-nés sont plus difficiles à détecter lorsque le corps a été incinéré que dans le cas contraire. 


\section{Dans le LaNGUedoc et la Provence...}

Les faits décrits à Gailhan ne sont pas isolés dans la Protohistoire régionale (Dedet, Schwaller, 1990), même s'ils prennent ici une ampleur particulière par suite de la précision des observations et de leur caractère systématique. Des restes de sujets des mêmes classes d'âge, fœtus, périnataux, nourrissons dans les premiers mois de leur vie, ont été signalés ou décrits avec des précisions très variables sur une quinzaine d'autres habitats languedociens et provençaux, entre le début du Premier Age du Fer et l'extrême fin du Second (fig. 27).

\section{Le Port, Salses (Pyrénées-Orientales)}

Un sujet ${ }^{6} \mathrm{du} \mathrm{VI}^{\mathrm{e}} \mathrm{s}$. avant $J$.-C. dans les fouilles de 1990 (renseignements A. Pézin).

\section{Pech Maho, Sigean (Aude)}

Un squelette de "nouveau-né» dans une fosse de l'espace $62 \mathrm{~B}$ et deux ou trois autres sujets repérés, tous datés des $\mathrm{IV}^{\mathrm{e}}-\mathrm{III}^{\mathrm{e}} \mathrm{s}$. avant J.-C. (renseignements Y. Solier).

\section{Cayla, Mailhac (Aude)}

Trente-huit individus ${ }^{7}$ dans des niveaux s'échelonnant du $\mathrm{VI}^{\mathrm{e}} \mathrm{s}$. avant au $\mathrm{II}^{\mathrm{e}} \mathrm{s}$. après J.-C. (Louis, Taffanel, 1955, p. 85, fig. 55 , p. 94, p. 121, fig. 97 et p. 123 ; Fabre, 1990, p. 408-409).

Niveaux du Cayla II (vi ${ }^{\mathrm{e}}$ s. avant J.-C.) : neuf sujets. Secleur 19 : un humérus isolé au centre d'une cellule d'habitation. Secteur 22, cour $F$ : deux squelettes dont un en décubitus dorsal, alignés contre le parement intérieur du rempart. Secteur 38a : deux squelettes dont celui d'un fœtus. Secteur 40 : dans la maison B, deux squelettes à $1 \mathrm{~m}$ environ l'un de l'autre, près de la paroi est, perpendiculairement à elle, chacun dans une petite dépression recouverte par une sorte de cailloutis; un squelette contre le parement intérieur du rempart; un autre squelette dont il manque le crâne.

Niveaux du Cayla III ( $\mathrm{v}^{\mathrm{e}}$, IV et première moitié du $11 \mathrm{I}^{\mathrm{e}}$ s. avant J.-C.) : douze sujets. Secteur 13 : un squelette dans un angle d'une salle. Secteur 17 : six ou sept squelettes, tous, sauf un, à l'intérieur de pièces d'habitation; parmi eux, cinq se trouvaient près de murs, parallèlement à eux ; cinq en décubitus

6 Par "sujet", nous désignons les restes n'ayant pas fait l'objet d'une étude anthropologique. Nous mettons entre guillemets les identifications proposées par les auteurs des fouilles pour les sujets qui n'ont pas fait l'objet d'une ètude anthropologique permettant de faire la distinction entre les morts avant terme, les mort-nés, les nouveau-nés et les nourrissons.

7 Plusieurs d'entre eux ont fait l'objet d'un mémoire de maitrise (Fabre, $1988 ; 1990$ ). dorsal, un en décubitus latéral droit, membres inférieurs fléchis et face vers le sol; les orientations des corps sont variées. Secteur 22, salle $D$ : deux squelettes sous le sol dans les angles sud et est de cet étroit réduit, à environ $0,80 \mathrm{~m}$ de distance l'un de l'autre; celui du sud est en décubitus latéral gauche, membres inférieurs repliés, tête au sud; celui de l'est, en décubitus dorsal, tête au sud-est, était muni d'un collier. Secteurs 27 et $38 c$ : un squelette dans chaque secteur.

Niveaux du Cayla IV (seconde moitié du III", II" et premier quart du $\mathrm{I}^{\mathrm{er}}$ s. avant $\mathrm{J}_{\text {.-C.) }}$ : un sujet (secteur $31 \mathrm{a})$.

Niveaux du Cayla V (vers 75 avant-II ${ }^{\circ}$ s. après J.-C.) : treize à quinze sujets. Secteur 13 : un squelette muni d'un bracelet, dans une salle, près d'un mur. Secteur 16 : dans un lieu non défini, deux squelettes très proches l'un de l'autre, en décubitus dorsal, l'un d'eux bordé par deux pierres; un troisième sujet incomplet, isolé. Secteur 23 : un squelette et des fragments crâniens d'un deuxième individu découverts dans une salle, près du mur ouest (datation mal assurée). Secteur 27 : deux squelettes. Secteur 33, salle est : un squelette en décubitus latéral droit, membres inférieurs fléchis, tête au nord-ouest, recouvert par une pierre plate de $30 \mathrm{~cm}$ sur $40 \mathrm{~cm}$. Secleur 33 , salle ouest : quatre squelettes le long du mur est, parallèlement à lui, dont un en décubitus dorsal et un en décubitus latéral droit replié; un squelette en position "f fotale» contre le mur nord; fragments crâniens d'un sixième individu. Secteur $36 a$ : un squelette.

\section{Montlaurès, Narbonne (Aude)}

Un squelette de «nouveau-né » en décubitus dorsal dans le cailloutis du sol d'une "curieuse construction en pierres mesurant $4 \mathrm{~m}$ sur $4,45 \mathrm{~m}$, dépourvue de porte", dont l'intérieur "était rempli d'un amoncellement de pierres formant un véritable tumulus" (chantier II, zone Est, pièce I, datée du $\mathrm{VI}^{\mathrm{e}} \mathrm{s}$. avant J.-C.) (Solier, Giry, 1973, p. 89). Trois morts périnataux enterrés à $1 \mathrm{~m}$ environ les uns des autres dans une zone non bâtie, de datation imprécise mais postérieure au $\mathrm{V}^{\mathrm{e}} \mathrm{s}$. avant J.-C.; un autre sujet découvert dans le comblement d'un silo daté du $\mathrm{III}^{\mathrm{e}} \mathrm{s}$. avant J.-C. (fouille 1990 ; renseignements C.-A. de Chazelles).

\section{La Monédière, Bessan (Héraull)}

Un squelette de "mort-né" ou de "nouveau-né" sous le sol d'une maison de la première moitiè du $\mathrm{VI}^{\mathrm{P}}$ s. avant J.-C., près d'une paroi (Nickels, 1989, p. 54,57$)$.

\section{Ensérune, Nissan-lez-Ensérune (Hérault)}

Plusieurs sujets découverts dans les fouilles de 


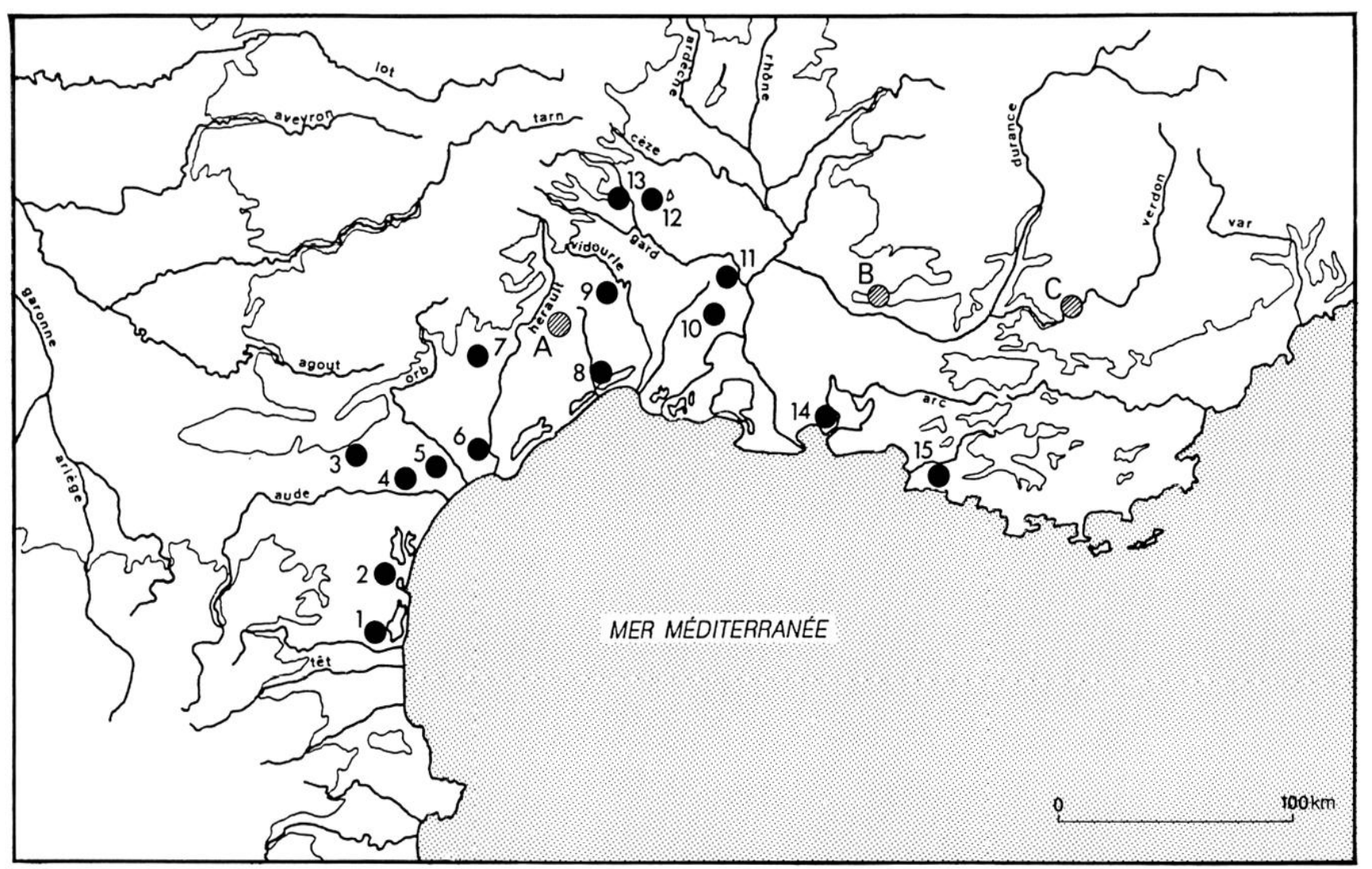

Fig. 27 - Carte de répartition des découvertes de restes de périnataux humains dans les habitats protohistoriques (cercles pleins) et préhistoriques (cercles hachurés) de la France méditerranéenne.

1. Le Port (Salses, Pyrénées-Orientales)

2. Pech-Maho (Sigean, Aude)

3. Cayla (Mailhac, Aude)

4 , Montlaurès (Narbonne. Aude)

5, Ensérune (Nissan-lez-Ensérune. Hérault)

6, La Monédière (Bessan, Hérault)

7, La Ramasse (Clermont-l'Hérault, Iérault)

8 , Lattara (Lattes, Hérault)

9. Plan de la Tour (Gailhan, Gard)

l'abbé L. Sigal, mais ni décrits, ni conservés (renseignements d'O. et $\mathbf{J}$. Taffanel).

\section{La Ramasse, Clermont-l'Hérault (Hérault)}

Deux morts périnataux découverts dans les banquettes courant tout autour de la salle d'habitation de l'unité domestique $n^{\circ} 3$, datés du début du ives. avant J.-C. La tête de l'un des deux était encadrée par deux pierres (renseignements D. Garcia et D. Orliac).

\section{Lattes (Hérault)}

Quatorze sujets dans des niveaux échelonnés entre le $\mathrm{v}^{\mathrm{e}} \mathrm{s}$. et la fin du $\mathrm{I}^{\mathrm{er}} \mathrm{s}$. avant J.-C. (Arnal et alii, 1974, p. 37, 46, 291, 292; Prades, 1984; Py, 1989, p. 58; Fabre, 1990, p. 392-403).

Fouilles H. Prades et Groupe archéologique Painlevé. Sondage 1: un squelette de mort-né ou de nou-
10, Mas Saint-Jean (Bellegarde, Gard)

11, Le Marduel (Saint-Bonnet-du-Gard, Gard)

12, Vié-Cioutat (Mons, Monteils, Gard)

13, L'Ermitage (Alès, Gard)

14, Saint-Blaise (Saint-Mitre-les-Remparts, Bouches-du-Rhoine)

15. Baou de Saint-Marcel (Marseille, Bouches-du-Rhòne)

A, Cambous (Viols-le-Fort, Hérault)

B, La Brémonde (Buoux, Vaucluse)

C, Grotte Murée (Montpezat, Alpes-de-Haute-Provence) veau-né des $\mathrm{IV}^{\mathrm{e}}-\mathrm{III} \mathrm{e}$ s. avant J.-C. Sondage 2 : un mort-né ou nouveau-né en décubitus dorsal, membres inférieurs fléchis, dans une petite fosse creusée le long d'un mur, daté du début du $\mathrm{v}^{\mathrm{C}} \mathrm{s}$. avant $J_{.-C .}$; un frontal de "périnatal" près d'un mur, daté des IV $^{\mathrm{e}}-\mathrm{III}{ }^{\mathrm{e}}$ s. avant J.-C. Sondage 3 : quelques pièces osseuses éparses d'un sujet "périnatal" daté du $v^{e} \mathrm{~s}$. avant J.-C. Sondage 26 : un fœtus de sept mois lunaires à sept mois et demi, en décubitus dorsal légèrement tourné vers la gauche, dans l'angle d'une salle, daté de la seconde moitié du $\mathrm{r}^{\mathrm{er}} \mathrm{s}$. avant J.-C.

Ilot 1 (fouilles 1985-1989). Plusieurs os d'un nouveau-né dans le remblai d'un sol (US 1145/1169/1165) de la salle $7 \mathrm{~A}$ (deuxième quart du III" s. avant J.-C.). Plusieurs os épars d'un mort-né ou nouveau-né dans le comblement d'une fosse (US 1244) et dans la 
couche d'abandon (US 1236) de la salle 6 (dernier quart du III's. avant $\mathbf{J}$.-C.). Ln os d'un nouveau-né dans une tranchée d'épierrement de mur (US 1012), de datation indéterminée.

Ilot 4 (fouilles 1985-1989). Dans l'angle nordouest de la salle 8 , dépôt du deuxième quart du $\mathrm{I}^{\mathrm{er}} \mathrm{s}$. avant $J$.-C. composé d'une urne placée à la verticale renfermant le squelette d'un fœtus humain de six mois, accompagnée d'une seconde urne couchée sur le côté, d'un squelette de chiot mort-né, d'ossements d'oiseau et d'une coquille de cardium polie (DP 241). Dans la salle 9 , près d'un mur, un autre dépôt daté du dernier quart du $\mathrm{I}^{\mathrm{er}} \mathrm{s}$. avant J.-C. : squelette de mort-né ou nouveau-né présentant un certain nombre d'anomalies d'ordre pathologique, placé au fond d'une urne dépourvue de couvercle et posée verticalement dans une couche de remblai (DP 240). Un squelette en connexion de nouveau-né dans le remblai de sol (US 4197) de la salle 9, près de l'angle nord-est, daté du troisième quart du $\mathrm{I}^{\mathrm{er}} \mathrm{s}$. avant J.-C. Un os d'un prématuré (neuf mois lunaires et demi de vie intra-utérine) dans le dépotoir (US 4210) accumulé dans un angle de la salle 9 au cours du troisième quart du $\mathrm{I}^{\mathrm{er}} \mathrm{s}$. avant J.-C. Plusieurs os d'un prématuré (huit à neuf mois lunaires de vie intrautérine) dans le remblai d'un sol (US 4239) de la salle 8 , daté du dernier quart du $\mathrm{II}^{\mathrm{P}}$ s. avant J.-C. ou du premier quart du siècle suivant. Un os d'un nouveau-né dans une tranchée d'épierrement de mur (US 4150) de datation indéterminée.

\section{Le Marduel, Saint-Bonnet-du-Gard (Gard)}

Cinq individus datés des $\mathrm{IV}^{\mathrm{e}}$ et $\mathrm{II}^{\mathrm{C}} \mathrm{s}$. avant $\mathrm{J}$.-C. (Py et alii, 1986, p. 71; Py el alii, 1989, p. 187-189; Py, 1987, p. 745; Fabre, 1990, p. 404-407). Salle 11 : un nouveau-né en décubitus latéral gauche, membres fléchis, dans une fosse creusée dans un remblai de sol, le long d'un mur; un second individu, non analysé, a été découvert à moins de $1 \mathrm{~m}$ du précédent, le long du même mur; tous deux, sans ètre forcément contemporains, datent du début du IV"s. avant J.-C. Salle 44 : un nouveau-né en décubitus latéral gauche, plaqué contre la paroi d'une fosse, membres inférieurs repliés; la fosse, fermée par une grande dalle, est creusée contre le mur ouest de la maison près du seuil (fin du IV"s. avant J.-C.). Salle 122 : un nouveau-né en décubitus ventral avec légère rotation partielle du tronc et du bassin vers la droite, membres inférieurs repliés, tête à l'est, dans un remblai de sol à $0,50 \mathrm{~m}$ d'un mur (début du $\mathrm{II}^{\mathrm{C}} \mathrm{s}$. avant J.-C.). Un hémi-frontal d'un autre nouveau-né dans un remblai postérieurement perturbé du même habitat (début du II s. avant J.-C.).

\section{Mas Saint-Jean, Bellegarde (Gard)}

Un individu paraissant mort en phase périnatale repéré, mais non fouillé, dans un gisement des viII ${ }^{\mathrm{e}-}$ $\mathrm{vII}^{\mathrm{e}}$ s. avant $J$.-C. (renseignements $\mathrm{Y}$. (iasco).

\section{Vié-Cioutal, Mons, Monteils (Gard)}

Un squelette de nouveau-né dans une petite fosse recouverte par un mur d'habitation de la première moitiè du $\mathrm{I}^{\mathrm{er}} \mathrm{s}$. avant J.-C. (fouillé par H. Duday et B. Dedet; en cours d'étude).

\section{Ermilage, Alès (Gard)}

Un nourrisson âgé de un à trois mois, déposé dans une petite cavité naturelle s'ouvrant dans l'encoche calcaire creusée pour bâtir la maison 13 et scellée par le mur de celle-ci dans la première moitié du $\mathrm{I}^{\mathrm{er}}$ s. avant J.-C. (Salles, 1986, p. 17).

\section{Saint-Blaise, Saint-Mitre-les-Remparts (Bouches-du-Rhône)}

Un sujet de la fin du vir" ou du début du $\mathrm{VI}^{\circ} \mathrm{s}$. avant J.-C. (Bouloumié, 1984, p. 95).

\section{Baou de Saint-Marcel, Marseille (Bouches-du-Rhône)}

Un fœtus de huit mois dont les restes ont été découverts «dispersés dans un espace grossièrement circulaire de $25 \mathrm{~cm}$ de diamètre, les os longs étant orientés est-ouest ", à l'intérieur de la maison Ib.N-2, sous le remblai du sol de fondation $\left(\mathrm{vI}^{\mathrm{r}} \mathrm{s}\right.$. avant J.-C.) (Arnaud, 1980; Gantès, Hayssiguier, 1980, p. 72).

Age au décès, mode de dépôt, position du corps, localisation de l'ensevelissement, lorsqu'ils sont connus, permettent de dégager un certain nombre de tendances qu'il est utile de comparer aux faits constatés à Gailhan (tabl. II et III, p. 104-106).

Comme à Gailhan, il s'agit la plupart du temps de sujets ayant atteint le terme de la gestation, morts à la naissance ou dans les premiers jours de leur vie. A Lattes, sur quatorze individus, douze sont des mort-nés ou des nouveau-nés à terme et deux seulement des fœtus. Proportion semblable au Cayla de Mailhac : sur huit individus analysés en 1990, il n'y a qu'un foxtus. Un foetus a été identifié également. an Baou de Saint-Marcel. Dans l'ensemble les fotus sont done largement minoritaires. Les nourrissons âgés de plus d'un mois sont encore plus rares : en l'ètat actuel des analyses, deux à Gailhan et un à l'Ermitage d'Alès.

Dans tous les cas étudiés, le dépôt individuel est la règle, comme à Gailhan. Mais, comme sur ce dernier site, des ensevelissements ont été souvent effectués à proximité les uns des autres dans une même cellule architecturale et dans un laps de temps relativement court: Cayla de Mailhac, salles $22 \mathrm{D}$ et 
$40 \mathrm{~B}$, cour $22 \mathrm{~F}$ (deux sujets dans chacune), salles 17 et 33 ouest (six individus dans chacune); Lattes, salle 9 de l'îlot 4 (deux sujets du troisième quart du $I^{\prime r}$ s. avant J.-C. auxquels s'ajoutera un troisième individu dans le quart de siècle suivant); La Ramasse, unité domestique 3 (deux individus dans la même salle); Le Marduel, salle 11 (deux sujets).

I a plupart du temps les corps sont déposés dans une petite fosse, hors de tout contenant, et sont rapidement recouverts de terre. Trois exceptions cependant, toutes tardives : à l'Ermitage d'Alès, dans la première moitié du $\mathrm{I}^{\mathrm{er}} \mathrm{s}$. avant J.-C., cadavre dans une cavité naturelle du rocher, décomposé dans un espace non colmaté; à Lattes, un foetus du deuxième quart du $\mathrm{I}^{\mathrm{er}} \mathrm{s}$. avant $\mathbf{J}$.-C. et un nouveau-né du dernier quart du mème siècle déposés chacun dans une urne.

Les squelettes recouverts de terre qui ont $\mathrm{pu}$ ètre relevés avec soin, traduisent partout des positions variées, comme à Gailhan : décubitus dorsal, latéral gauche, latéral droit ou, plus rarement, ventral.

Les fosses ne présentent pas d'aménagement particulier. Deux exceptions toutefois : deux pierres semblant placées de part et d'autre du crâne d'un des sujets de I a Ramasse; présence de galets roulés allogènes au site dans la fosse du nouveau-né de ViéCioutat. En dehors du Marduel, salle 44, et du Cayla de Mailhac, salle 33 est, où une dalle horizontale repose sur le dessus du comblement de la fosse, nulle part on a repéré d'élément de fermeture. Il n'y a pas non plus semble-t-il de signalisation du dispositif en surface.

Presque toujours ces fœtus, nouveau-nés et nourrissons sont dépourvus de toute pièce de parure, d'accompagnement ou d'offrande. Seuls deux sujets du Cayla de Mailhac dérogent à la règle (un sujet de la salle $22 \mathrm{D}$ paré d'un collier et celui de la salle 13 qui portait un bracelet), ainsi qu'un fotus de Lattes enfermé dans une urne à côté d'une deuxième urne et d'offrandes animales (DP 241).

I.orsqu'elle est précisée, la localisation de ces ensevelissements est presque toujours liée à l'unité domestique : salle d'habitation, cour domestique ou autre lieu non couvert environnant la maison. A Gailhan, nous l'avons vu, c'est surtout la cour domestique qui est utilisée à cet effet. Mais la situation varie, en fait, d'une agglomération à l'autre en fonction de l'urbanisme en vigueur et des fouilles. Ainsi, à Lattes et au Marduel, où, à la différence de Gailhan, les maisons sont serrées les unes contre les autres et les cours domestiques fort rares, tous les dépôts sont effectués à l'intérieur des salles d'habita- tion, tandis que la voirie est délaissée pour cet usage. C'est aussi à l'intérieur de salles d'habitation qu'ont été découverts les sujets de Ia Monédière, Ia Ramasse et du Baou de Saint-Marcel. Au Cayla de Mailhac, où les fouilles ont privilégié les lieux construits, dans leur grande majorité, les morts périnataux ont été découverts dans des pièces d'habitation. Toutefois des dépôts sont attestés dans la cour domestique $22 \mathrm{~F}$ ou dans des espaces non bàtis aux abords des maisons (fouilles 40 ou 17).

Dans tous ces lieux, couverts ou non, l'inhumation est placée indifféremment vers le centre de la cellule ou vers la périphérie, près des murs ou dans les angles. On ne relève que deux cas de dépòts, au demeurant tardifs (première moitié du $I^{\mathrm{e}^{\mathrm{r}}} \mathrm{s}$. avant J.-C.), effectués en liaison aver la construction de l'habitation: Vié-Cioutat ef l'Ermitage d'Alès.

Prenons en compte à prisent la rhronologie de ces manifestations. I.es enser ulissemunls qui se singularisent le plus des autres. sorit par leur forme (les deux dépôts en urne IOP 210 et IOP :11 de Lattes). soit par la présence d'offrandes (dépôt 241 de Lattes), soit encore par leur localisation scellée par la construction (Vié-Cioutat, Ermitage d'Alès) datent tous du I $^{\text {er }}$ s. avant J.-C. Et l'un des deux sujets du Cayla de Mailhac pourvu d'un élément de parure, celui du secteur 13 , est de même époque ou mème plus récent. Toutes les autres inhumations constituent un ensemble homogène où seuls se distinguent de très rares foetus et individus morts assez longtemps après la naissance et un nouveau-né paré d'un collier.

Ces découvertes dans des habitats languedociens ont parfois donné lieu à plusieurs interprétations. Le sacrifice a été évoqué à Montlaurès pour l'individu de la pièce I, zone Est du chantier II, sans que cette hypothèse soit réellement retenue (Solier, Giry, 1973, p. 89). Les structures, sommairement décrites, sont en effet problématiques : s'agit-il d'une habitation, d'un local annexe ou d'un edifice particulier? Plus récemment, un rite de fondation, n'impliquant pas forcément le sacrifice du nouveau-né, a été avancé pour expliquer les découvertes faites au Marduel (Py, 1987, p. 743-745). Mais il n'y a pas d'argument. convaincant pour une telle hypothèse sur ce site. En revanche, celle-ci nous paraît devoir ètre évoquée dans les cas des dépôts effectués sous les murs ou dans les parois des maisons du $\mathbf{I}^{\mathrm{er}}$ s. avant J.-C. de Vié-Cioutat et de l'Ermitage d'Alès.

En fait, parmi tous les cas d'ensevelissements de sujets périnataux connus à ce jour en Languedor, Roussillon, Provence, il y a lieu de distinguer trois 
ensembles qui ont toutes les chances de refléter des préoccupations différentes.

1 - Les deux sujets de Vié-Cioutat et de l'Ermitage d'Alès, dont la situation par rapport à la construction de la maison parait indiquer un rite de fondation, sans qu'il y ait forcément infanticide. Un tel rite impliquant un nouvcau-né ou un nourrisson ne semble pas apparaître dans la région avant le $\mathrm{I}^{\mathrm{er}} \mathrm{s}$. avant $\mathrm{J}$.-C. et resterait par ailleurs très rarement pratiqué.

2 -Les deux sujets de Lattes placés dans des urnes au $\mathrm{I}^{\mathrm{er}} \mathrm{s}$. avant $\mathrm{J}$.-C. sont aussi à mettre à part. Leur caractère exceptionnel dans le Sud de la France incline à penser qu'ils témoignent de rites particuliers (dépôt de fondation ou individu remarquable ; on notera à ce propos que le nouveau-né (DP 240) présentait des malformations) plutôt que de pratiques funéraires au sens strict.

3 - Pour le reste, c'est-à-dire en fait la totalité des individus antérieurs au $\mathrm{I}^{\mathrm{er}} \mathrm{s}$. avant J.-C. découverts en Languedoc-Roussillon et Provence et décrits avec quelque précision, on retrouve tous les traits caractéristiques des inhumations mises au jour à Gailhan. Compte tenu du déficit de cette classe d'àge dans les nécropoles de la région dont l'étude ostéologique a èté effectuée, il est donc très probable que les pratiques funéraires décelées à Gailhan pour les sujets morts durant la période périnatale, enterrés dans les unités domestiques sans rituel ou tout au plus accompagnés de rites funéraires ne laissant pas de trace tangible, ont également intéressé la plupart des sites du Sud de la France inventoriés ici. Certes le nombre de ces découvertes peut paraitre faible sur chacun de ces sites, en regard de la surface fouillée et du taux de mortalité infantile que l'on est en droit d'attendre pour cette époque. Mais ces chiffres doivent être considérés comme très largement sousestimés. En effet le repérage de tels vestiges, très fragiles, a dû largement souffrir de méthodes de fouilles non appropriées et du faible intérêt porté pendant longtemps au matériel osseux. Et si des squelettes ont été repérés dans certaines fouilles anciennes, ce sont surtout les recherches récentes qui en ont multiplié les exemples.

Lne telle coutume plonge peut-être ses racines dans le passé régional. En effet des squelettes de nouveau-nés ont été découverts dans des habitats du Campaniforme, grotte Murée à Montpezat (Alpes-deHaute-Provence) (Courtin, 1961, p. 187), du Néolithique final, deux sujets à la Brémonde (Buoux, Vaucluse) (Mahieu, 1984-1985, p. 142) ou du Chalcolithique, un individu dans un vase près d'un mur à l'intérieur d'une des maisons du village de Cambous
(Viols-le-Fort, Hérault) (Canet, Roudil, 1978, p. 173). A ces périodes, la présence de nourrissons est exceptionnelle dans les sépultures collectives, comme elle l'est également à l'Age du Fer dans les nécropoles et il n'est pas impossible que cette situation soit révélatrice d'un statut social particulier de ces individus dès ces périodes (Mahieu, 1984-1985, p. 153). Aucune découverte dans la région ne se rapporte à l'Age du Bronze, mais cette absence est pour le moment peu significative, les habitats des différentes phases de cette période ayant fait l'objet de fouilles d'extension très réduite.

A l'Age du Fer, ces enterrements domestiques ne concernent pas toutes les agglomérations. Plusieurs sites fouillés récemment sur une grande superficie et dont le matériel osseux a été étudié, n'en ont, semble-t-il, livré aucune trace comme Roque de Viou à Saint-Dionisy (Gard) au Bronze final III B et au IV $^{\mathrm{e}}$ s. avant. J.-C., Nages (Gard) du III $^{\mathrm{e}}$ au I ${ }^{\mathrm{er}}$ s. avant J.-C., Vié-Cioutat aux $\mathrm{v}^{\mathrm{e}-\mathrm{IV}} \mathrm{v}^{\mathrm{e}}$ s. avant J.-C. La coutume funéraire en vigueur à Gailhan n'est donc pas générale en Languedoc. D'autres formules propres à certaines agglomérations ont pu exister, que nous ne connaissons pas: incinération? Abandon dans la nature? Etc.

Enfin on remarquera que les agglomérations pratiquant l'enterrement des nouveau-nés dans les habitations se distribuent sur l'ensemble du Languedoc et de la Provence rhodanienne et que les changements socio-économiques qui touchent ces régions durant l'Age du Fer à la suite des courants commerciaux méditerranéens ne semblent affecter en rien cet usage. De ce point de vue également, rien ne paraît distinguer l'aire culturelle "rhodanienne" (Languedoc oriental et Provence rhodanienne) du Languedoc occidental qui fait partie du domaine ibéro-languedocien ${ }^{8}$.

\section{Bernard Dedet \\ Henri Duday et Anne-Marie Tillier}

8 En Espagne du Nord-Est et de l'Est, outre les formules de dépòts que nous avons déjá évoquées (sujets regroupés à l'intérieur de "salles cultuelles communautaires" ou en relation avec un élément constitutif de la maison, ou encore en liaison avec des animaux sacrifiés), les inhumations de morts périnataux dans les maisons sont également très bien attestées, selon des modalités semblables à celles utilisées dans le sud de la France. Cela peut ètre constaté dès avant la mise en place du complexe ibérique, ainsi que le montrent les découvertes de la conque de l'Ébre au Bronze final, comme La Pedrera à Vallfogona de Balaguer (Lerida) (Gallart, Junyent, 1989, p. 57), Carretela à Aitona (Lerida) et Azafranales à Fraga (Iluesca) (Maya, 1986, p. 45), ou au début du Premier Age du Fer au 
Tableau I - Caractères métriques principaux des grands os longs des membres et des os des ceintures scapulaire et pelvienne. Les valeurs, relevées selon les méthodes de Fazekas et Kosa, sont indiquées en millimètres: $\mathrm{d}=\mathrm{droite} ; \mathrm{g}=$ gauche.

\begin{tabular}{|c|c|c|c|c|c|c|c|c|c|c|c|c|c|c|c|c|c|c|c|c|c|}
\hline & $\mathrm{A}$ & 1 & A & 2 & $\mathrm{~A} 3$ & & $\mathrm{A4}$ & $\mathrm{A}$ & & A 6 & $\mathrm{~B} 1$ & B2 & $\mathrm{B}:$ & & B & 4 & B5 & C3 & $\mathrm{C} 4$ & C10 & C11 \\
\hline & $\mathrm{d}$ & $\mathrm{g}$ & d & $\mathrm{g}$ & d & d & $\mathrm{g}$ & $\mathrm{d}$ & $\mathrm{g}$ & d & $\mathrm{g}$ & $\mathrm{d}$ & d & $\mathrm{g}$ & d & $g$ & d & $\mathrm{g}$ & $\mathrm{g}$ & g & d \\
\hline $\begin{array}{l}\text { Humérus } \\
\text { longueur } \\
\text { largeur distale }\end{array}$ & $\begin{array}{l}64,6 \\
16,7\end{array}$ & $\begin{array}{l}64,6 \\
17,0\end{array}$ & $\begin{array}{l}65,8 \\
16,2\end{array}$ & $\begin{array}{l}66,0 \\
15,9\end{array}$ & $\begin{array}{l}65,7 \\
17,3\end{array}$ & $\begin{array}{l}66,5 \\
17,8\end{array}$ & $\begin{array}{l}65,5 \\
17,7\end{array}$ & $\begin{array}{l}60,4 \\
14,2\end{array}$ & $\begin{array}{l}60,5 \\
15,2\end{array}$ & $\begin{array}{l}69,3 \\
18,4\end{array}$ & 14,9 & $\begin{array}{l}>68,7 \\
>15,7\end{array}$ & & & & $\begin{array}{l}61,9 \\
16,0\end{array}$ & 15,2 & & $\begin{array}{r}>75,2 \\
18,1\end{array}$ & & \\
\hline $\begin{array}{l}\text { Radius } \\
\text { longueur }\end{array}$ & 52,5 & 52,5 & 51,8 & & 52,7 & 53,0 & 52,5 & 46,8 & 46,8 & 55,5 & & & & & & & $\# 54,0$ & & & & \\
\hline $\begin{array}{l}\text { Ulna } \\
\text { longueur }\end{array}$ & 60,4 & 60,2 & 59,7 & & 59,2 & 60,5 & 60,4 & 55,1 & 54,2 & 64,3 & & & & & & & & & & & \\
\hline $\begin{array}{l}\text { Fémur } \\
\text { longueur } \\
\text { largeur distale }\end{array}$ & $\begin{array}{l}76,1 \\
20,7\end{array}$ & $\begin{array}{l}76,2 \\
21,7\end{array}$ & $\begin{array}{l}77,1 \\
18,0\end{array}$ & $\begin{array}{l}77,3 \\
18,4\end{array}$ & \begin{tabular}{|l}
76,8 \\
18,8
\end{tabular} & $\begin{array}{l}75,4 \\
20,4\end{array}$ & $\geqslant 74,1$ & $\begin{array}{l}69,2 \\
18,7\end{array}$ & $\begin{array}{l}69,5 \\
18,9\end{array}$ & & 18,5 & 79,8 & & 18,7 & $\begin{array}{l}69,8 \\
20,8\end{array}$ & & & $\begin{array}{l}55,5 \\
13,8\end{array}$ & & & \\
\hline $\begin{array}{l}\text { Tibia } \\
\text { longueur }\end{array}$ & 65,1 & 65,3 & 67,1 & 67,0 & 66,5 & 65,5 & 66,0 & 59,5 & 60,2 & & & & & & 60,8 & & & & & 68,1 & $>55,4$ \\
\hline $\begin{array}{l}\text { Fibula } \\
\text { longueur }\end{array}$ & 61,6 & 61,4 & 63,3 & 63,1 & & 60,7 & & & 56,2 & & & & & & 57,6 & & & & & & \\
\hline $\begin{array}{l}\text { Clavicule } \\
\text { longueur }\end{array}$ & 44,2 & 43,7 & 43,1 & 42,5 & 44,4 & 44,8 & 45,1 & 43,1 & 43,0 & & & & & & & & & & & & \\
\hline $\begin{array}{l}\text { Scapula } \\
\text { longueur } \\
\text { largeur } \\
\text { longueur de l'épine }\end{array}$ & $\begin{array}{l}35,2 \\
28,5 \\
33,1\end{array}$ & $\begin{array}{l}34,5 \\
29,4 \\
32,0\end{array}$ & & & 36,5 & 28,4 & $\begin{array}{l}30,2 \\
27,1\end{array}$ & $\begin{array}{l}30,7 \\
26,6 \\
29,8\end{array}$ & $\begin{array}{l}26,8 \\
29,9\end{array}$ & & & $\# 37,5$ & & & & & & & & & \\
\hline $\begin{array}{l}\text { Ilion } \\
\text { longueur } \\
\text { largeur }\end{array}$ & $\begin{array}{l}31,0 \\
32,2\end{array}$ & $\begin{array}{l}31,1 \\
32,2\end{array}$ & $\begin{array}{l}34,7 \\
31,2\end{array}$ & $\begin{array}{l}34,7 \\
31,4\end{array}$ & & $\begin{array}{l}37,0 \\
32,3\end{array}$ & & & $\begin{array}{l}30,1 \\
28,1\end{array}$ & \begin{tabular}{|c|}
38,8 \\
34,0
\end{tabular} & & & & 30,4 & & & & & & & \\
\hline $\begin{array}{l}\text { Ischion } \\
\text { longueur } \\
\text { largeur }\end{array}$ & $\begin{array}{l}20,0 \\
13,2\end{array}$ & 20,2 & $\begin{array}{l}17,2 \\
11,7\end{array}$ & $\begin{array}{l}17,3 \\
11,8\end{array}$ & & $\begin{array}{l}19,2 \\
13,0\end{array}$ & 19,2 & & $\begin{array}{l}16,1 \\
11,1\end{array}$ & 20,3 & & & $\begin{array}{l}17,6 \\
12,3\end{array}$ & $\begin{array}{l}17,6 \\
12,0\end{array}$ & $\begin{array}{l}17,8 \\
11,6\end{array}$ & & & & & & \\
\hline $\begin{array}{l}\text { Pubis } \\
\text { longueur }\end{array}$ & 15,0 & 15,3 & & & & 18,0 & 18,2 & & & & & & & 14,5 & & & & & & & \\
\hline
\end{tabular}

Cerro de la Ciruz à Cortes (Navarre) (Maluquer de Motes, 1958. p. 143). Comme en Languedoc-Provence, il s'agit de dépòts individuels dans de petites fosses creusées sous le sol des maisons, un ou plus rarement deux par maison, sans mobilier d'accompagnement: La Pedrera au début du Bronze final; Puig de la Misericordia à Vinaròs (Castellon) au $\mathrm{VI}^{\mathrm{p}} \mathrm{s}$. avant J.-C. (Oliver Foix, Gomez Bellard, 1989, p. 51-54); Penya del Moro à Sant Just Desvern (Barcelone) entre 550 et 350 avant J.-C. (Barberá, Sanmarti, 1976-1978, p. 300); Puig de la .Vau à Benicarló et Sant Josep à Vall de Uixó (Castellon) au $\mathrm{v}^{\mathrm{e}} \mathrm{s}$. avant J.-C. (Oliver Foix, Gomez. Bellard, 1989, p. 54-58); Puntal dels Llops à Olocau (Valence) à la fin du v" s. avant J.-C. (Guérin, Martinez Valle, 1987-1988, p. 240); La Illa d'en Reixac à Ullastret (Gérone) au Ive s. avant J.-C. (Agusti el alii. à paraître); La Hova à Laguardia (Alava) aux IV'-III s. avant J.-C. (ibid.): Turo de Can Olivé à Cerdanyola (Barcelone) entre 250 et 100 avant J.-C. (Barberá el alii, 1960-1961, p. 214. fig. 16 et p. 219): La Romana à La Puebla de Hijar (Teruel) aux $\mathrm{IJ}^{\mathrm{P}}-\mathrm{IJ}^{\mathrm{P}}$ s. avant J.-C. (Beltrán Lloris, 1976-1978, p. 307309); La Serreta a Alcoy (Valence) vers les II"-Irr s. avant J.-(C. (Tarradell, 1965). Dans d'autres cas, les périnataux sont déposés dans une urne : La Pedrera; Cerro de la Cruz a Cortes de Navarra; Sant Josep à Vall de Uixó au v"s. avant J.-C.; Castellet de Bernabe à Liria (Valence) au début du $\mathbf{W}^{\prime \prime}$ s. avant J.-C. (Guérin, Martinez Valle, 1987-1988, p. 231-2:38) : sous une banquette à Los Villares à Caudete de las Fuentes (Valence) dans la seconde moitié du $\mathrm{v}^{\mathrm{r}} \mathrm{s}$. avant J.-C.. (ibid., p. 240): La Sena à Villar del Arzobispo (Valence) au début du $W^{*}$ s. avant J.-C. (ibid., p. 238-240). Certains de ces dépòts incluent un bracelet ou une offrande (Cerro de la Cruz à Cortès de Vavarra, La Hoya, La Romana). Sud de la France, péninsule ibérique ... la liste des aires géographiques n est pas limitative et le corpus de telles pratiques est à faire. Ainsi par exemple dans le latium et les contrées situées au nord du Tibre, les petits enfants sont absents des nécropoles et sont ensevelis dans l'habit at, au Premier Age du Fer (Bartoloni et alii, 1982, p. 259-260) ... 
Tableau II - Tableau synoptique des squelettes découverts in silu. Abréviations utilisées : X-né : nouveau-né: Prémat. : prématuré : $m$ : mois: ${ }^{\cdot}$ : à proximité d'une ou de deux parois: ${ }^{\prime}$ : sous une paroi ou scellée par elle $;(b)$ : dans une banquette: (d) : fosse pourve d'une dalle de couverture: $(g)$ : présence de galets; I.D. : décubitus dorsal ; D.V. : décubitus ventral ; D.L.D). : décubitus lateral droit; D.I.(i. : décubitus lateral gauche.

\begin{tabular}{|c|c|c|c|c|c|c|}
\hline & Age & Localisation & Dépòt & Position & Accompagnement & Datation \\
\hline Gailhan Al & $\mathrm{N}$-né & Cour $15 \mathrm{~A}$ & Fosse & D.L.G. & 0 & $400-350$ \\
\hline Gailhan A2 & $\mathrm{N}$-né & Cour $17.1^{\circ}$ & Fosse & D.L.G. & 0 & $425-400$ \\
\hline Gailhan A3 & N-né & Cour 22 & Fosse & D.L.G. & 0 & $425-400$ \\
\hline Gailhan A4 & N-né & Cour 22 & Fosse & D.D. & 0 & 425-400 \\
\hline Gailhan A5 & N-né prémat. & Cour $22^{*}$ & Fosse & D.V. & 0 & 425-400 \\
\hline Gailhan A6 & $\mathrm{N}$-né & Cour 22 & Fosse & D.L.G. & 0 & 425-400 \\
\hline Gailhan B2 & Nourrisson $2 \mathrm{~m}$ & Cour 17.2 & Fosse & $?$ & 0 & $400-350$ \\
\hline Cayla $22 \mathrm{~F}$ & Périnatal & Cour $22 \mathrm{~F}^{*}$ & $?$ & D.D. & 0 & $600-500$ \\
\hline Cayla 22F & Périnatal & Cour $22 \mathrm{~F}^{*}$ & $?$ & $?$ & 0 & $600-500$ \\
\hline Cayla $38 \mathrm{~A}$ & Périnatal & $?$ & $?$ & $?$ & 0 & $600-500$ \\
\hline Cayla 38A & Fœtus & $?$ & $?$ & $?$ & 0 & $600-500$ \\
\hline Cayla 40B & Périnatal & Maison $40 \mathrm{~B}^{*}$ & Fosse & $?$ & 0 & $600-500$ \\
\hline Cayla 40B & Périnatal & Maison $40 \mathrm{~B}^{*}$ & Fosse & $?$ & 0 & $600-500$ \\
\hline Cayla 40 & Périnatal & Lieu non cou. & $?$ & $?$ & 0 & $600-500$ \\
\hline Cayla 40 & Périnatal & Lieu non cou. & $?$ & $?$ & 0 & $600-500$ \\
\hline Cayla 13 & Périnatal & Maison * & $?$ & $?$ & 0 & $500-250$ \\
\hline Cayla 17 & Périnatal & Maison & $?$ & D.D. & 0 & $500-250$ \\
\hline Cayla 17 & Périnatal & Maison & $?$ & $?$ & 0 & $500-250$ \\
\hline Cayla 17 & Périnatal & Maison & $?$ & $?$ & 0 & $500-250$ \\
\hline Cayla 17 & Périnatal & Maison & $?$ & $?$ & 0 & $500-250$ \\
\hline Cayla 17 & Périnatal & Maison & $?$ & $?$ & 0 & $500-250$ \\
\hline Cayla 17 & Périnatal & Lieu non cou. & $?$ & $?$ & 0 & $500-250$ \\
\hline Cayla 17 & Périnatal & Maison & $?$ & D.L.D. & 0 & $500-250$ \\
\hline Cayla 22D & Périnatal & Maison $22 \mathrm{D}^{*}$ & $?$ & D.L.G. & 0 & $500-250$ \\
\hline Cayla 22D & Périnatal & Maison $22 \mathrm{D}^{*}$ & $?$ & D.D. & Collier & $500-250$ \\
\hline Cayla 27 & Périnatal & $?$ & $?$ & $?$ & 0 & $500-250$ \\
\hline Cayla 38C & Périnatal & $?$ & $?$ & $?$ & 0 & $500-250$ \\
\hline Cayla 31A & Périnatal & $?$ & $?$ & $?$ & 0 & $250-75$ \\
\hline Cayla 13 & Périnatal & Salle ${ }^{*}$ & $?$ & $?$ & Bracelet & $-75+200$ \\
\hline Cayla 16 & Périnatal & $?$ & $?$ & D.D. & 0 & $-75+200$ \\
\hline Cayla 16 & Périnatal & $?$ & $?$ & D.D. & 0 & $-75+200$ \\
\hline Cayla 23 & Périnatal & $?$ & $?$ & $?$ & 0 & $-75+200$ \\
\hline Cayla 27 & Périnatal & $?$ & $?$ & $?$ & 0 & $-75+200$ \\
\hline Cayla 27 & Périnatal & $?$ & $?$ & $?$ & 0 & $-75+200$ \\
\hline Cayla 33 & Périnatal & Salle Est & Fosse (d) & D.L.D. & 0 & $-75+200$ \\
\hline
\end{tabular}




\begin{tabular}{|c|c|c|c|c|c|c|}
\hline Cayla 33 & Périnatal & Salle Ouest & $?$ & D.D. & 0 & $-75+200$ \\
\hline Cayla 33 & Périnatal & Salle Ouest & $?$ & D.L.D. & 0 & $-75+200$ \\
\hline Cayla 33 & Périnatal & Salle Ouest & $?$ & $?$ & 0 & $-75+200$ \\
\hline Cayla 33 & Périnatal & Salle Ouest & $?$ & $?$ & 0 & $-75+200$ \\
\hline Cayla 33 & Périnatal & Salle Ouest & $?$ & $?$ & 0 & $-75+200$ \\
\hline Cayla 33 & Périnatal & Salle Ouest & $?$ & $?$ & 0 & $-75+200$ \\
\hline Montlaurès & Périnatal & Salle 1 Est & $?$ & $?$ & 0 & $600-500$ \\
\hline Montlaurès & Périnatal & Silo & $?$ & $?$ & 0 & $300-200$ \\
\hline La Monédière & Périnatal & Maison ${ }^{*}$ & $?$ & $?$ & 0 & $600-550$ \\
\hline La Ramasse & Périnatal & U.D. $3^{*}(\mathrm{~b})$ & $?$ & $?$ & 0 & $400-350$ \\
\hline La Ramasse & Périnatal & U.D. $3^{*}(\mathrm{~b})$ & $?$ & $?$ & 0 & $400-350$ \\
\hline Lattes sond. 1 & Périnatal & $?$ & $?$ & $?$ & 0 & $400-200$ \\
\hline Lattes sond. 2 & N-né & $?^{*}$ & Fosse & D.D. & 0 & $500-450$ \\
\hline Lattes sond. 26 & Fœtus & Salle* & $?$ & D.D. & 0 & $50-0$ \\
\hline Lattes DP 241 & Fœtus & Salle $8^{\circ}$ & Urne & Replié & Urne, faune & $75-50$ \\
\hline Lattes DP 240 & N-né & Salle $9^{*}$ & Urne & $?$ & 0 & $25-0$ \\
\hline Lattes 4197 & N-né & Salle 9 & $?$ & $?$ & 0 & $50-25$ \\
\hline Marduel 11 & N-né & Salle $11^{\circ}$ & Fosse & D.L.G. & 0 & $400-375$ \\
\hline Marduel 11 & N-né & Salle $11^{\circ}$ & $?$ & $?$ & 0 & $400-375$ \\
\hline Marduel 44 & N-né & Salle $44^{\circ}$ & Fosse (d) & D.L.G. & 0 & $325-300$ \\
\hline Marduel 122 & N-né & Salle $122^{\circ}$ & $?$ & D.V. & 0 & $200-175$ \\
\hline Vié-Cioutat & Périnatal & Salle * & Fosse (g) & $?$ & 0 & $100-50$ \\
\hline Ermitage & Nourrisson 3m & Maison $13^{*}$ & Cavité & $?$ & 0 & $100-50$ \\
\hline
\end{tabular}


Tableau III - Tableau synoptique des individus découverts non en place et des os isolés.

\begin{tabular}{|c|c|c|c|}
\hline & Age & Localisation & Datation \\
\hline Gailhan B1 & N-né & Cour $15 \mathrm{~A}$ & $400-350$ \\
\hline Gailhan B3 & N-né & Maison 21 & $425-400$ \\
\hline Gailhan B4 & $\mathrm{N}$-né & Cour 22 & $425-400$ \\
\hline Gailhan B5 & N-né & Cour 24 & $400-350$ \\
\hline Gailhan C1 & $\mathrm{N}$-né & Cour 6-7 & $400-350$ \\
\hline Gailhan C2 & Périnatal & Cour 6-7 & $450-400$ \\
\hline Gailhan C3 & Fotus & Cour 8 & $400-350$ \\
\hline Gailhan C4 & Nourrisson & Cour 15A & $400-350$ \\
\hline Gailhan C5 & Périnatal & Cour 15A & $400-350$ \\
\hline Gailhan C6 & $\mathrm{N}$-né & $?$ & $400-350$ \\
\hline Gailhan C7 & Fœtus & $?$ & $400-350$ \\
\hline Gailhan C8 & N-né & $?$ & $400-350$ \\
\hline Gailhan C9 & N-né & ruine Maison 21 & $400-350$ \\
\hline Gailhan C10 & $\mathrm{N}$-né & Cour 22 & $400-350$ \\
\hline Gailhan C11 & N-né & Cour 22 & $425-400$ \\
\hline Gailhan C12 & N-né & Cour 24 & $400-350$ \\
\hline Cayla 19 & Périnatal & Maison & $600-500$ \\
\hline Cayla 16 & Périnatal & $?$ & $-75+200$ \\
\hline Cayla 23 & Périnatal & $?$ & $-75+200$ \\
\hline Cayla 36a & Périnatal & $?$ & $-75+200$ \\
\hline Lattes Sond. 2 & Périnatal & $?$ & $400-200$ \\
\hline Lattes Sond. 3 & Périnatal & $?$ & $500-400$ \\
\hline Lattes 1012 & N-né & $?$ & $?$ \\
\hline Lattes $1145 / 65 / 69$ & N-né & $?$ & $275-250$ \\
\hline Lattes 1236/44 & N-né & $?$ & $225-200$ \\
\hline Lattes 4210 & Prématuré & Salle 9 & $50-25$ \\
\hline Lattes 4239 & Prématuré & Salle 8 & $125-75$ \\
\hline Lattes 4150 & N-né & $?$ & $?$ \\
\hline Baou Saint Marcel & Fœtus & Case IbN-2 & $600-500$ \\
\hline
\end{tabular}




\section{BIBLIOGRAPHIE}

Agusti B., Llorens J.-M., Lopez J., Martin A., Mataro M., Toledo A.

à paraitre : Enterrements domestiques d'individus périnataux dans l'Illa d'en Reixac, Ullastret, Gérone, Espagne, in : Actes du Colloque Anthropologie Préhistorique : résultats el lendances, Sarrians, septembre 1989

Arnal J., Majurel R., Prades H.

1974 : Le port de Lattara (Lattes, Hérault), Bordighera-Montpellier, Institut International d'Études Ligures, 341 p., 135 fig.

Arnaud G., Arnaud S.

1980 : Les sondages Ib.-. Yord des Baou de Saint-Marcel à Marseille, III, Étude des restes humains, Documents d'Archéologie Meridionale, 3, p. 89-90.

Barandiarán J.-M.

1966 : Los diverses aspectos históricos de la cultura vasca, in : IVo symposium de Prehistoria péninsular, Pampelune, p. 299312.

\section{Barberá J., Sanmartí E.}

1976-1978 : El poblado ibérico de la Penya del Moro (Sant Just Desvern, Barcelona), in : Simposi internacional : els origens del món ibèric, Barcelona-Ampúries, 1977, Ampurias, 38-40, p. 295305

Barberá J., Pascual R., Caballé M., Rovira J.

1960-1961 : El poblado preromano del "Turo de Can Olivé" de Cerdanyola (Barcelona), Ampurias, 22-23, p. 183-221.

Barberá J., Campillo D., Miró C., Molist N.

1989 : Las inhumaciones infantiles y otros ritos en el poblado ibérico de la Penya del Moro de Sant Just Desvern (Barcelona), in: Inhumaciones infantiles en el ámbito mediterráneo español (siglos VII a. E. al II d. E.), Cuadernos de Prehistoria y Arqueologia Castellonenses, 14, p. 161-171.

Bartoloni G., Cataldi Dini M., Zevi F.

1982 : Aspetti dell'ideologia funeraria nella necropoli di Castel di Decima, in : La Morl, les morls dans les sociètés anciennes. Paris, Éd. de la Maison des Sciences de l'Homme, p. 257-273.

Beltrán Lloris $\mathrm{M}$.

1976-1978 : Enterramientos infantiles en el poblado ibérico de La Romana (La Puebla de Ilijar, Teruel), in: Simposi internacional : els origens del món ibèric, Barcelona-Ampuries, 1977. Ampurias, 38-40, p. 307-315.

Blayo $\mathrm{Y}$.

1975: La mortalité en France de 1740 à 1829, Population, 30 , $\mathrm{n}^{\circ}$ spécial, p. 123-142.

Bloch R.

1975 : Habitats et nécropoles au Premier Age du Fer en Italie Centrale, in: L'habital et la nécropole à l'Age du Fer en Europe occidentale et centrale, Actes du I ler colloque archéologique de la IVe section de lEPHE, Paris 1975, Paris, H. Champion. p. 13-19.

Bouloumié B.

1984 : Un oppidum gaulois à Saint-Blaise en Provence, Histoire el Archéologie, Les Dossiers, 84, p. 6-96.
Canet H., Roudil J.-L.

1978: Le village chalcolithique de Cambous (Viols-en-Laval, Hérault), Gallia Préhistoire, 21, p. 143-188.

\section{Cartier M.}

1986 : En Chine, la famille, relais du pouvoir, in : Histoire de la tamille, I, Paris, Armand Colin, p. 445-477.

\section{Courtin $\mathbf{J}$.}

1961 : La Préhistoire récente de la vallée du Verdon, Cahiers Ligures de Préhistoire el d'Archéologie, 10/11, p. 181-189.

\section{Dedet B.}

1980: Premières recherches sur l'oppidum du Plan de la Tour à Gailhan, Gard, sondages 1975-1977, Association pour la Recherche Archéologique en Languedoc Oriental, Cahier $\mathrm{n}^{\circ} 8$, Caveirac. $132 \mathrm{p}$.

1987 : Habilat et vie quotidienne en Languedoc au milieu de l'Age du Fer : L'unité domestique $n^{\circ} 1$ de Gailhan (Gard), 17 suppl. à la Revue Archéologique de Narbonnaise (RAN), 230 p., 171 fig. 1990 : Une maison à absides sur l'oppidum de Gailhan (Gard) au milieu du $v^{e} s$. avant J.-C. La question du plan absidial en Gaule du Sud, Gallia, 47, p. 29-55.

à paraître a : La maison languedocienne durant la Protohistoire : formes et utilisation de l'espace, in : Habitats et structures domestiques en Méditerranée occidentale durant la Protohistoire, Actes du Colloque International d'Arles, 19-21 octobre 1989. Documents d'Archéologie Française (DAF).

à paraitre b : Riles funéraires prolohistoriques dans les Garrigues languedociennes. Approche elhno-archéologique, $24^{\circ}$ suppl. à la $R A N, 413$ p., 128 fig.

Dedet B., Schwaller M.

1990 : Pratiques cultuelles et funéraires en milieu domestique sur les oppida languedociens, Documents d'Archéologie Méridionale, 13, p. 137-161.

Duday $\mathrm{H}$.

1981 : Étude des restes osseux provenant de la nécropole de "Las Peyros" à Couffoulens (Aude), RAN, XIV, p. 54-70.

1989: La nécropole du Peyrou à Agde (Hérault). Étude anthropologique, in: Nickels A., Marchand G., Schwaller M., Agde, la nécropole du Premier Age du Fer, $19^{\mathrm{e}}$ suppl. à la $R A N$, p. $459-472$.

Duday H., Dedet B.

1985: Une inhumation protohistorique de nouveau-né sur l'oppidum du Plan de la Tour à Gailhan (Gard), in: $110^{\circ}$ Congrès National des Sociètés Savantes, Montpellier 1985. Archéologie, p. 89-95.

Fabre V.

1988 : Les inhumations domestiques de périnataux, Mémoire de maitrise, Univ. Paul-Valéry, Montpellier, 182 p. (dactyl.).

1990 : Rites domestiques dans l'habitat de Lattes : sépultures et dépòts d'animaux. Lattara, 3. p. 391-416.

Fazekas I.G., Kosa F.

1978: Forensic Fetal Osteology. Budapest. Akadémiai Kiado. $414 \mathrm{p}$. 
Gallart J., Junyent E.

1989 : Un nou lall estratigràfic a la Pedrera, Vallfogona de Balaguer, Térmens, La Noguera, Lleida, Espai $i$ Temps, Estudi General de Lleida, $124 \mathrm{p}$.

Gantès L.-F., Rayssiguier G.

1980 : Les sondages Ib-Nord des Baou de Saint-Marcel à Marseille, I, Étude archéologique, Documents d'Archéologie Meridionale, 3 , p. $65-85$.

\section{Gracia F., Munilla G., Mercadal O., Campillo D.}

1989 : Enterramientos infantiles en el poblado ibérico de la Moletta del Remei (Alcanar, Montsia), in: Inhumaciones infantiles en el ámbito mediterráneo español (siglos VII a. E. al II d. E.), Cuadernos de Prehistoria y Arqueologia Castellonenses, 14 , p. $133-159$.

Gras M., Rouillard P., Teixidor J.

1989 : L'univers phenicien, Paris, Arthaud, $284 \mathrm{p}$.

\section{Guérin P., Martinez Valle R.}

1987-1988: Inhumaciones infantiles en poblados ibéricos del area Valenciana, Saguntum, Papeles del Laboratorio de Arqueologia de Valencia, 21, p. 231-265.

Guérin P., Calvo Galvez M., Grau Almero F., Guillen Calatayud P.-M.

1989: Tumbas infantiles en el Castellet de Bernabe (Liria, Valencia), in: Inhumaciones infantiles en el ámbito mediterráneo español (siglos VII a. E. al II d. E.), Cuadernos de Prehistoria y Arqueologia Castellomenses, 14, p. 63-93.

\section{Guerrero V.-M.}

1989 : Posibles sacrificios infantiles en la cultura Talayótica de Mallorca, in: Inhumaciones infantiles en el ámbito mediterráneo español (siglos VII a. E. al II d. E.), Cuadernos de Prehistoria y Arqueologia Castellonenses, 14, p. 191-109.

\section{Gusi Jener F.}

1970 : Enterramientos infantiles ibéricos en vivienda, Pyrenae, 6, p. $65-72$.

1989 : Posibles recintos necroláticos infantiles ibéricos en Castellón, in: Inhumaciones infantiles en el ambito mediterráneo español (siglos VII a. E. al II d. E.), Cuadernos de Prehistoria y Arqueologia Castellonerses, 14, p. 19-42.

\section{Leclerc J., Masset Cl.}

1982 : Les tombes collectives, in : La morl dans la Préhistoire, IIisloire et Archéologie, Les Dossiers, 66, p. 52-58.

Louis M., Taffanel O., Taffanel J.

1955 : Le premier Age du Fer Languedocien, I, Les habitats, Bordighera-Montpellier, Institut International d'Études Ligures, $208 \mathrm{p}$.

\section{Mahieu E.}

1984-1985 : Fortus et nouveau-nès prèhistoriques, Bulletin du Musée d'Anthropologie Préhistorique de Monaco, 28, p. 137-154.

Maluquer de Motes J.

1958 : El yacimienlo hallstáttico de Cortes de Navarra, esludio critico, $I I$, Pampelune, $151 \mathrm{p}$.

\section{Masset C.}

1986 : Préhistoire de la famille, in : Ilistoire de la famille, I, Paris, Armand Colin, p. 79-97.

Maya J.-L.

1986 : Incineracio i ritual funerari a les Valls del Segre i del Cinca, Cola Zero, 2, p. 39-47.

\section{Neraudeau J.-P.}

1987 : La loi, la coutume et le chagrin. Réflexions sur la mort. des enfants, in : la mort, les morls et l'au-delà dans le monde romain. Acles du Colloque de Caen, 20-22 novembre 1985, Centre de publications de l'Université de Caen, p. 195-208.

Nickels A.

1989 : La Monédière à Bessan (Hérault), le bilan des recherches, Documents d'Archéologie Méridionale, 12, p. 51-119.

\section{Oliver Foix A., Gomez Bellard F.}

1989 : Nuevos enterramientos infantiles ibéricos de inhumación en Castellón, in: Inhumaciones infantiles en el ámbito mediterráneo español (siglos VII a. E. al II d. E.), Cuadernos de Prehistoria y Arqueologia Castellonenses, 14, p. 51-62.

\section{Perrenoud A.}

1975 : L'inégalité sociale devant la mort à Genève au Xvır s., Population, 30, $\mathrm{n}^{0}$ spécial, p. 221-243.

Prades $\mathrm{H}$.

1984 : Fœtus Lattarenses, Journal Communal de Laltes, 24, p. 12-13.

\section{Py $\mathbf{M}$.}

1987 : Culture, économie et société protohistoriques dans Ia région nîmoise, Thèse d'état, Univ. de Montpellier, 3 vol. (dactyl.). 1989 : Formes d'habitat et pratiques domestiques à Lattes (IJérault) aux $\mathrm{II}^{\mathrm{C}}-1 \mathrm{I}^{\mathrm{p}} \mathrm{s}$. avant notre ère : exemple du quartier Saint-Sauveur, in : Ilabitats et structures domestiques en Méditerranée occidentale durant la Protohistoire, Pré-Actes du colloque international d'Arles 1989 , p. 54-59.

Py M., Lebeaupin D., Bessac J.-Cl., de Chazelles C.-A., Duday $\mathrm{H}$.

1986 : Stratigraphie du Marduel (Saint-Bonnet-du-(iard), III, Les niveaux des $\mathrm{II}^{\mathrm{F}}$ et $\mathrm{I}^{\mathrm{pr}} \mathrm{s}$. avant notre ère sur le Chantier Central, Documents d'Archéologie Méridionale, 9, p. 9-80.

Py M., Lebeaupin D., Duday H., Fabre V., Tillier A.-M. 1989 : Stratigraphie du Marduel (Saint-Bonnet-du-(iard), IV, I.es niveaux des ${ }^{2} V^{r}$ et III $^{\prime \prime}$, avant notre ère sur le Chantier Central, Documents d'Archéologie Méridionale, 12, p. 121-190.

\section{Salles J.}

1986 : Alès, l'Ermilage; maison $n^{\circ} 13$, Alès, Groupe Alésien de Recherche Archéologique, Activités et Travaux, Centre Culturel André Chamson.

Solier Y., Giry J.

1973 : Les recherches archéologiques à Montlaurès : État des questions, in: Narbonne, Archéologie el Histoire, Narbonne 1972, 1, Montpellier, Fédération historique du Languedoc méditerranéen et du Roussillon, p. 77-111.

Tarradell $\mathbf{M}$.

1965 : Enterramientos infantiles en el interior de habitaciones ibéricas, Pyrenae, 1, p. 174-175.

Thomas L.-V.

1980: Anthropologie de la mort, Paris, Payot, $538 \mathrm{p}$.

1982 : La morl africaine. Idéologie funéraire en Afrique noire, Paris, Payot, 272 p.

Ubelaker D.H.

1978: IIuman Skeletal Remains, Taraxacum, Washington, $119 \mathrm{p}$.

\section{Van Gennep A.}

1946 : Manuel de folklore français contemporain $I, D u$ berceau a la tombe. 1. Naissance, baplème, fiançailles; 2, Mariage, funérailles, Paris, Picard, 830 p. 